NBER WORKING PAPER SERIES

\begin{abstract}
ANSWERING THE CALL OF AUTOMATION: HOW THE LABOR MARKET ADJUSTED TO THE MECHANIZATION OF TELEPHONE OPERATION
\end{abstract}

\author{
James Feigenbaum \\ Daniel P. Gross \\ Working Paper 28061 \\ http://www.nber.org/papers/w28061
}
NATIONAL BUREAU OF ECONOMIC RESEARCH
1050 Massachusetts Avenue
Cambridge, MA 02138

November 2020, Revised April 2022

\begin{abstract}
We thank David Autor, Brian Beach, Ed Glaeser, Shane Greenstein, Walker Hanlon, Bill Kerr, Frank Levy, Bob Margo, Pascual Restrepo, and especially Daron Acemoglu and Claudia Goldin for feedback. We also thank numerous seminar and conference audiences and discussants Daron Acemoglu, Martha Bailey, and Dan Rees for helpful comments. We thank Senan HoganHennessy, Greg Saldutte, Thomas Pearson, and Danielle Williamson for outstanding research assistance, and Elizabeth Crowley, Jesse Benedict, Yves Kertesz, and Amanda LaFauci for help collecting the data, as well as Harvard Business School for nancial support. We especially would like to thank Sheldon Hochheiser and the AT\&T Archives and History Center for access to AT\&T archival records, feedback, and fact-checking. This is a revised version of a paper which previously circulated with the title "Automation and the Future of Young Workers: Evidence from Telephone Operation in the Early 20th Century." All errors are our own. The views expressed herein are those of the authors and do not necessarily reflect the views of the National Bureau of Economic Research.
\end{abstract}

NBER working papers are circulated for discussion and comment purposes. They have not been peer-reviewed or been subject to the review by the NBER Board of Directors that accompanies official NBER publications.

(C) 2020 by James Feigenbaum and Daniel P. Gross. All rights reserved. Short sections of text, not to exceed two paragraphs, may be quoted without explicit permission provided that full credit, including ( $)$ notice, is given to the source. 
Answering the Call of Automation: How the Labor Market Adjusted to the Mechanization of Telephone Operation James Feigenbaum and Daniel P. Gross

NBER Working Paper No. 28061

November 2020, Revised April 2022

JEL No. J21,J24,J62,J63,M51,M54,N32,O33

\begin{abstract}
Telephone operation was among the most common jobs for young American women in the early 1900s. Between 1920 and 1940, AT\&T adopted mechanical switching technology in over half of the U.S. telephone network, replacing manual operation. Although automation eliminated most of these jobs, it did not affect future cohorts' overall employment: the decline in operators was counteracted by reinstating demand in middle-skill clerical jobs and lower-skill service jobs. Using a new genealogy-based census-linking method, we show that incumbent telephone operators were most impacted, and a decade later more likely to be in lower-paying occupations or have left the labor force.
\end{abstract}

James Feigenbaum

Department of Economics

Boston University

270 Bay State Road

Boston, MA 02215

and NBER

jamesf@bu.edu

Daniel P. Gross

Fuqua School of Business

Duke University

100 Fuqua Drive

Durham, NC 27708

and NBER

daniel.gross@duke.edu 
Automation anxiety has surged in the U.S. and other developed economies (Autor 2015), fueled by warnings of a sweeping wave of automation (e.g., Brynjolfsson and McAfee 2014). Yet the degree to which automation reduces employment, and for whom, is increasingly seen as ambiguous: automation can in theory be offset by countervailing forces, from productivity growth to the invention of new tasks in which displaced labor has comparative advantage (Acemoglu and Restrepo 2018, 2019a,b). Basic questions include whether, where, and how quickly labor demand recovers from major automation events, and who if anybody suffers its consequences.

In this paper, we study one of the largest job-specific automation shocks in modern history: the automation of telephone operation. In the 1920s, telephone operator was among the most common jobs for young American women, and telephone operators were a staple of everyday life across the country. ${ }^{1}$ But between 1920 and 1940, telephone exchanges serving over half of the U.S. telephone network were mechanized, replacing most functions of local operators, one city at a time. By comparison, the fraction of U.S. female employment exposed to this shock is similar to the fraction of the current U.S. workforce employed as cashiers, office clerks, or customer service workers - major service sector jobs which are increasingly being automated (BLS 2019a), raising questions of what will happen to these workers and to future generations of job-seekers after they are. ${ }^{2}$

We document the effects of mechanizing telephone operation on both incumbent workers and future generations. To do so, we construct a dataset measuring the local adoption of mechanical call switching and combine it with census data on the complete U.S. population and a longitudinallylinked sample of women. Our exercise comprises two distinct but closely related analyses, on two samples, answering two questions: (i) how did automating telephone service affect future generations of young women entering the labor market, and (ii) how did it affect incumbent telephone operators? We show that after a city was "cut over" to mechanical operation, the number of 16 to 25 year old women in subsequent cohorts employed as telephone operators immediately and permanently fell by 50 to $80 \%$. These jobs comprised around $2 \%$ of employment for this group, and even more for those under age 20-and given turnover rates, this shock may have foreclosed entry-level job opportunities for as much as 10 to $15 \%$ of peak cohorts.

Despite its magnitude, this shock did not reduce employment rates of young women in the treated

\footnotetext{
${ }^{1}$ Telephone operation in the telephone industry was the third-largest occupation-industry pair for white, Americanborn women under age 25 in 1920, and the single largest for those under 20.

${ }^{2}$ Telephone operation accounted for roughly $1.9 \%$ of female employment in 1920 and $2.1 \%$ in 1930 . For comparison, in May 2017, cashiers, office clerks, and customer service representatives comprised $2.3 \%, 1.9 \%$, and $1.7 \%$ of U.S. employment, respectively (BLS Occupational Employment Statistics for SOC 41-2011 (Cashiers), $43-9061$ (Office Clerks, General), and 43-4051 (Customer Service Representatives)).
} 
cities. The reason does not appear to be that mechanical switching had aggregate effects on productivity or capital investment, as the technology was industry-specific and had modest impacts on prices and service quality. Instead, the reduction in telephone operators was offset by growth of demographically-similar jobs with similar or slightly lower wages (e.g., typists and secretaries, restaurant workers). The specificity of this countervailing employment growth in a select set of occupations that were demographically similar to telephone operators suggests task reinstatement restored the employment levels of future cohorts (Acemoglu and Restrepo 2018). The trajectory of incumbent operators, however, was different: telephone operators in cities with cutovers were subsequently less likely to be working the next decade we observe them, and conditional on working were more likely to have moved to lower-paying occupations.

To understand this paper, it is useful to first describe AT\&T, including the large size and composition of its operating force and its eventual mechanization. From AT\&T's founding in the mid-1870s to the late 1910s, telephone calls were manually connected by operators working the switchboards at telephone exchanges around the country. Though initially male, by the early 1900s operators were almost entirely young, white, American-born women. By 1920, AT\&T was the largest U.S. employer, accounting for over one percent of the non-farm U.S. workforce (similar to Walmart today), and by far the largest employer of women. Around this time, however, AT\&T began advising its operating companies to adopt mechanical switching, which diffused gradually across the U.S. telephone network over time. Under this technology, telephone sets were given rotary dials, and each turn of the dial actuated switching equipment at the telephone exchange, allowing users to place their own calls. A rich historical record and quantitative evidence both indicate that AT\&T's impetus for automation was the increasing complexity of manual operation in large markets, rather than labor market conditions. The effect of adopting mechanical switching was to nearly eliminate an entire major category of work, one city or exchange at a time.

Our analysis combines three sources of data. First, we measure cutovers to dial service across the continental U.S. using AT\&T archival records and data collected from thousands of local newspaper articles. Of the nearly 3,000 cities in our sample, 332 have their first cutover by 1940. For most of the paper, we will focus on the 2,846 cities with $\leq 100,000$ population in 1920 (261 with cutovers by 1940), where subscribers were typically converted to dial all at once. Second, to study successive cohorts of young women, we aggregate individual-level complete count census data from 1910 to 1940 to a city panel. This panel allows us to measure, for example, employment rates for spe- 
cific ages and demographic groups in each city, or local populations in specific occupation-industry cells. Third, to study incumbent operators, we need to link these women across censuses. Because traditional census record-linking techniques are not capable of following young women over time (due to name changes prompted by marriage), we develop a new, generalizable approach to census linking: to build our linked sample of women, we use public genealogical data from the genealogy platform FamilySearch, match to complete count census records, and reweight to account for the representativeness of FamilySearch data and our linking method. ${ }^{3}$

To estimate the effects of automating telephone operation on future generations of young women, we use an event study design to compare outcomes for successive cohorts before versus after a city's first cutover to dial. We show that employment, marriage, fertility, and school enrollment rates were trending similarly in the decades before automation across similar-sized cities with and without cutovers. We find that the automation of telephone operation led to a large, swift, and permanent decline in the number of young, white, American-born women in future cohorts working as operators. Yet we do not find that the shock reduced employment rates: the negative shock to telephone operator demand was instead counteracted by growth in other occupations, especially secretarial work and restaurant work, which absorbed the women who might have otherwise been telephone operators. Complementary evidence identifies similar effects in the growth of job classifieds for these occupations after cutovers, suggesting reinstating labor demand-though we also show that displacement effects appear to dominate in environments which are less conducive to task reinstatement for our population (young women), such as in manufacturing-intensive cities or those with slack aggregate demand due to the Great Depression.

To trace the effects on incumbents, we link women in 1920 and 1930 to the next decennial census and compare operators to (extremely) similar working women-matched on age, race, nativity, marital status, fertility, and neighborhood-initially living in cities where telephone operation was or was not automated over the following decade. We find that incumbent operators were more affected. Relative to non-operator women in the same city and telephone operators in untreated

\footnotetext{
${ }^{3}$ Four other recent papers attempt to link women census to census. Price et al. (2019) and Marchingiglio and Poyker (2020) link only women whose marital status does not change across censuses. Drawing on marriage certificates as an intermediate step, Withrow (2020) studies rural women in the early 20th century and Craig et al. (2019) focus on one state (Massachusetts) with good marriage record coverage in the late 19th century. In our case, linking already-married telephone operators in 1920 or 1930 to their census record ten years later may be feasible, but it would restrict our analysis to a small, non-modal population of operators. A systematic bias may affect a linked sample of only the single telephone operators who remain single in future censuses, as links would be conditioned on a potentially endogenous outcome (marital status). For our national sample of telephone operators, the uneven coverage of marriage certificates across states would be very challenging for our analysis.
} 
cities, we find that treated operators were significantly less likely to be working as operators ten years later. While some found other jobs in the telephone industry, others (especially older workers) left the workforce, and those who remained employed were more likely to have switched to lower-paying occupations. The magnitudes of these effects are tempered somewhat by the fact that many women exited the workforce as they aged, but because telephone operation-despite high turnover - was one of the few opportunities for women with the potential to be a career, the loss of these jobs was costly for those who would have otherwise chosen to keep them.

Collectively, our results show that local economies can adjust to large automation shocks over relatively short horizons and continue to absorb the steady stream of young workers entering the labor market, when countervailing labor demand develops to take advantage of the newly abundant factor, in activities where that labor has comparative advantage. ${ }^{4}$ In the 1920 s and 1930 s, much like now, contemporaries feared these opportunities were gone and never coming back-but those fears proved to be misplaced, as other jobs grew to take their place. Yet in contrast to, e.g., Bessen (2015), our finding that incumbent operators were affected also demonstrates that automation is not entirely benign to the workers whose functions it performs.

Our paper adds to a burgeoning empirical literature studying the effects of automation on workers and labor markets. ${ }^{5}$ This literature often finds that automation displaces some workers (e.g., Bessen et al. 2019), but varies for which workers and with what net impacts on employment (Chiacchio et al. 2018, Dauth et al. 2018, Graetz and Michaels 2018, Acemoglu and Restrepo 2020, Adachi et al. 2020, Aghion et al. 2021, Humlum 2021, Koch et al. 2021). ${ }^{6}$ However, the empirical literature studying the forces which might blunt this displacement is less developed. One stream of research studies direct offsets in the form of countervailing employment growth in the same firms or industries where automation is adopted: in some cases, productivity improvements result in firms and industries which adopt automation directly offsetting displacement via complementary demand or growth (e.g., Aghion et al. 2021, Humlum 2021, Koch et al. 2021). Endogenous task reinstatement

\footnotetext{
${ }^{4}$ The results also bring useful nuance to the Acemoglu and Restrepo (2018) view of task reinstatement: it is not that clerical work or food service was new to the economy, but rather businesses and industries found new uses for newly abundant workers. Task creation may thus be firm- or sector-specific, and reinstatement can be driven as much by diffusion (of new tasks into other sectors of the economy) as by invention (of new tasks, wholesale).

${ }^{5}$ In addition to the automation literature, our results add to research on skill-biased technical change (Acemoglu 1998, Autor et al. 1998, 2003), including historical scholarship (Goldin and Katz 2008, Gray 2013) and studies of white-collar jobs that primarily employ women (e.g., Dillender and Forsythe 2019).

${ }^{6}$ A closely related literature studies the effects of technology-driven occupational decline on workers. See, for example, Janssen and Mohrenweiser (2018), Edin et al. (2019), Cuccu and Royuela (2022). Our results on incumbent telephone operators connect to this literature, which broadly finds that workers in declining occupations suffer earnings and employment losses, with these are larger for younger or lower-skilled workers.
} 
across the economy as an equilibrating mechanism is more difficult to directly demonstrate (though it has been suggested by evidence in, e.g., Acemoglu and Restrepo 2019b, Autor et al. 2021). As a result, basic questions such as whether employment grows in occupations not directly related to automating technology, and under what conditions, are unresolved.

Telephone operation is in many ways an opportune setting for studying these issues. One reason is its scale: as a large, geographically-dispersed, and entry-level job, automating telephone operation could have aggregate effects on both incumbent workers and future cohorts. A second is precision: telephone operation is a well-defined, well-measured occupation whose automation was discrete and can be precisely measured. In contrast to studies where automation is measured as industrial robot adoption or as a general category of capital investment, the specificity of mechanical call switching allows us to isolate what technology was adopted, which jobs it displaced, and which workers (or categories of workers) were implicated. In short, we can relate the technology to the specific task it performed and the workers who would have otherwise performed it.

This precision creates distinctive opportunities. As a practical matter, it allows us to implement a clean, straightforward identification strategy, exploiting the staggered mechanization of call switching. Conceptually, we can connect closely to task-based theoretical frameworks of automation, with clarity on (i) which segments of the labor market to study and (ii) what alternative occupations these workers might substitute into. Exploiting this precision, this paper is to our knowledge among the first to offer economy-level evidence of endogenously reinstating labor demand targeting the specific category of workers which mechanical call switching displaced.

An additional contribution of this paper is in documenting how mechanization affected both existing and future would-be operators. This adds to the literature a unified view of how automation affects the full range of exposed workers, including future generations - a population difficult to study in other settings. Similar to Humlum (2021), our results suggest these effects exist on a continuum. Workers with the least time to adjust (and most invested in the occupation) suffer the largest consequences, whereas future generations are better able to adapt.

The historical setting of our paper, and the specificity of the job and industry, may raise questions of external validity. ${ }^{7}$ In this case, our concerns are relatively low, for two reasons. First, we believe the insights we draw are general, particularly when interpreted through the lens of task-based theories

\footnotetext{
${ }^{7}$ For example, overall female labor force participation was relatively low and growing in this period-though for the demographic we focus on, it was by 1940 close to current levels. It is also an era when educational attainment was rapidly growing across cohorts. Cohort differences, however, will be accounted for by fixed effects.
} 
of automation and economic growth. Second, related work often produces valuable insights from similarly-specific jobs, industries, technologies, or settings with their own institutional complexity. History also presents opportunities: only over long periods can we identify the (rare) occasions when technology abruptly displaces a major occupation, and with long panels, we can study how such events affect successive cohorts of workers over long horizons.

Finally, that the telephone industry was concentrated in a single firm (AT\&T) bears implications for this paper in both execution and generality. Because AT\&T's system was geographically distributed, and its automation specific and heavily-documented, we can exploit this variation to study its effects without requiring heavy structure. We also believe AT\&T's sheer size as America's largest employer for much of the 20th century makes it inherently important. As a technology company and the 20th century archetype for monopoly, it provides a historical comparison point for large firms like Amazon and Walmart which often have market power with customers or suppliers and have been rapidly adopting labor-saving technology in core activities. Historical study can help us presage what may happen if automation at large employers recurs.

We proceed as follows. Section 1 reviews the history of the U.S. telephone industry, the automation of telephone operation, and concurrent trends in the labor market for young women. Section 2 introduces our data on telephone operators, local labor markets, and mechanical switching. Section 3 describes characteristics of telephone operators and cities with cutovers. In Section 4, we confirm that cutovers significantly reduced the number of telephone operators in a city. In Section 5 , we examine what happened to subsequent generations of young women after these jobs were automated away. In Section 6 we contrast these results with the outcomes of incumbent telephone operators. Section 7 concludes with lessons and remaining questions.

\section{Historical Background}

\section{$1.1 \quad$ AT\&T and the U.S. telephone industry}

The history of the U.S. telephone industry is largely the history of AT\&T, the dominant service provider in the U.S. for most of the 20th century. Bell Telephone (AT\&T's predecessor) was founded in 1877, a year after Alexander Graham Bell's successful demonstration of the telephone. One year later it opened its first telephone exchange in New Haven, CT, and within a few years it had licensed exchanges in all major U.S. cities, begun building long-distance connections between them (under 
its AT\&T subsidiary), and acquired a manufacturing company (Western Electric). In 1899, AT\&T became the parent of the Bell system, which eventually comprised dozens of subsidiary operating companies serving different geographic territories around the country.

For its first 17 years, AT\&T was a patent-protected monopolist, but the expiration of the original Bell patents in 1894 attracted entry by thousands of "independent" operating companies, which built competing networks in large cities and entered markets (especially rural areas) where AT\&T had not. By the 1920s, the U.S. telephone industry employed over 300,000 people, served nearly 15 million telephones, and connected more than 65 million calls per day (Appendix Table A.1). AT\&T served around half of telephones in the early 1900s, after which it began acquiring independents across the U.S. in a drive to provide coast-to-coast universal service, and its national share was back up to $79 \%$ by the early 1930 s. AT\&T market shares were even higher in urban markets, where Bell companies were typically the sole telephone service provider.

\subsection{Telephone operators and manual call switching}

The functional units of each operating company were individual telephone exchanges, each typically connecting to up to 10,000 subscribers in its immediate vicinity. These exchanges in turn connected to each other via trunk lines. All subscribers' lines fed into a switchboard at their local telephone exchange, where human telephone operators physically connected calls by plugging wires into and out of jacks on the board - a task referred to as "call switching". Their work was fast-paced and labor-intensive, with millions of calls connected across the U.S. telephone network each day. It was also costly to scale: every $N$ th subscriber created $N-1$ new possible connections, requiring operators to learn more switchboard positions and calls to pass through more operators and switchboards. In large cities, the number of users implied billions of potential connections. As the network grew, the number of operators needed to keep up with call volume swelled. ${ }^{8}$

Although the first generation of telephone operators was mostly male, AT\&T decided early on that young women were more likely to have the qualities it sought in operators. By 1910, operators were almost exclusively women. Based on its employment criteria and position in the wage distribution for young women, telephone operation was effectively middle-skill work. In a Women's Bureau

\footnotetext{
${ }^{8}$ During this period, demand for operators was also growing in other industries, especially at large organizations that sought operators to work private switchboards (e.g., large firms, hospitals, hotels). These switchboards connected telephones within an organization to each other as well as to an outside line of the local telephone company, through which external calls (incoming or outgoing) could be routed.
} 
report, Erickson (1946) summarized the job requirements as follows:

[A]n applicant was expected to be a high school graduate, at least 18 but not much older, in good physical condition, and living at home or with close relatives. Good eyesight and good hearing ... are carefully checked in the general examination for physical soundness. Some companies further screen applicants by means of mental and aptitude tests. A pleasing voice, alertness, manual dexterity for handling equipment and tools of the job, legible penmanship, ability to make simple calculations rapidly and accurately, a sense of teamwork for cooperating with other operators in establishing connections, a stable disposition not easily ruffled by irritable customers, and courteousness are among the personal characteristics listed as qualifications ...

Besides the minimum age requirements, most of these qualifications appear to have applied throughout the 1910 to 1940 period we study in this paper. Contemporary accounts from former operators suggest it was seen as a desirable job, offering higher wages, greater challenge, and more human interaction than alternatives like factory work (Best 1933), though the physical and mental demands of rapid-fire call switching for hours at a time were also high, and internal AT\&T memos describe operator turnover of up to $40 \%$ per year (O'Connor 1930).

In 1920, telephone operators were roughly $2 \%$ of the U.S. female workforce and $4 \%$ of nearly three million young, white, American-born working women. With $40 \%$ turnover rates, as much as $15 \%$ of cohorts born at the turn of the century might have ever been an operator. ${ }^{9}$ Among young women age 16 to 20, for example, "telephone operator" was the fifth largest occupation, and given its concentration in one industry, "telephone operator in the telephone industry" was the single most common occupation-industry pair for this group. AT\&T as a whole was the largest U.S. employer of women in the 1910s, and by the early 1920s it was the country's largest employer overall, with telephone operators comprising around half of its workforce.

\subsection{Transition to mechanical switching}

The first mechanical switching system was invented and refined in the early 1890s. The "automatic" system added a rotary dial to telephone sets and mechanical switching equipment at telephone exchanges. Each turn of the dial transmitted an electrical pulse, which actuated a sequence of selectors

\footnotetext{
${ }^{9}$ Taking the population and age distribution of operators in the 1910 to 1940 censuses, interpolating the intercensal years, and imputing the number of incumbent versus new operators each year, we estimate that $13.7 \%$ of white, American-born women in cohorts born circa 1900 was a telephone operator at some point between 1910 and 1940. The basic logic is that for a telephone company to maintain a set of 100 operators, 40 new operators must be hired each year, and over the course of ten years, 400 unique women might be employed.
} 
at the exchange until a circuit was completed between the caller and the telephone dialed, without manual intervention. Over the next 25 years, mechanical switching was adopted by only a handful of independents. Though AT\&T began experimenting with mechanical equipment in 1902, the technology did not compare favorably to manual operation on cost or performance, and AT\&T continued with manual operation until improvements in the technology and rising costs of manual operation made automation more attractive (Feigenbaum and Gross 2021).

In 1917, AT\&T's engineering department began recommending that its operating companies adopt mechanical switching for local service in large, multi-exchange cities and continue with manual operation in smaller, single-exchange cities (Gherardi 1917), though ultimately operating companies' management decided whether and when to automate every individual exchange. Preparing an exchange for mechanical switching typically required 2-3 years of preparation-e.g., to get regulatory approval, prepare the mechanical equipment, distribute dial telephone sets, and draw up new telephone numbering plans and directories. Operationally, however, cutovers from manual to dial (when the wires were cut from the manual switchboards and connected to the mechanical equipment) were discrete events which took only a few minutes.

Mechanical switching specifically replaced operators in connecting local calls, and AT\&T records from the 1910s projected that the automatic equipment would reduce the number of operators in large cities by up to 70 to $80 \%$ (Gherardi 1917). But even after automation, operators were still needed for long-distance calling, information and emergency services, and any remaining subscribers with manual service. Because these were more complex tasks, the residual operating needs required better trained, more experienced operators, who tended to be older. Automatic switching also increased demand for technicians to maintain the automatic equipment, who tended to be men. Technological change in this instance was thus not only skill-biased, but also age and gender-biased, due to occupational sorting by both AT\&T and its workforce.

In Figure 1 we illustrate the aggregate diffusion of mechanical switching across the Bell system, using administrative data from AT\&T records. Adoption began in the late 1910s and accelerated rapidly - with $32 \%$ of Bell telephones on dial by 1930 and $60 \%$ by 1940 - but it took almost 60 years (to 1978) to diffuse through the entire network, by which time AT\&T had already begun adopting digital switching. Our focus for this paper is the 1910 to 1940 period. ${ }^{10}$ In Section 2 we document

\footnotetext{
${ }^{10}$ We use complete count census data to measure local population outcomes, which at the time of writing were only available through 1940. Even with data for later years, 1940 would be a natural stopping point, since World War II brought cutovers to a halt due to restrictions on the use of copper wire for telephone installations, and also presented a distinct shock to female labor demand (e.g., Goldin and Olivetti 2013, Jaworski 2014).
} 
cross-sectional variation, and in Section 3 we will return to discussing the drivers of automation, vis-à-vis both narrative and empirical evidence, in more detail.

[Figure 1 about here]

By 1940, telephone operation in the telephone industry comprised $<1.5 \%$ of employment for young, white, American-born women (down from its peak of $\approx 4 \%$ ) and had fallen to the 11 th most common occupation-industry pair for those under age 20.

\subsection{Broader context: Trends in female labor force participation}

Prior to the early 1900s, the stigma of being a working woman was quite high, and income effects dominated. Even among unmarried women, work was relatively uncommon, as just over one-third of unmarried white women were working in 1880. Over the following decades, the environment changed steadily in the labor market for women. From the 1900s to mid-century, there was a large, steady increase in demand for clerical and office workers (Goldin 1984). In 1900, only around 20\% of non-farm working women were in white-collar jobs. This group rose to around $35 \%$ of working women by 1920 and nearly $50 \%$ by 1950. Office work was "nicer, cleaner, shorter-hour, and thus more 'respectable'" (Goldin 2006), though it could be repetitive, and turnover was still high and returns to experience low. With the rise in demand for these jobs came an increase in the share of unmarried white women working. More than half of unmarried white women were working in 1910, rising steadily to $60 \%$ in 1940 - reflecting a labor force participation rate for this demographic, and especially young women, close its current level (see BLS 2022).

Changes in female labor force participation, educational attainment, and social norms are all important background trends in this period. Marriage bars-formal policies or legislation that discouraged or precluded the hiring of married women or the retention of women upon marriage - were among the more distinctive features of certain jobs in the early 1900s (Goldin 1988), though their incidence rose and fell over time. ${ }^{11}$ Our study also covers the period when graduates of America's High School Movement hit the labor market (Goldin 1998): across women born from 1890 to 1925, mean educational attainment grew from just over 8 years for the 1890 birth cohort to nearly 11 years for the 1925 cohort (Goldin and Katz 2008). These differences across cohorts will be subsumed by

\footnotetext{
${ }^{11}$ Though most common among public school teachers, Goldin (1988) finds marriage bars present in some clerical employment. AT\&T did not, informally or formally, bar married women from working as operators.
} 
fixed effects in our empirical design, which exploits the staggered diffusion of mechanical switching across cities and includes many cities without cutovers, which comprise a control group. Moreover, if marriage bars or increasing school attendance were coincident with the time and place of mechanization, we would expect to see concomitant declines in employment rates in our cohort-level analysis - in contrast to the muted effects we will find below.

\section{Data and Geographic Coverage}

In this section, we describe our new, hand-collected dataset on local cutovers to mechanical switching compiled from AT\&T archival records and historical newspaper articles, data aggregated from the complete count decennial censuses that allow us to measure populations in precise demographic cells from 1910 to 1940, and a longitudinally-linked sample of women telephone operators which we use to study individual-level adjustments to automation.

\subsection{Data on local adoption of mechanical switching}

Telephone operation was mechanized one exchange at a time. Because these investments were made independently by AT\&T's local operating companies, there is no consolidated, administrative list of cutovers across the AT\&T system (Hochheiser 2017). However, we located in the AT\&T corporate archives a single document from 1937 which lists the earliest cutover and percent of subscribers on dial service for 164 U.S. cities (and seven Canadian cities) with a population of over 50,000, 120 of which were partially or fully dial by the end of that year (AT\&T 1937).

To expand the sample to more cities, we turn to historical newspapers. Dial cutovers were nearly always locally reported, due to the public's need to know when to begin using their dial telephones and public interest in the technology and in the fate of displaced operators. We developed two targeted search terms and searched for reports of cutovers between 1917 and 1940 in three online, searchable repositories of digitized historical newspapers-Newspapers.com, NewspaperArchive.com, and GenealogyBank.com - with the goal of maximizing our geographic coverage. Appendix B describes the data collection in detail. In total, we reviewed over 26,000 newspaper pages to locate articles describing cutovers and record three pieces of information: (i) when each took place, (ii) the cities affected, and (iii) whether it was a telephone company exchange or private switchboard. ${ }^{12}$

\footnotetext{
${ }^{12}$ Our search effort is centered around Boolean search terms which return a list of candidate articles on dial cutovers,
} 
Combining these data sources, our final sample contains 688 U.S. cities that were cut over to dial before the 1940 census. The vast majority of cutovers are in the Bell system, although a few are by independents, including a handful before 1919, the year AT\&T first began adopting mechanical switching. Figure 2 maps the cities with cutovers in our data. Merging these data with 1940 city populations from the census, we find that by 1940, 86 of the largest 100 U.S. cities, and $40 \%$ of the largest 500 , had at least one cutover, and $53.8 \%$ of the U.S. urban population lived in cities where telephone service was mechanical. The fraction of this population exposed to dial was highest in the Northeast (at 58.9\%) and lowest in the South (47.8\%).

[Figure 2 about here]

Using the AT\&T administrative data, we verify that our newspaper-derived cutover dating is accurate and that cutovers in small- and medium-sized cities were typically one-shot events. As Appendix Figure B.5 shows, for cities in both the AT\&T and newspaper datasets, the earliest cutover we identify in newspapers is nearly always the same as that reported in the AT\&T data (the few cases where a newspaper-reported cutover preceded an AT\&T cutover were independents). Appendix Figure B.2 provides evidence that cities of under 100,000 people in 1920 typically had one cutover in which the entire service area was converted to dial, whereas larger cities were converted in a piecemeal fashion-motivating our empirical focus on smaller cities.

\subsection{Data on local outcomes}

We use IPUMS complete count U.S. census data (Ruggles et al. 2019) to measure local outcomes between 1910 and 1940. Throughout this paper, we restrict attention to the adult (16+) non-farm population in the continental U.S. only. We aggregate this population up into a fine-grained panel, measuring city-level outcomes by sex, age, race, ethnicity, birthplace (U.S. or foreign), occupation, and industry. Importantly for our purposes, telephone operator is one of 283 coded occupations in the IPUMS data (code 370), and the telephone industry is one of 162 coded industries (code 578),

which were then read by research assistants, who were instructed to determine whether the article does in fact describe a cutover, the cities affected and timing, whether it affects local telephone service (versus long-distance, or private branch exchanges), and any other pertinent details. Most cutovers are reported multiple times, either in multiple newspapers or in multiple issues of the same newspaper, such that the data are largely internally-validated; in all such cases, we review and harmonize the collected information, using duplicate reports to fill in gaps. While many articles provide the exact cutover date, some only provide an approximate (or anticipated) date, week, month, season, or year. Because we measure outcomes at decadal frequency (using census data), our analysis will not be sensitive to small measurement error. See Appendix B for details. 
making it possible for us to measure the precise size of a city's operating force and identify workers directly exposed to cutovers. For each of these subgroups, we measure several outcomes, including employment, educational status, marriage, and fertility. ${ }^{13}$

The IPUMS data report individuals' state and county, a raw city string (as it was transcribed from the original manuscripts), and an IPUMS-standardized city name, where applicable. Because standardized city names are not always provided or fully consistent, we undertake an independent, manual effort to harmonize city spellings (see Appendix B). We then identify the cities that (i) are observed in each census from 1910 to 1940, and (ii) have at least 2,000 people in the complete count data in 1920 . We drop 14 cities with $\leq 500$ people in any year, 56 cities with anomalous reporting of occupation (Appendix B), 31 cities with ambiguous cutover timing, and all New York City boroughs, yielding a final balanced panel of 2,922 cities, of which 332 are in our data as having their first cutover by April 1, 1940 (the date of the 1940 Census). ${ }^{14}$

\subsection{Linked sample of female telephone operators}

To understand the long-run effects of telephone cutovers on the operators themselves, we have to follow the operators over time. However, linking women across censuses is extremely challenging. Census linking — whether automated or manual —is based on "stable" features recorded in the census like first name, last name, year of birth, and place of birth (Abramitzky et al. 2021). Because most women changed their names at marriage, these features are only stable for men, and most studies following individuals over time in the early twentieth century therefore focus only on men. ${ }^{15}$ To link the women in our sample, we develop and implement a novel linking procedure, making use of a popular genealogy platform and the "work" of many expert family historians linking the women in their family trees across censuses and marriage; in effect, we rely on genealogists and descendants, rather than prediction, to tell us which records belong to the same person.

\footnotetext{
${ }^{13}$ In preparing these data, we create a new occupation code that identifies individuals who are reported as either (i) not being in the labor force or (ii) having a non-working occupation (e.g., housewives, students, retirees, disabled persons, inmates) or unknown occupation, and we define the working population as all others, i.e., all persons who both (i) report as being in the labor force, and (ii) have a working occupation.

${ }^{14}$ We drop the handful of cities with a population $\leq 500$ in 1910 to eliminate those where inference is made difficult by small samples - though this is immaterial to our analysis, which will be weighted on population. In addition, in a handful of (primarily small) cities, there was at least one year in the data with zero or near-zero working-age adults reporting an occupation. Many of these cities are geographically adjacent - such as Bangor, ME and Brewer, ME in 1920 (Appendix Figure B.6) - suggesting these are attributable to enumeration errors and should be excluded. We drop New York City because it is difficult to discern cutovers in different boroughs in newspaper articles and because it is an outlier in the sheer number of cutovers experienced.

${ }^{15}$ One exception is Olivetti and Paserman (2015), who pseudo-link people over time using their likely socio-economic status, as inferred from their first names, to avoid linking women on surnames.
} 
We link in four steps. First, we identify all women working as telephone operators in the telephone industry in the 1920 and 1930 complete count census data (Ruggles 2002). After limiting to women in our focal cities, we have 96,183 women in 1920 and 61,110 women in $1930 .{ }^{16}$ Second, we look for each of these women on FamilySearch, a public genealogy platform with an open wiki-style family tree (Price et al. 2019), where users create pages for deceased individuals - usually their own ancestors - and attach links to historical records, including entries from Federal Censuses, marriage records, and birth certificates. Not all telephone operators have a page on FamilySearch: we are able to find $34.6 \%$ of operators in 1920 and $37.0 \%$ in 1930 on the tree. ${ }^{17}$

Third, we query the FamilySearch tree for links to the next census. That is, we begin with the set of operators who were attached to the tree in year $t \in\{1920,1930\}$, the census in which they were an operator. We check whether or not each operator's profile on FamilySearch has been linked to a record from the census in $t+10$. Conditional on being on the tree, $48.8 \%$ of records in our sample from 1920 are linked ahead to the 1930 census and $49.6 \%$ of 1930 records to 1940 .

Finally, for the set of operators with FamilySearch records attached to censuses in $t$ and $t+10$, we use census record metadata - reel, page, and line number - to make links back to the complete count, restricted-use IPUMS data. This process yields a sample of 16,253 operators linked from 1920 to 1930 and another 11,220 linked from 1930 to 1940, the latter number lower because we exclude operators in cities already cutover to dial. For all of these operators, we observe the full set of census covariates in $t$ and $t+10$, allowing us to study what happens to operators a decade later, including their occupation, industry, marital status and fertility.

These data would be sufficient for comparing incumbent operators in cities with versus without cutovers, but because cutovers affect all local operators, we would not be able to control for cityspecific trends. We thus supplement these data by identifying, for each operator, a matched comparison set of women from the same census enumeration district (akin to a neighborhood of roughly

\footnotetext{
${ }^{16}$ This sample omits a small number of male operators from our analysis as well as a small number of operators younger than 16 or older than 60 . Only operators in cities with cutovers after 1920 are included. We further limit to operators in cities with population $\leq 100,000$ in 1920 , where cutovers were typically one-shot events, matching the sample we use when we study the next generation of potential operators (see Section 4). For the 1930 sample, we further restrict the sample by filtering out cities with cutovers before 1930, as these women are selected on being operators after their city was cut over to dial service.

${ }^{17}$ Whether or not an operator - or anyone else - is attached to the FamilySearch tree is inevitably nonrandom. Pages are built, and records attached, by people working on family history today, and the FamilySearch platform is affiliated with the Church of Jesus Christ of Latter-day Saints. As long as the bias in who is likely or not likely to be on the tree is uncorrelated with the timing of cutovers, our event study strategy - comparing operators across cities and before and after cutovers - should produce an unbiased estimate of the cutover treatment effect. In Appendix B.3.3, we describe in more detail what predicts whether or not an operator is on the tree and shows that match rates are not a function of our treatment in Table B.3.
} 
1,000 residents) who were also working and of the same age ( \pm 5 years), sex, race, nativity (U.S. versus foreign-born), parental nativity, marital status, and with or without children, and we apply the same linking procedure to track them from a base year to the next census. This effort produces matched controls for about three-quarters of operators in 1920 and 1930, with an average of 4.7 control women per operator. With this expanded sample we can add operator-specific fixed effects to condition comparisons to between treated operators and their matched controls.

An example can clarify why linking women is difficult, and why the FamilySearch data can help. Suppose we start with a telephone operator in 1920 in New York named Daisy Fay. We see in the 1920 census that Daisy was born in 1902 in Kentucky. With traditional census linking methods like Abramitzky et al. (2021) or Ferrie (1996), we would search for records in the 1930 Census with the name Daisy Fay, born in 1902 in Kentucky, likely with some tolerance for transcription errors or enumeration errors in these fields. However, if Daisy marries Tom Buchanan in 1922, we would have no way of knowing that Daisy Fay is likely known as Daisy Buchanan in 1930. Worse, if another woman named Daisy born in Kentucky around 1902 marries and takes a surname of Fay, we could falsely match two women who are not the same person. With our FamilySearch-based approach, we instead search for Daisy Fay on FamilySearch in 1920. If her 1920 record is attached to a page, we consider her on the tree. We then look to see if a FamilySearch user has also attached her to the census in 1930, possibly triangulating with knowledge of her name after marriage or her marriage date, either from personal knowledge or an attached marriage or birth certificate (or in Daisy's case, a prominent work of American literature). If she is attached in FamilySearch to both the 1920 and 1930 censuses, she will make our sample.

The set of operators in this sample is inevitably not random. This selection is not a threat to inference: we show in Appendix B.3 that rates of being on the tree or being linked from one census to the next are not correlated with our cutover treatment. While selection could still bias our estimates of the effect of cutovers on incumbent operators, selection in linking is not a problem unique to our source and setting. Bailey et al. (2017) document the general unrepresentativeness of most historical linked samples made via algorithms. To account for this bias, we follow Bailey et al. (2017) and construct inverse propensity weights (IPW). We describe the process in more depth in Appendix B, but in short, we use initial covariates to predict which records are more likely to be linked ahead. Key features include age, race, middle initial and name, name commonness, name length, marital status and fertility. We also control for differential linking by state of birth and 
state of residence in the base year, which helps us account for selection into the FamilySearch platform vis-à-vis descendants or genealogists today, among other issues. Many features have the predicted signs. Women with more common first names are less likely to be linked. Women from larger families or with children are more likely to be linked, likely because larger families increase the chance a descendant uses the FamilySearch platform. In addition, because FamilySearch is affiliated with the Church of Jesus Christ of Latter-Day Saints, women living in Utah or born in Utah are significantly more likely to be on the tree and linked ahead.

\section{Characteristics of Telephone Operators and Cutover Cities}

\subsection{Characteristics of telephone operators}

Table 1 gives a summary view of the young, white, American-born female population from 1910 to 1940, splitting the sample into 16-to-20 and 21-to-25 age groups. Labor force participation fell sharply for the younger group in this period (from $42.5 \%$ to $28.3 \%$ ), as more completed high school, while rising for the older group (from $37.7 \%$ to $45.2 \%$ ). In the $1920 \mathrm{~s}$, around 4 to $4.5 \%$ of working 16 to 20 year-olds at any given time were telephone operators, but this figure masks heterogeneity, as it approached $7 \%$ in western states. Considering that many women were operators for only a short period, usually early in their careers, the fraction of young women in the labor force that was ever an operator - and thus, the fraction of future cohorts that might suffer from the loss of these opportunities - would have been substantially larger (see Section 1).

[Table 1 about here]

We can measure the characteristics of telephone operators directly in the census data-including counting how many were young women. Table 2 reports the total population of telephone operators age 16+ from 1910 to 1940, split out by industry (telephone industry versus others), along with their demographics. The total number of operators working in the telephone industry was growing rapidly at the beginning of the century and peaked in 1930, at 180,000. Roughly $90 \%$ of these operators were white, American-born women throughout the period, but from 1910 to 1940, the occupation went from employing primarily younger $(\leq 25)$ to older $(26+)$ women, who were often senior operators, and more likely to be married and have families - suggesting that for some women, telephone operation was not just a job, but a career. Although non-telephone industries employed 
only 2,400 switchboard operators in 1910 (mostly men), by 1940 this population had grown to over 41,000 workers and mirrored the demographic characteristics of operators in the telephone industry. Telephone operation thus went from being a young women's job to an older women's job over the period covered in this paper, as local service was automated.

[Table 2 about here]

\subsection{Characteristics of cities with cutovers}

Why did different cities adopt dial when they did? Understanding this variation is an essential step for us to identify the effects of cutovers on labor market outcomes. In concurrent work (Feigenbaum and Gross 2021), we study what propelled AT\&T's automation of telephone operation and why it took nearly 60 years to complete. Drawing on both historical AT\&T company records and empirical evidence, we find that automation was primarily a response to the technical demands of a large and growing telephone network. The complexity of manual operation-and in turn, labor requirements and marginal costs - increased rapidly in network size, as the number of possible connections grew quadratically in subscribers. Lipartito (1994) similarly explains that manual switching was viewed by AT\&T as "a potentially serious bottleneck" as service expanded.

We verify this in Table 3, where we relate cutover occurrence and timing to city characteristics in the cross-section, measured in or circa 1910 (pre-treatment) where possible, and otherwise for the earliest period observed. The outcome variable in Columns (1) to (3) is an indicator for whether a city had a cutover pre-1940, and in Columns (4) to (6) is the year of its first cutover, measured in years. We regress these outcomes by OLS on a wide range of city characteristics, including population, demographics, education and income, labor force characteristics, and telephone operator union activity. Across all columns, population is the primary determinant of cutover occurrence and timing, explaining more variation then any other variable -including state fixed effects, which are included in all columns. ${ }^{18}$ In a full horserace regression, we find that cities with cutovers before 1940 were larger, richer, and more likely to have unionized telephone operators (Column 3), though population has nearly ten times the explanatory power of other variables. Conditional on having a pre-1940 cutover, larger cities had earlier cutovers (Column 6). ${ }^{19}$

\footnotetext{
${ }^{18}$ The $R^{2}$ of a regression of $\mathbb{1}$ (Any cutover pre-1940) on state fixed effects alone is 0.04 , and that of cutover year on state fixed effects alone is 0.05 . The partial $R^{2}$ of $\log$ population in each case is around 0.2.

${ }^{19}$ Appendix C provides additional evidence. Appendix Table C.1 shows mean city characteristics by the timing of a
} 
[Table 3 about here]

The results in this table underscore the importance of population in explaining cutovers, consistent with the unit economics of telephone service provision in large and rapidly-growing markets (see Feigenbaum and Gross 2021). In addition to city and year fixed effects, we will thus include year-specific controls for city population throughout our analysis, which can account for concurrent trends taking place in cities of different size. Later in the paper, we will also examine pre-trends and provide balance tests on changes in outcomes of interest, which will reinforce our confidence in our ability to identify the effect of cutovers on other outcomes.

Here it is also worth noting that there is residual idiosyncrasy in the timing of cutovers. Although it is easy to think of AT\&T as a monolith, recall that AT\&T was a holding company, parent to two dozen regional operating companies which comprised the Bell System. It was ultimately the operating companies' managers who made the decision to 'flip the switch', and sometimes, similar cities were automated at different times for independent reasons. For example, Lawrence, MA was cut over to dial in December 1924. Lowell, MA - a similar mid-size manufacturing town only 10 miles away - was not cut over until March 1939. Worcester, MA - slightly larger, but industrially similar — was cut over in June 1930 (Appendix A).

\section{Effects of Automation on Demand for Telephone Operators}

Our primary goal in this paper is to understand how the technology shock of mechanical switching affected the labor markets for both future generations of young women and incumbent operators. However, any such effects could only occur if mechanical switching - and our measure of its adoption by city - led to a decline in demand for telephone operators. In this section, we establish that both the number of telephone operators and the share of young, white, American-born women who were operators fell significantly after a city adopted mechanical switching.

city's first cutover, illustrating these patterns in the raw data. Appendix Figure C.2 shows that cutovers were not related to prior changes in labor market outcomes that are the focus of this paper, except for an increasing share of young women working in telephone operation - consistent with AT\&T's problem. Appendix Table C.6 shows that cutovers were not related to other, potentially-coincident technological changes. 


\subsection{Empirical approach}

We take two empirical approaches to studying the effects of dial. Here and in Section 5, we analyze effects on local labor markets with an event-study specification, exploiting the staggered adoption of mechanical switching and comparing outcomes before and after each city's first observed cutover. In Section 6, we turn to our linked samples and estimate the effects of cutovers on individual operators, comparing those in cities with cutovers to those without, controlling for a rich set of individual- and city-level covariates. Throughout, our focus will be the sample of cities with population $\leq 100,000$ in 1920 , where automation was typically a discrete event. ${ }^{20}$

Concretely, we estimate the following event-study specification:

$$
Y_{i j t}=\sum_{s} \beta_{s} D_{i t}^{s}+\zeta_{i j}+\eta_{j t}+X_{i j t} \phi+\varepsilon_{i j t}
$$

on a panel at the city-age-year level, where $i, j$ and $t$ index city, age, and census year, respectively; $\zeta_{i j}$, and $\eta_{j t}$ are associated fixed effects; and $X_{i j t}$ are time-varying controls. Events are measured at the city level, and $s$ indexes event time with respect to a city's first cutover, omitting the period immediately before this event, which serves as the reference point for the event study estimates $\left(\beta_{s}\right)$. In our primary specifications, we measure $s$ in 10 -year intervals, to be consistent with the decadal frequency with which outcomes are measured in the census. For certain analyses, we also estimate two-year intervals to better understand adjustment dynamics, with the important caveat that each bin (in event time) will contain different treated cities, since each city is measured once every ten years (and will thus be included in every fifth bin).

In nearly all specifications we will restrict attention to a single subpopulation (e.g., white, Americanborn women age 16 to 25 , pooled or by age). Our outcome variables generally take the form of the log number of people in that subpopulation of a certain type (e.g., the log number of telephone operators), or the fraction of that type (e.g., the fraction who are telephone operators), in which

\footnotetext{
${ }^{20}$ Recall from Section 2 that the focal city sample contains 2,922 cities, of which 332 have a cutover in our data before the 1940 census. For our event study strategy, we pare this sample to the 2,846 cities with 1920 population $\leq 100,000$ and without a cutover before 1917. This latter restriction is applied because our newspaper-based data collection was limited to articles published between 1917 and 1940, and our coverage of cutovers pre-1917 is therefore incomplete - although we do not consider this to be problematic, as pre-1917 cutovers were only performed by smaller, independent telephone companies (rather than AT\&T), and the results are not sensitive to this choice. We further reduce this sample to the 2,845 cities for which we have a balanced panel of young, white, American-born women. Of these 2,845 cities, 261 have a cutover pre-1940 census. In Appendix C.7, we also consider the "large" cities in the AT\&T data, for which we know the fraction of subscribers with dial service by 1940, and study long-difference outcomes as a function of this intensive measure of adoption.
} 
case we weight our regressions by population (the denominator). We are thus estimating pre- versus post-cutover changes across cities that had cutovers at different times, with fixed effects and other controls being estimated off of these cities as well as all other in our sample which did not have a cutover by 1940. We cluster standard errors at the city level.

Our standard set of controls $\left(X_{i j t}\right)$ consists of log city population by age and year, which account for differential trends taking place in larger and smaller cities over time, and which are especially important because city size is closely related to cutovers (Section 3). ${ }^{21}$ Although year fixed effects alone can account for national trends, many of these forces were trending locally at the same time as cutovers, and differentially so in cities of different sizes. As an empirical matter, these controls eliminate differential pre-trends across the outcomes we study.

After establishing that the immediate effect of cutovers is a permanent, approximately-level decline in the fraction of young women who were telephone operators, which is a difference-in-difference result, we will replace event studies with difference-in-difference specifications for other outcomes, often by individual ages, with the following specification:

$$
Y_{i j t}=\beta \cdot \mathbb{1}(\text { Post-Cutover })_{i t}+\alpha_{i}+\gamma_{j}+\delta_{t}+\zeta_{j t}+X_{i j t} \phi+\varepsilon_{i j t}
$$

\subsection{Effects of dial on operator jobs}

Were operator jobs eliminated by cutovers? Appendix Figure C.1 provides event study estimates of the effects of cutovers on employment shares in telephone operation. In the full (working age) population of men and women, cutovers cause a small but significant decrease in this share, of around 0.2 percentage points (p.p., in blue). However, as we know from Table 2, the vast majority of telephone operators were from a specific subgroup. As we narrow our focus to these demographic groups more likely to be operators, the magnitude of the effect grows, with declines in employment of roughly 0.9 p.p. among women (red) and 1.7 p.p. among young, white, American-born women (green). Relative to baseline operator employment share of $\approx 3.9 \%$ for young women (and $1.8 \%$ for all women), the decline is substantial, especially for entry level workers with weaker labor force attachment. This large exposure to the shock among young, white, American-born women motivates our focus in most of the rest of the paper on this demographic group.

\footnotetext{
${ }^{21}$ When the outcome is a log population of a certain type (e.g., log number of young, white, American-born women who are telephone operators), we also control for the log size of the focal demographic.
} 
Figure 3 shows the effects of cutovers on the (log) number of young, white American-born women who were telephone operators in the telephone industry, first in 10-year intervals (Panel A) and then in two-year intervals (Panel B), with associated 95\% confidence intervals. Cutovers caused a sharp decline in the number of young operators: though the number of young operators was on average growing moderately in the decades before a city's first cutover to dial, even conditional on overall population - consistent with AT\&T's motivations for adoption (as in Feigenbaum and Gross 2021) - it subsequently dropped by 50 to $80 \%$ (Panel A). Our higher-frequency estimates indicate that the cutover effect kicked in immediately (Panel B). ${ }^{22}$

[Figure 3 about here]

In Figure 4 we shift our focus from the number of operators to the fraction of young women's jobs that were automated away by cutovers. Panel (A) plots the high-frequency event study estimates for the percent of young, white, American-born women who were telephone operators, where it becomes apparent that automating local telephone operation immediately and permanently eliminated nearly $2 \%$ of area jobs for the group. This effect is measured in terms of the fraction of young women who were operators at a moment in time (the month the census was taken), but given high turnover, eliminating $2 \%$ of jobs may cut off entry-level job opportunities for several times as many people. Although we have thus far been estimating event studies, this view of the data also makes clear that the effect is in essence a difference-in-difference (DID) result, motivating our use of a DID strategy throughout the rest of the paper. Panel (B) estimates this DID, splitting the sample by individual ages (16 to 25 ). We see that mechanical switching hit the youngest ages the hardest, workers we might expect to be most vulnerable to labor force detachment in the face of such a large and long-lasting negative shock to labor demand.

[Figure 4 about here]

In Appendix C.5, we evaluate the robustness of these results to other estimation methods. A flurry of recent papers has highlighted the potential drawbacks of using two-way fixed effects (TWFE) models to estimate event studies with staggered treatment, especially in the presence of treatment effect heterogeneity or dynamic effects, and when most or all of the sample is treated. To a first

\footnotetext{
${ }^{22}$ Because we observe very few cities $20+$ years post-cutover (these are cities with a pre-1920 cutover observed in 1940), standard errors for the final event study bin are generally larger than for other periods.
} 
order, we do not expect these threats to be problematic in our setting for two reasons: (i) we have a very large sample of never-treated cities in the control group (over $90 \%$ of the cities in our sample are never-treated), and (ii) Figure 4 suggests this shock was a pure difference-in-difference, without time-varying effects. Even so, in Appendix Figure C.5 we present the event study estimates above using the estimators of Sun and Abraham (2021), Callaway and Sant'Anna (2021), and Borusyak et al. (2021), where we find consistent results across all four approaches. In light of this evidence, we will use TWFE estimators for the remainder of the paper.

We present two other robustness checks in the Appendix. First, although we are estimating these effects in all cities in the continental U.S. meeting our sampling criteria, our measurement of cutovers is in part dependent on the geographic coverage of our historical newspaper data sources. Incomplete measurement should in general only attenuate our results, as we would be mistakenly binning unobserved treated observations with the control group, and for this reason we believe our estimates to be a lower bound. To allay residual concerns about selection, we estimate the same regressions on a sample of cities which we know to have continuous coverage in our data sources from 1917 to 1940, where we find similar (if not slightly larger) effects on operator employment (Appendix C.6). Second, we also estimate the effects of dial in larger cities using the AT\&T sample and a long differences strategy - exploiting the intensity of local dial penetration in large cities from 1920 to 1940 - and find quantitatively similar results (Appendix C.7).

\section{$5 \quad$ Effects on Future Cohorts of Young Women}

Contemporary sources offer hints of what might have happened to incumbent operators and future cohorts of young women after dial, which we use as a guide in organizing our analysis. Newspaper articles sometimes discuss the fate of operators, including marriage (e.g., see Appendix A). A report produced by the Women's Bureau of the U.S. Department of Labor (Best 1933) provides a more nuanced view, informed by home visits to survey displaced operators in two cities, one of which experienced a one-shot cutover like those in our sample. Of the 78 women surveyed, a year later 18 were re-employed by the telephone company, and 33 in other industries - 10 in retail, 8 in clerical

jobs, 7 as PBX operators, 4 in factories, and others as waitresses, nurses, or beauticians - although many had spent time unemployed and subsequently had lower wages.

The report also noted that displaced operators were a "large enough group to be of public interest," 
and as a result, the telephone company "sought the cooperation of the [local] chamber of commerce ... in finding possible work for the operators affected" (Best 1933). This yielded jobs in "office work, sales work in stores, and counter work in restaurants." Some women moved to exchanges in other cities. But whereas incumbent operators may have had this informal safety net, future generations of young women who would have been operators in a world without dial had no such protections. Our interest here is specifically how these future cohorts fared.

The question which looms largest is whether cutovers reduced employment rates. Table 4 estimates the effects of cutovers on the fraction of young, white, American-born women who are working, in school, married, and have families, breaking out the results by age (16 to 25, 16 to 20, and 21 to 25). In the first column, we present the effect of cutovers on the fraction of each subgroup working as telephone operators, which serves as a reference point for effect sizes in other outcomes. We find no effects on the fraction of young women working, in school, married, or with children for any group, with relatively precise zeros. We can rule out unemployment increases of the magnitude of the shock itself at just above the $10 \%$ significance level, and can rule out greater impacts at lower levels, indicating that automating telephone operation does not appear to have sealed a larger population of young women's pathway into the workforce. ${ }^{23}$

[Table 4 about here]

If automation did not increase unemployment, what were these young women doing instead? To discipline our analysis of the effects of cutovers on employment in other occupations, we use information from Best (1933), occupation- and sex-specific wage distributions from NICB (1926), and data on the most common occupations for young women from the complete count data itself (Appendix Table A.2). Best (1933) identifies white-collar office work, factory work, service work, and sales counter work as candidate alternatives. Several of these are also among the most common occupations for young women, and the NICB data in particular reveals that typists, stenographers, and office machine operators had similar wages to telephone operation (Appendix Table A.3), which we consider the closest substitutes. In the analyses below, we restrict our attention to service sector jobs, where most of the adjustments appear to have been.

Table 5 estimates the DID effects of cutovers on the share of working young, white, American-born

\footnotetext{
${ }^{23}$ The standard error on this estimate suggests heterogeneity, which we will explore below. Note that the full-sample null effect is reinforced by evidence throughout the appendix, where in various robustness checks and subsamples, this estimate clusters around zero, and is not statistically significant.
} 
women in telephone operation versus in six other jobs: (i) office machine operators, (ii) typists, stenographers, and secretaries, (iii) other office clerks, (iv) sales clerks, (v) beauty parlor workers, and (vi) restaurant workers. ${ }^{24}$ Growth in middle-skill secretarial jobs and low-skill service jobs offset most of the operator jobs lost to automation. When examined by age, we find that "older" young women often moved into similar-paying secretarial jobs, whereas those of younger ages were more likely to be in lower-paying service jobs, like waitressing. ${ }^{25}$

[Table 5 about here]

Our robustness checks mirror those described in Section 4.2: Appendix C.6 presents estimates for cities with continuous newspaper coverage from 1917 to 1940, where we find qualitatively similar results. In this subsample, we see slightly more substitution into sales clerking, but standard errors are sufficiently large that we cannot rule out that the results are the same as in Table 5 . We also find similar results for our large city, long-differences sample, where if anything, even more of the occupational substitution was into waitressing, including at older ages.

\subsection{Pre-trends and balance tests}

A potential threat to this analysis is the possibility of confounding trends. For example, if cutovers were more likely to occur where young women's labor demand was growing, this could have softened the impact on employment. In Appendix Figure C.2 we provide balance tests, comparing prior-decade changes for cities which (i) experienced their first cutover in the next decade, to those which (ii) would not be cut over to dial for at least another decade. Importantly, there are no systematic changes in overall employment rates in the run-up to cutovers. We see modest evidence that employment rates in telephone operation were growing faster from 1920 to 1930 in cities with cutovers in the 1930s. In Appendix Figures C.3 and C.4, we plot the full event studies for these

\footnotetext{
${ }^{24}$ The effect of cutovers on telephone operation employment in Column (1) of both Tables 4 and 5 are of different magnitudes because each table is measuring outcomes within (slightly) different subpopulations. In Table 4, we study outcomes as a share of the white, American-born, female population, while in Table 5 we focus on white, American-born, women who are working. In both cases, we want the denominator in the first column to match the denominators in the rest of the table, to serve as a useful reference point.

${ }^{25}$ The magnitudes of these effects reinforce that young women's employment grew disproportionately in these occupations. Had future generations reallocated according to base employment rates, the share of young women in secretarial work would have increased by by $1.52 \times \frac{11.61}{100-1.52}=0.179$ p.p. (versus the estimated 0.54 p.p.), and the share in restaurant work to increase by $1.52 \times \frac{4.15}{100-1.52}=0.064$ p.p. (versus 0.83 p.p.). Other common occupations for women in this period besides the ones shown in the table include factory work, private household work, teaching, and nursing. We do not find that these occupations grew significantly after cutovers.
} 
outcomes, by age group, where we see little evidence of pre-trends; any such trends are only seen $\geq 20$ years prior to cutovers and are unlikely to be directly related.

\subsection{Why was employment so stable?}

The lack of an effect on overall employment raises the question of why local labor markets adjusted so smoothly to automating call switching. We explore five mechanisms through which labor demand might have recovered from this event, one general and then four drawn from task-based models of automation and economic growth. First, the specific episode of mechanization we study may coincide with broader technological changes which increased productivity growth and labor demand across the economy. Second, there could be direct effects of the technology on job creation: jobs or tasks that are direct complements of mechanical call switching. Third, an increase to aggregate productivity: as the cost of producing in automated tasks declines, the economy can grow, increasing demand for labor in non-automated activities. Fourth, automation could lead to capital accumulation which can in turn increase the returns to labor. Finally, and per Acemoglu and Restrepo (2019a) the most important, is task reinstatement: the endogenous creation of new functions and activities in which labor has comparative advantage.

We rule out contemporaneous technological changes that might have coincided with dial cutovers and offset its impacts. The two most transformative technologies of this period were electricity and motor vehicles, each of which diffused rapidly between 1900 and 1940 and had significant impacts on the organization of production. To evaluate whether these changes coincided locally with telephone industry automation, in Appendix C.8 we identify associated occupations and estimate whether

they grew or contracted after mechanical switching was adopted. We find that telephone operators per capita fell sharply after cutovers, but we find no concurrent changes in, e.g., electricians, auto mechanics, or truck drivers per capita. We interpret this evidence as indicating that cutovers did not locally coincide with the diffusion of these other technologies.

Did mechanical switching create any offsetting labor demand directly? For example, mechanization may have generated demand for technicians to maintain the mechanical equipment (though these were, in practice, predominantly male), or office clerks to perform non-automated residual operator tasks. Insofar as it supported a growing telephone network, mechanization may have also generated demand from other employers for private (internal) switchboard operators. We can rule out any such changes as a source of labor demand for young women: we see no effect of cutovers 
on the hiring of this demographic into non-operator jobs in the telephone industry, or on hiring into telephone operator jobs in other industries. Figure 5 presents these results, first with a pooled event study (top row) and then with DIDs by age (bottom row).

We next tackle the aggregate productivity hypothesis. In principle, automation can increase aggregate productivity sufficiently that growing labor demand exceeds displacement. The fact that mechanical switching was a limited (industry-specific) technology, and that countervailing employment growth was limited to a few occupations, already hints against this possibility. To evaluate this more formally, in Appendix C.9.1 we estimate the technical efficiency savings of mechanical switching outside of the telephone industry. Aggregating AT\&T's estimated 2.4 seconds saved per

call across all business calls yields a total annual time savings of less than 1.5 hours per business telephone. The time savings are thus small, and the telecommunications that automation supported were not otherwise different from those under manual switching. In newspaper articles, we also see that cutovers were typically accompanied by telephone rate increases, ruling out productivity growth from falling communication costs (Appendix Figure A.4). Because its aggregate impacts (beyond displacement) were so limited, we likewise believe that mechanical switching was unlikely to trigger capital accumulation or improvements in automation in other sectors.

\subsubsection{Task reinstatement: Labor demand in clerical and restaurant work}

The most straightforward interpretation, in our view, is that although automation displaced labor from telephone operation, through a mix of task creation and reallocation, the economy endogenously generated demand for would-be operators. This possibility is particularly persuasive given that these countervailing occupations matched their characteristics and comparative advantage. Employment, however, is an equilibrium outcome of both supply and demand. To validate the view that labor demand grew in these occupations, as employers found new uses for these types of workers, we need a way to specifically measure labor demand.

To approximate labor demand, we searched Newspapers.com for help-wanted classified advertisements by city, job title, and year. These searches return counts of newspaper issues in each city and year with a hit. Though these advertisements represent vacancies, rather than total demand, under the assumption that job listings are proportional to changes in demand (conditional on city and year fixed effects), they should be a sufficient statistic for demand growth. In Appendix C.9.2 we estimate the difference-in-differences effect of cutovers on the growth of job advertisements for 
four titles: typists, stenographers, secretaries, and waitresses. We find that help-wanted advertisements for typists and waitresses register a significant, roughly $20 \%$ increase after dial cutovers, with no such effects observed for stenographers or secretaries. As we explain in the appendix, the magnitudes of these effects are consistent with those in Table 5.

We see this evidence as supporting task reinstatement as an explanation for the muted effects of mechanical switching on young women's employment rates. Although these occupations were not new to the economy, firms and industries found new uses for these types of workers. This suggests task creation may be firm- or sector-specific, and reinstatement can be due as much to diffusion of tasks into new sectors as by the extensive creation of new tasks - though at the same time, as Autor et al. (2021) show for the 1940-1980 period, clerical occupations were growing quickly mid-century and the task content of these jobs was concurrently changing.

\subsubsection{Mediators of task reinstatement}

A corollary question is under what conditions the economy creates new demand that restores employment levels. For example, complementary technology or innovation-led structural transformation may also influence task creation, as the returns to generating new tasks that fit with the modern technological environment increase. Certain sectors may be more productive at task creation, especially for specific segments of the labor market. When aggregate demand is slack, task creation may be weakly incentivized and productivity impacts modest, such that displacement effects of automation may dominate - generating employment declines.

We explore these hypotheses in Appendix C.9.3. We first examine the technological environment, focusing again on the diffusion of electricity and automobiles, both of which increased productivity and led to factor reallocation across space and sectors. We next consider local economic diversity, conjecturing that cities with a more diverse employment base may be more resilient to automation shocks. We compute, for each city, a Herfindahl index of 1910 employment across economic sectors. We also use these data to measure cities' 1910 manufacturing share of employment, which provides a distinct view of local economic structure. We also study heterogeneity across cities which were more versus less severely exposed to the Great Depression, using the Fishback et al. (2005) measure of county per-capita retail sales contractions from 1929 to 1933.

We do not find any differential effects of cutovers across cities by technological conditions. They do, however, relate to two economic factors: manufacturing intensity and Great Depression sever- 
ity. Because manufacturing was a predominantly male industry, manufacturing-intensive cities may have been less conducive environments for task reinstatement for young women. We also find that in cities with the most severe contractions during the Great Depression, cutovers were followed by employment declines. This suggests that aggregate demand has a direct impact on whether, when, and to what degree labor demand can recover from large automation shocks. That the estimated effect is monotonic in depression severity reinforces this takeaway.

\section{Effects on Incumbent Telephone Operators}

We also ask what happened to incumbent telephone operators after the installation of mechanical switching. We estimate the effects of cutovers on women who were telephone operators in the most recent census, many of whose jobs were replaced by the new technology.

\subsection{Empirical approach}

Our empirical strategy is straightforward. Using our sample of women telephone operators in 1920 and 1930 (year $t$ ) linked to their next census record (in $t+10$ ), comparing them to a matched set of women from the same census enumeration district, and retaining our focus on women in "small" cities with population $\leq 100,000$ in 1920 , we estimate the effects of a cutover in the intervening decade on individual operators' outcomes ten years later:

$$
Y_{i c t}^{t+10}=\beta_{1} \cdot \mathbb{1}(\text { Operator })_{i} \cdot \mathbb{1}(\text { Cutover })_{c t}+\beta_{2} \cdot \mathbb{1}(\text { Operator })_{i}+\delta_{c t}+X_{i} \phi+\varepsilon_{i c t}
$$

where $Y_{i c t}^{t+10}$ represents an outcome in year $t+10$ for a woman $i$ who lived in city $c$ in year $t$, $\mathbb{1}$ (Cutover) $)_{c t}$ indicates that city $c$ was cut over to dial between $t$ and $t+10, \delta_{c t}$ are city-year fixed effects, and $X_{i}$ are individual-level controls. ${ }^{26}$ In our most demanding specification, we replace the city-year fixed effects with operator-year fixed effects, which conditions comparisons to within individual operators and their associated control women. In the tables below, we present results

\footnotetext{
${ }^{26}$ This specification will thus estimate differential outcomes in the post-period of telephone operators which were versus were not subject to a cutover in the intervening decade, relative to outcomes of similar women from the same local area. The control group is matched on age $( \pm 5)$, sex, race, nativity, parents' nativity, marital status, and fertility, all measured in year $t$, and conditioned on having an occupation in year $t$. Individual controls consist of fixed effects for age, race, birthplace, and marital status in year $t$.
} 
pooling the 1920-30 and 1930-40 linked samples. We cluster standard errors by city and use inverse propensity weights to account for selection in our linking procedure (Bailey et al. 2017).

\subsection{Effects on incumbent telephone operators}

We begin our analysis in Table 6 by studying the effects of cutovers on the probability that a year- $t$ operator: (i) was still a telephone operator in the telephone industry in $t+10$, (ii) had a non-operator job in the telephone industry, or (iii) was an operator in another industry. We initially show results for year- $t$ operators of all ages (Columns 1 and 2), and subsequently break out the effects for those age 16-20 (Columns 3 and 4), 21-25 (Columns 5 and 6), and 26+ (Columns 7 and 8). All columns include individual-level controls. Odd-numbered columns add city-year fixed effects, and even-numbered columns operator-year fixed effects.

\section{[Table 6 about here]}

Echoing our results from Section 4, cutovers significantly reduced the likelihood of employment as telephone operators in the telephone industry. Table 6, Panel (A) shows that women who were operators in the base year were 8 p.p. less likely to be operators ten years later if exposed to a cutover (Columns 1 and 2). This effect shaves roughly one-third off of the base rate at which these women continued working as telephone operators in non-cutover cities, relative to their matched controls. The cutover effects are largest for women aged $26+$, the set of operators who were most likely to remain employed as operators without a cutover.

What did these former telephone operators do instead? Natural alternatives are other jobs in the telephone industry or working as a private switchboard operator in a different industry. However, the data reject the importance of either of these margins of adjustment. Former telephone operators were very unlikely to do either, independent of cutovers or as a result of them (Table 6, Panels B and C). Although the odds of working other jobs in the telephone industry or as a telephone operator in another industry increased modestly after a cutover for women under 25, these effects can only account for a small fraction of overall operator displacement (compare the magnitudes on the cutover interactions in Panel A with Panels B and C).

We show in Table 7, Panel (A) that cutovers pushed many incumbent operators out of the labor entirely. Operators who were over age 25 in the base year were roughly 7 p.p. less likely to still be 
working after a cutover, relative to peers in untreated cities - accounting for more than half of the displacement of operators in this age group. However, cutovers had smaller and less statistically precise effects on younger women's employment (those under 25 in the base year).

[Table 7 about here]

We supplement this evidence by studying in Panels (B) and (C) the likelihood that a year- $t$ operator got married or had children between $t$ and $t+10$ (conditional on initially having been single/having had no children in year $t$, respectively), since family may have been an alternative to work for this population and time period. The evidence suggests that cutovers may have increased the odds that older, unmarried operators subsequently wed, though the results are of marginal significance and small relative to base rates of entry into marriage for our sample. Cutovers had no discernible effects on marriage or fertility among younger operators.

In Table 8, we find that operators who continued working were roughly 11 p.p. (or early 40\%) more likely than their peers to switch careers, and suggestive evidence that their new occupations were lower status after automation. Panel (A) estimates the effects of cutovers on the probability of changing occupation or industry, where career switching is visible. Though this change was all but implied for a job that was automated by a monopsonist employer, the results are similar when the outcome is an indicator for changing occupation alone or changing industry alone. In Panels (B) and $(\mathrm{C})$, we estimate the effect of cutovers on log occupation score (a commonly-used occupationlevel proxy for income, measuring occupations' median income - and which we calculate specifically for women in 1940, the first year that income is measured in the census) and the likelihood that a worker was in a lower-paying occupation in $t+10$ than in $t .{ }^{27}$ The occupation score of operators who were exposed to cutovers and are still working a decade later on average fell by $5 \%$, at the same time as their untreated peers' occupation scores increased 8\%, with similar effects across ages. Roughly $10 \%$ of these women end up in a lower-paying job a decade later.

[Table 8 about here]

\footnotetext{
${ }^{27}$ We study whether operators in year $t$ were in higher- versus lower-paying jobs ten years later, rather than focusing on whether year- $t$ operators transitioned into specific occupations after cutovers, because older women tended to be distributed across many more occupations. To answer this question we construct occupation scores for women in 1940 as the median earnings reported among all women in 1940 in each occupation, analogous to how IPUMS creates occupation scores for the entire population in 1950.
} 


\subsection{Connections to cohort results}

Taken together, the results from Sections 5 and 6 suggest the effects of automation on employment vary by age. Older incumbent workers, who may have spent years building occupationand firm-specific human capital that is suddenly obsolete, are more adversely affected. Younger workers - including future generations not yet in the labor force, or not even yet born-are more adaptive to an evolving labor market. This, in short, is where the two results meet.

These heterogeneous effects of automation by age are consistent with the task-based view of automation, where mismatched tasks and skills can impede labor market adjustments (Acemoglu and Restrepo 2019a), as well as with recent evidence from Humlum (2021), who finds that the welfare impacts of industrial robots are concentrated in older displaced workers. They also echo findings from the larger literature on displacement. Though Jacobson et al. (1993) report that displaced workers' earnings losses "depend only slight on their age," subsequent work has documented agebased heterogeneity (e.g., Farber 1997). Older workers' skills are often specific and thus difficult to transfer. ${ }^{28}$ These difficulties are only magnified when automation eliminates an entire occupation and forecloses future opportunities in that field, as in this paper.

\section{Conclusion}

The automation of telephone operation is among the largest discrete automation shocks in history. The specificity of the job, which is coincident with the automated task (call switching), makes it a unique opportunity to study what happens to employment when technology replaces an entire major category of work, and to connect the evidence to task-based theories of automation and technical change. Using panel variation in the local adoption of mechanical switching and population outcomes from complete count census data from 1910 to 1940, we show that dial cutovers presented a large negative shock to local labor demand for young, white, American-born women, with the number of young operators dropping by upwards of $80 \%$ - a near-total collapse in entry-level hiring in one of the country's largest occupations for young women. Around $2 \%$ of jobs for this group were permanently replaced by machines upon the flip of a switch.

These $2 \%$ of jobs represented entry-level opportunities for several times as many young women, and one fear is that its automation might choke off future generations from the labor force. More

${ }^{28}$ See, e.g., Poletaev and Robinson (2008), Carrington (1993), Neal (1995), Gibbons and Waldman (2004). 
broadly, whether an abrupt shock of this scale can be offset by countervailing demand growth is an open question. We find that it did not reduce future cohorts' employment rates. Instead, demand in comparable middle-skill office jobs and lower-skill service jobs grew to absorb future generations of young workers, and did so fairly quickly. The adverse consequences of automation were concentrated in incumbent telephone operators, who were subsequently less likely to be working, and conditional on working, more likely to be in lower-paying occupations.

We consider these results to be a distinctive reference point in the growing literature on how automation affects workers and labor markets. We find that dislocations do occur, but new demand for labor can develop fairly quickly after existing tasks get automated. A residual question, however, is how much bearing historical episodes have for the present-i.e., whether "this time is different". Though a complete answer is beyond the scope of this paper, a few points are worth noting. Through the lens of theory, the factors at play are thought to be time-invariant. Jobs which were growing in this period (like office work) were a natural source of countervailing labor demand-yet our evidence indicates that they specifically, differentially grew after telephone operation was automated, suggesting this growth was endogenous to automation. The necessity of complementary investments also required that cutovers be planned in advance - a fact we see firsthand in newspaper reporting. This advance notice may have allowed young women nearing working age to change their educational investments and early career choices, smoothing the adjustment process. Most automation threats today are slated to take place over longer horizons, and it is unlikely $2 \%$ of local jobs will spontaneously be automated with less warning.

This historical case study raises many other questions. For example, when the workplace is a key nexus for social ties (as it was for operators), automation or other shocks that eliminate jobs may also break or weaken these ties, or preclude them from forming at all. If so, industrial decline might link to declining community and social capital. Technological change may also have spillover effects from affected workers to their families, not only due to the resulting economic insecurity but also because in some blue-collar professions, jobs themselves can be intergenerationally transmitted. History provides fertile ground for further research on these and other questions, which we believe is warranted given growing concerns about automation today.

\section{References}

Abramitzky, Ran, Leah Boustan, Katherine Eriksson, James Feigenbaum, and Santiago Pérez. 2021. "Automated linking of historical data," Journal of Economic Literature, Vol. 59, No. 3, pp. 865-918. 
Acemoglu, Daron. 1998. "Why Do New Technologies Complement Skills? Directed Technical Change and Wage Inequality," The Quarterly Journal of Economics, Vol. 113, No. 4, pp. 1055-1089.

Acemoglu, Daron and Pascual Restrepo. 2018. "The Race between Man and Machine: Implications of Technology for Growth, Factor Shares, and Employment," American Economic Review, Vol. 108, No. 6, pp. 1488-1542.

_ 2019a. "Artificial Intelligence, Automation, and Work," in Agrawal, Ajay, Joshua Gans, and Avi Goldfarb eds. The Economics of Artificial Intelligence: An Agenda, Chicago: University of Chicago Press, pp. 197-236.

_ 2019b. "Automation and New Tasks: How Technology Displaces and Reinstates Labor," Journal of Economic Perspectives, Vol. 33, No. 2, pp. 3-30.

- 2020. "Robots and Jobs: Evidence from U.S. Labor Markets," Journal of Political Economy, Vol. 128, No. 6, pp. 2188-2244.

Adachi, Daisuke, Daiji Kawaguchi, and Yukiko U. Saito. 2020. Robots and Employment: Evidence from Japan, 1978-201\%. Working paper.

Aghion, Philippe, Céline Antonin, Simon Bunel, and Xavier Jaravel. 2021. What Are the Labor and Product Market Effects of Automation? New Evidence from France. Working paper.

AT\&T. 1937. First Dial Cutover and Per Cent Dial Stations of Total Stations (as of 12-31-37) in Cities of 50,000 Population or Over. In Freeman (1937), "History of the Development of the Panel Machine Switching System," available at AT\&T Archives and History Center (Warren, NJ), Box 106-10-02-07.

Autor, David H. 2015. "Why Are There Still So Many Jobs? The History and Future of Workplace Automation," Journal of Economic Perspectives, Vol. 29, No. 3, pp. 3-30.

Autor, David H., Lawrence F. Katz, and Alan B. Krueger. 1998. "Computing Inequality: Have Computers Changed the Labor Market?" Quarterly Journal of Economics, Vol. 113, No. 4, pp. 1169-1213.

Autor, David H., Frank Levy, and Richard J. Murnane. 2003. "The Skill Content of Recent Technological Change: An Empirical Exploration," The Quarterly Journal of Economics, Vol. 118, No. 4, pp. 1279-1333.

Autor, David H., Anna Salomons, and Bryan Seegmiller. 2021. The Origins and Content of New Work, 1940-2018. Working paper.

Bailey, Martha J., Connor Cole, Morgan Henderson, and Catherine Massey. 2017. How Well Do Automated Methods Perform in Historical Samples? Evidence from New Ground Truth. NBER Working Paper 24019.

Bessen, James E. 2015. Learning by Doing: The Real Connection between Innovation, Wages, and Wealth. New Haven: Yale University Press.

Bessen, James E., Maarten Goos, Anna Salomons, and Wiljan Van den Berge. 2019. Automatic Reaction: What Happens to Workers at Firms that Automate? Boston University School of Law, Law and Economics Research Paper No. 19-2.

Best, Ethel. 1933. The Change from Manual to Dial Operation in the Telephone Industry. Bulletin of the Women's Bureau No. 110.

Borusyak, Kirill, Xavier Jaravel, and Jann Spiess. 2021. Revisiting event study designs: Robust and efficient estimation. arXiv preprint arXiv:2108.12419.

Brynjolfsson, Erik and Andrew McAfee. 2014. The Second Machine Age: Work, Progress, and Prosperity in a Time of Brilliant Technologies. New York: W.W. Norton \& Company.

Callaway, Brantly and Pedro HC Sant'Anna. 2021. "Difference-in-Differences with Multiple Time Periods," Journal of Econometrics, Vol. 225, No. 2, pp. 200-230.

Carrington, William J. 1993. "Wage losses for displaced workers: Is it really the firm that matters?" Journal of Human Resources, pp. 435-462. 
Chiacchio, Francesco, Georgios Petropoulos, and David Pichler. 2018. The Impact of Industrial Robots on EU Employment and Wages: A Local Labour Market Approach. Working paper.

Craig, Jacqueline, Katherine Eriksson, and Gregory T. Niemesh. 2019. Marriage and the Intergenerational Mobility of Women: Evidence from Marriage Certificates 1950-1910. Working paper.

Cuccu, Liliana and Vicente Royuela. 2022. Just reallocated? Robots, displacement and job quality. Working paper.

Dauth, Wolfgang, Sebastian Findeisen, Jens Suedekum, and Nicole Woessner. 2018. Adjusting to Robots: Worker-Level Evidence. Opportunity \& Inclusive Growth Institute Working Paper 13.

Dillender, Marcus and Eliza Forsythe. 2019. Computerization of White Collar Jobs. Upjohn Institute Working Paper 19-310.

Edin, Per-Anders, Tiernan Evans, Georg Graetz, Sofia Hernnäs, and Guy Michaels. 2019. Individual consequences of occupational decline.: CEPR DP No. 13808.

Erickson, Ethel. 1946. The Woman Telephone Worker. Bulletin of the Women's Bureau No. 207.

Farber, Henry. 1997. "The Changing Face of Job Loss in the United States, 1981-1995," Working Papers 761, Princeton University, Department of Economics, Industrial Relations Section. URL: https://EconPapers.repec.org/RePEc:pri:indrel:382.

Feigenbaum, James J. and Daniel P. Gross. 2021. Organizational Frictions and Increasing Returns to Automation: Lessons from ATEST in the Twentieth Century. Working paper.

Ferrie, Joseph P. 1996. "A New Sample of Males Linked from the Public use Microdata Sample of the 1850 U.S. Federal Census of Population to the 1860 U.S. Federal Census Manuscript Schedules," Historical Methods: A Journal of Quantitative and Interdisciplinary History, Vol. 29, No. 4, pp. 141-156.

Gherardi, Bancroft. 1917. Memorandum for J. J. Carty, Chief Engineer. Appendix to Freeman (1937), "History of the Development of the Panel Machine Switching System," available at AT\&T Archives and History Center (Warren, NJ), Box 106-10-02-07.

Gibbons, Robert and Michael Waldman. 2004. "Task-specific human capital," American Economic Review, Vol. 94, No. 2, pp. 203-207.

Goldin, Claudia. 1984. "The Historical Evolution of Female Earnings Functions and Occupations," Explorations in Economic History, Vol. 21, No. 1, pp. 1-27.

1988. Marriage Bars: Discrimination Against Married Women Workers, 1920's to 1950's. NBER Working Paper 2747.

. 1998. "America's Graduation from High School: The Evolution and Spread of Secondary Schooling in the Twentieth Century," The Journal of Economic History, Vol. 58, No. 2, pp. 345-374.

. 2006. "The Quiet Revolution that Transformed Women's Employment, Education, and Family," AER: Papers and Proceedings, Vol. 96, No. 2, pp. 1-21.

Goldin, Claudia and Lawrence F. Katz. 2008. The Race between Education and Technology. Cambridge: Harvard University Press.

Goldin, Claudia and Claudia Olivetti. 2013. "Shocking Labor Supply: A Reassessment of the Role of World War II on Women's Labor Supply," American Economic Review, Vol. 103, No. 3, pp. 257-62.

Graetz, Georg and Guy Michaels. 2018. "Robots at Work," Review of Economics and Statistics, Vol. 100, No. 5, pp. 753-768.

Gray, Rowena. 2013. "Taking Technology to Task: The Skill Content of Technological Change in Early Twentieth Century United States," Explorations in Economic History, Vol. 50, No. 3, pp. 351-367.

Hochheiser, Sheldon. 2017. Conversation with Sheldon Hochheiser, ATET Corporate Historian. 
Humlum, Anders. 2021. Robot Adoption and Labor Market Dynamics. Working paper.

Jacobson, Louis S, Robert J LaLonde, and Daniel G Sullivan. 1993. "Earnings losses of displaced workers," American Economic Review, pp. 685-709.

Janssen, Simon and Jens Mohrenweiser. 2018. The shelf life of incumbent workers during accelerating technological change: Evidence from a training regulation reform. IZA DP No. 11312.

Jaworski, Taylor. 2014. "“You're in the Army Now:" The Impact of World War II on Women's Education, Work, and Family," The Journal of Economic History, Vol. 74, No. 1, pp. 169-195.

Koch, Michael, Ilya Manuylov, and Marcel Smolka. 2021. "Robots and Firms," The Economic Journal, Vol. 131, No. 638, pp. 2553-2584.

Lipartito, Kenneth. 1994. "When Women Were Switches: Technology, Work, and Gender in the Telephone Industry, 1890-1920," American Historical Review, Vol. 99, No. 4, pp. 1075-1111.

Lleras-Muney, Adriana, Joseph Price, and Dahai Yue. 2020. The Association Between Educational Attainment and Longevity using Individual Level Data from the 1940 Census. NBER Working Paper 27514.

Marchingiglio, Riccardo and Michael Poyker. 2020. The Economics of Gender-Specific Minimum-Wage Legislation. Working paper.

Michelman, Valerie, Joseph Price, and Seth D. Zimmerman. 2020. The Distribution of and Returns to Social Success at Elite Universities.

National Industrial Conference Board (NICB). 1926. Clerical Salaries in the United States.

Neal, Derek. 1995. "Industry-specific human capital: Evidence from displaced workers," Journal of labor Economics, Vol. 13, No. 4, pp. 653-677.

O'Connor, W. J. 1930. Effects of Dial Operation on Employment in the Telepone Business (May 31). Available at AT\&T Archives and History Center (Warren, NJ), Box 127-01-01-07.

Olivetti, Claudia and M. Daniele Paserman. 2015. "In the Name of the Son (and the Daughter): Intergenerational Mobility in the United States, 1850-1940," American Economic Review, Vol. 105, No. 8, pp. 2695-2724.

Poletaev, Maxim and Chris Robinson. 2008. "Human capital specificity: evidence from the Dictionary of Occupational Titles and Displaced Worker Surveys, 1984-2000," Journal of Labor Economics, Vol. 26, No. 3, pp. 387-420.

Price, Joseph, Kasey Buckles, Jacob Van Leeuwen, and Isaac Riley. 2019. Combining Family History and Machine Learning to Link Historical Records. NBER Working Paper 26227.

Price, Joseph, Christian vom Lehn, and Riley Wilson. 2020. The Winners and Losers of Immigration: Evidence from Linked Historical Data. NBER Working Paper 27156.

Ruggles, Steven. 2002. "Linking Historical Censuses: A New Approach," History and Computing, Vol. 14, No. 1-2, pp. 213-224.

Ruggles, Steven, Sarah Flood, Ronald Goeken, Josiah Grover, Erin Meyer, Jose Pacas, and Matthew Sobek. 2019. IPUMS USA: Version 9.0 [dataset]. Minneapolis, MN https://doi.org/10.18128/D010.V9.0.

Sun, Liyang and Sarah Abraham. 2021. "Estimating Dynamic Treatment Effects in Event Studies with Heterogeneous Treatment Effects," Journal of Econometrics, Vol. 225, No. 2, pp. 175-199.

U.S. Bureau of Labor Statistics (BLS). 2019. Occupational Outlook Handbook. Accessed September 2019 for Cashiers, General Office Clerks, and Customer Service Representatives.

— 2022. Employment Situation Report. Accessed March 2022.

Withrow, Jennifer. 2020. The Farm Woman's Problem: Farm Crisis in the U.S. South and Migration to the City, 1920-1940. Working paper. 
Table 1: Employment of white, American-born women age 16-20 and 21-25, 1910-1940

\begin{tabular}{|c|c|c|c|c|c|c|c|c|}
\hline & \multicolumn{4}{|c|}{ Age range: $16-20$} & \multicolumn{4}{|c|}{ Age range: $21-25$} \\
\hline & 1910 & 1920 & 1930 & 1940 & 1910 & 1920 & 1930 & 1940 \\
\hline Population (1000s) & 2427.6 & 2690.9 & 3618.4 & 4043.3 & 2295.9 & 2769.8 & 3509.4 & 4148.5 \\
\hline Working population (1000s) & 1032.3 & 1215.6 & 1409.0 & 1143.0 & 865.8 & 1124.9 & 1556.9 & 1873.5 \\
\hline Labor force participation & $42.5 \%$ & $45.2 \%$ & $38.9 \%$ & $28.3 \%$ & $37.7 \%$ & $40.6 \%$ & $44.4 \%$ & $45.2 \%$ \\
\hline Percent tel. oper. in tel. ind. & $3.2 \%$ & $4.5 \%$ & $4.0 \%$ & $1.3 \%$ & $2.3 \%$ & $3.3 \%$ & $3.3 \%$ & $1.5 \%$ \\
\hline \multicolumn{9}{|c|}{ Percent tel. operators in tel. industry, by census region (\%) } \\
\hline Northeast & 2.4 & 3.6 & 3.7 & 0.8 & 1.9 & 3.3 & 3.2 & 1.1 \\
\hline Midwest & 3.6 & 4.8 & 4.2 & 1.4 & 2.5 & 3.3 & 3.3 & 1.6 \\
\hline South & 3.5 & 5.6 & 4.4 & 1.7 & 2.3 & 3.1 & 3.2 & 1.6 \\
\hline West & 5.2 & 6.8 & 4.0 & 2.4 & 2.8 & 4.4 & 3.5 & 2.4 \\
\hline \multicolumn{9}{|c|}{ Percent tel. operators in tel. industry, by city size (in 1920) (\%) } \\
\hline Population $2-5 \mathrm{k}$ & 4.3 & 5.1 & 4.0 & 1.3 & 3.1 & 3.8 & 3.5 & 1.4 \\
\hline Population $5-10 \mathrm{k}$ & 3.7 & 4.5 & 3.5 & 1.3 & 2.8 & 3.4 & 3.3 & 1.5 \\
\hline Population $10-20 \mathrm{k}$ & 3.2 & 4.2 & 3.7 & 1.3 & 2.3 & 3.0 & 3.1 & 1.4 \\
\hline Population $20-50 \mathrm{k}$ & 2.8 & 3.8 & 3.9 & 1.2 & 2.0 & 2.7 & 3.0 & 1.5 \\
\hline Population $50-100 \mathrm{k}$ & 2.6 & 4.0 & 3.4 & 1.2 & 1.6 & 2.6 & 2.8 & 1.5 \\
\hline Population 100-200k & 3.0 & 4.8 & 4.0 & 1.6 & 1.9 & 3.1 & 3.2 & 1.6 \\
\hline Population $>200 \mathrm{k}$ & 3.3 & 4.9 & 4.8 & 1.3 & 2.2 & 3.7 & 3.7 & 1.5 \\
\hline
\end{tabular}

Notes: Table reports employment characteristics for white, American-born women age 16-20 and 21-25, by year. Employment rates in telephone operation are computed as a percentage of the working population. Breakdowns by city size are for the 3,027 cities in our primary sample (see Appendix B).

Table 2: Characteristics of telephone operators, 1910-1940

\begin{tabular}{|c|c|c|c|c|c|c|c|c|}
\hline & \multicolumn{4}{|c|}{ Telephone industry } & \multicolumn{4}{|c|}{ Other industries } \\
\hline & 1910 & 1920 & 1930 & 1940 & 1910 & 1920 & 1930 & 1940 \\
\hline Population (1000s) & 73.03 & 134.63 & 182.04 & 152.70 & 2.40 & 5.74 & 22.83 & 41.17 \\
\hline \multicolumn{9}{|l|}{ Composition (\%) } \\
\hline Percent female & 90.1 & 94.6 & 96.2 & 91.9 & 22.3 & 66.6 & 86.4 & 87.4 \\
\hline \& native-born & 86.7 & 90.8 & 92.3 & 88.8 & 20.9 & 62.7 & 82.1 & 83.9 \\
\hline \& white/non-Hisp & 86.3 & 90.5 & 92.0 & 88.2 & 20.8 & 61.8 & 81.3 & 83.1 \\
\hline \& young (16-25) & 71.8 & 68.5 & 59.2 & 27.8 & 14.4 & 39.8 & 41.0 & 22.2 \\
\hline Percent married & 7.6 & 11.9 & 22.7 & 40.3 & 40.3 & 30.7 & 30.7 & 39.6 \\
\hline Percent has children & 5.6 & 8.2 & 12.4 & 22.1 & 28.0 & 21.0 & 17.4 & 23.4 \\
\hline
\end{tabular}

Notes: Table shows the number of telephone operators in the U.S. complete count Census data in the telephone industry and in other industries (i.e., at private company switchboards) from 1910 to 1940, as well as their demographic composition. 
Table 3: Determinants of automation: What explains cutovers?

\begin{tabular}{|c|c|c|c|c|c|c|}
\hline & \multicolumn{3}{|c|}{ Any cutover by $1940 ?$} & \multicolumn{3}{|c|}{ Timing of earliest cutover } \\
\hline & (1) & $(2)$ & $(3)$ & (4) & (5) & $(6)$ \\
\hline Ln(Population) & $\begin{array}{c}0.146^{* * *} \\
(0.007)\end{array}$ & $\begin{array}{c}0.138^{* * *} \\
(0.007)\end{array}$ & $\begin{array}{c}0.137^{* * *} \\
(0.007)\end{array}$ & $\begin{array}{c}-1.744^{* * *} \\
(0.200)\end{array}$ & $\begin{array}{c}-1.746^{* * *} \\
(0.218)\end{array}$ & $\begin{array}{c}-1.986^{* * *} \\
(0.247)\end{array}$ \\
\hline Percent black & & $\begin{array}{c}-0.002^{* *} \\
(0.001)\end{array}$ & $\begin{array}{l}-0.004 \\
(0.003)\end{array}$ & & $\begin{array}{c}0.126^{* *} \\
(0.063)\end{array}$ & $\begin{array}{c}0.085 \\
(0.165)\end{array}$ \\
\hline Percent foreign & & $\begin{array}{l}-0.000 \\
(0.001)\end{array}$ & $\begin{array}{l}-0.001 \\
(0.002)\end{array}$ & & $\begin{array}{c}0.024 \\
(0.047)\end{array}$ & $\begin{array}{c}0.063 \\
(0.137)\end{array}$ \\
\hline Percent MS grads, 1940 & & $\begin{array}{l}-0.000 \\
(0.001)\end{array}$ & $\begin{array}{l}-0.000 \\
(0.001)\end{array}$ & & $\begin{array}{c}-0.111 \\
(0.111)\end{array}$ & $\begin{array}{l}-0.133 \\
(0.112)\end{array}$ \\
\hline Percent HS grads, 1940 & & $\begin{array}{c}0.001 \\
(0.002)\end{array}$ & $\begin{array}{c}0.002 \\
(0.002)\end{array}$ & & $\begin{array}{l}-0.017 \\
(0.099)\end{array}$ & $\begin{array}{l}-0.022 \\
(0.114)\end{array}$ \\
\hline Ln(Avg. income, 1940) & & $\begin{array}{c}0.117^{* * *} \\
(0.033)\end{array}$ & $\begin{array}{c}0.107^{* * *} \\
(0.033)\end{array}$ & & $\begin{array}{c}0.315 \\
(2.762)\end{array}$ & $\begin{array}{c}0.882 \\
(2.860)\end{array}$ \\
\hline Average occupation score & & $\begin{array}{l}-0.000 \\
(0.003)\end{array}$ & $\begin{array}{c}0.001 \\
(0.004)\end{array}$ & & $\begin{array}{c}0.225 \\
(0.341)\end{array}$ & $\begin{array}{c}0.365 \\
(0.367)\end{array}$ \\
\hline Unionized by 1920 & & $\begin{array}{c}0.086^{* *} \\
(0.036)\end{array}$ & $\begin{array}{c}0.086^{* *} \\
(0.036)\end{array}$ & & $\begin{array}{l}-2.042 \\
(1.285)\end{array}$ & $\begin{array}{l}-1.793 \\
(1.297)\end{array}$ \\
\hline Had strike by 1920 & & $\begin{array}{c}0.065 \\
(0.052)\end{array}$ & $\begin{array}{c}0.064 \\
(0.052)\end{array}$ & & $\begin{array}{c}0.566 \\
(1.498)\end{array}$ & $\begin{array}{c}0.717 \\
(1.478)\end{array}$ \\
\hline Percent female & & & $\begin{array}{l}-0.002 \\
(0.003)\end{array}$ & & & $\begin{array}{c}0.197 \\
(0.134)\end{array}$ \\
\hline Percent f/n & & & $\begin{array}{c}0.006 \\
(0.006)\end{array}$ & & & $\begin{array}{c}0.076 \\
(0.360)\end{array}$ \\
\hline Percent $\mathrm{f} / \mathrm{n} / \mathrm{w}$ & & & $\begin{array}{l}-0.006 \\
(0.006)\end{array}$ & & & $\begin{array}{l}-0.112 \\
(0.328)\end{array}$ \\
\hline Percent $\mathrm{f} / \mathrm{n} / \mathrm{w} / \mathrm{y}$ & & & $\begin{array}{c}0.002 \\
(0.003)\end{array}$ & & & $\begin{array}{c}-0.022 \\
(0.342)\end{array}$ \\
\hline $\mathrm{F} / \mathrm{n} / \mathrm{w} / \mathrm{y}$ pct. working & & & $\begin{array}{c}0.000 \\
(0.001)\end{array}$ & & & $\begin{array}{c}0.044 \\
(0.050)\end{array}$ \\
\hline $\mathrm{F} / \mathrm{n} / \mathrm{w} / \mathrm{y}$ pct. operators & & & $\begin{array}{l}-0.005 \\
(0.006)\end{array}$ & & & $\begin{array}{l}-0.290 \\
(0.405)\end{array}$ \\
\hline $\mathrm{N}$ & 2992 & 2986 & 2986 & 332 & 332 & 332 \\
\hline$R^{2}$ & 0.25 & 0.26 & 0.26 & 0.31 & 0.34 & 0.35 \\
\hline Y mean & 0.13 & 0.13 & 0.13 & 1929.08 & 1929.08 & 1929.08 \\
\hline State FEs & Y & $\mathrm{Y}$ & $\mathrm{Y}$ & $\mathrm{Y}$ & $\mathrm{Y}$ & $\mathrm{Y}$ \\
\hline
\end{tabular}

Notes: Table presents horserace regressions of (i) an indicator for whether a city had its first cutover by 1940 (Columns 1 to 3) and (ii) the timing of that first cutover (measured in decimal years; Columns 4 to 6). All explanatory variables are measured for cities in 1910 except for income and educational attainment, which were only collected by the census in 1940. Percentages are measured in whole units (out of 100). Population and population percentages reflect the adult population only, and $\mathrm{f} / \mathrm{n} / \mathrm{w} / \mathrm{y}$ is shorthand for female, American-born, white/non-Hispanic, and young (age 16 to 25). Heteroskedasticity-robust SEs in parentheses. 
Table 4: Changes in work, education, marriage, and fertility patterns around cutovers

\begin{tabular}{|c|c|c|c|c|c|}
\hline \multicolumn{6}{|c|}{ Panel A: White, American-born women ages 16 to 25} \\
\hline & \multicolumn{5}{|c|}{ Percent of the group that is: } \\
\hline & Tel. oper. & Working & In school & Married & Has children \\
\hline Post-cutover & $\begin{array}{c}-0.66^{* * * *} \\
(0.05)\end{array}$ & $\begin{array}{c}0.04 \\
(0.43)\end{array}$ & $\begin{array}{c}0.10 \\
(0.25)\end{array}$ & $\begin{array}{c}0.12 \\
(0.30)\end{array}$ & $\begin{array}{c}0.24 \\
(0.21)\end{array}$ \\
\hline $\mathrm{N}$ & 113752 & 113752 & 113752 & 113752 & 113752 \\
\hline$R^{2}$ & 0.42 & 0.83 & 0.95 & 0.95 & 0.93 \\
\hline Cities & 2845 & 2845 & 2845 & 2845 & 2845 \\
\hline Cut over & 261 & 261 & 261 & 261 & 261 \\
\hline \multirow[t]{4}{*}{ Y Mean } & 1.15 & 40.35 & 21.30 & 34.92 & 19.85 \\
\hline & \multicolumn{5}{|c|}{ Panel B: White, American-born women ages 16 to 20} \\
\hline & \multicolumn{5}{|c|}{ Percent of the group that is: } \\
\hline & Tel. oper. & Working & In school & Married & Has children \\
\hline Post-cutover & $\begin{array}{c}-0.75^{* * *} \\
(0.08)\end{array}$ & $\begin{array}{c}0.02 \\
(0.57) \\
\end{array}$ & $\begin{array}{c}0.22 \\
(0.46) \\
\end{array}$ & $\begin{array}{c}-0.01 \\
(0.25) \\
\end{array}$ & $\begin{array}{c}0.25^{* *} \\
(0.13) \\
\end{array}$ \\
\hline $\mathrm{N}$ & 56884 & 56884 & 56884 & 56884 & 56884 \\
\hline$R^{2}$ & 0.45 & 0.86 & 0.92 & 0.90 & 0.85 \\
\hline Cities & 2845 & 2845 & 2845 & 2845 & 2845 \\
\hline Cut over & 261 & 261 & 261 & 261 & 261 \\
\hline Y Mean & 1.21 & 37.09 & 38.49 & 16.57 & 7.28 \\
\hline \multicolumn{6}{|c|}{ Panel C: White, American-born women ages 21 to 25} \\
\hline & \multicolumn{5}{|c|}{ Percent of the group that is: } \\
\hline & Tel. oper. & Working & In school & Married & Has children \\
\hline Post-cutover & $\begin{array}{c}-0.57^{* * *} \\
(0.05)\end{array}$ & $\begin{array}{c}0.06 \\
(0.46)\end{array}$ & $\begin{array}{c}-0.01 \\
(0.13)\end{array}$ & $\begin{array}{c}0.24 \\
(0.39) \\
\end{array}$ & $\begin{array}{c}0.23 \\
(0.31)\end{array}$ \\
\hline $\mathrm{N}$ & 56868 & 56868 & 56868 & 56868 & 56868 \\
\hline$R^{2}$ & 0.36 & 0.74 & 0.75 & 0.82 & 0.79 \\
\hline Cities & 2845 & 2845 & 2845 & 2845 & 2845 \\
\hline Cut over & 261 & 261 & 261 & 261 & 261 \\
\hline Y Mean & 1.09 & 43.66 & 3.85 & 53.55 & 32.60 \\
\hline
\end{tabular}

Notes: Tables present difference-in-difference estimates, by age, of the effects of local dial adoption on the percent of young, white, American-born women in successive cohorts who are in the labor force, in school, married, and have children, for cities with population $\leq 100 \mathrm{k}$ in 1920 . The left-most column provides the effect of cutovers on the percent of these women who were telephone operators in the telephone industry, as a reference point. All regressions include city and year fixed effects, and log city size $\mathrm{x}$ year controls. *, **, *** represent significance at the $0.1,0.05$, and 0.01 levels, respectively. SEs clustered by city in parentheses. 
Table 5: Changes in employment shares in select occupations around cutovers



Notes: Tables present difference-in-difference estimates, by age, of the effects of local dial adoption on young, white, American-born women's employment shares in select occupations, across successive cohorts, for cities with population $\leq 100 \mathrm{k}$ in 1920 . The left-most column provides the effect of cutovers on the percent of these women who were telephone operators in the telephone industry, as a reference point. The other occupations across columns are: (i) office machine operators, (ii) typists, stenographers, and secretaries, (iii) other office clerks, (iv) sales clerks, (v) beauty parlor workers, and (vi) restaurant workers. All regressions include city and year fixed effects, and $\log$ city size $\mathrm{x}$ year controls. $*, * *, * * *$ represent significance at the $0.1,0.05$, and 0.01 levels, respectively. SEs clustered by city in parentheses. 
Table 6: Effects of dial cutovers on the probability of being a telephone operator or having a non-operator job in the telephone industry

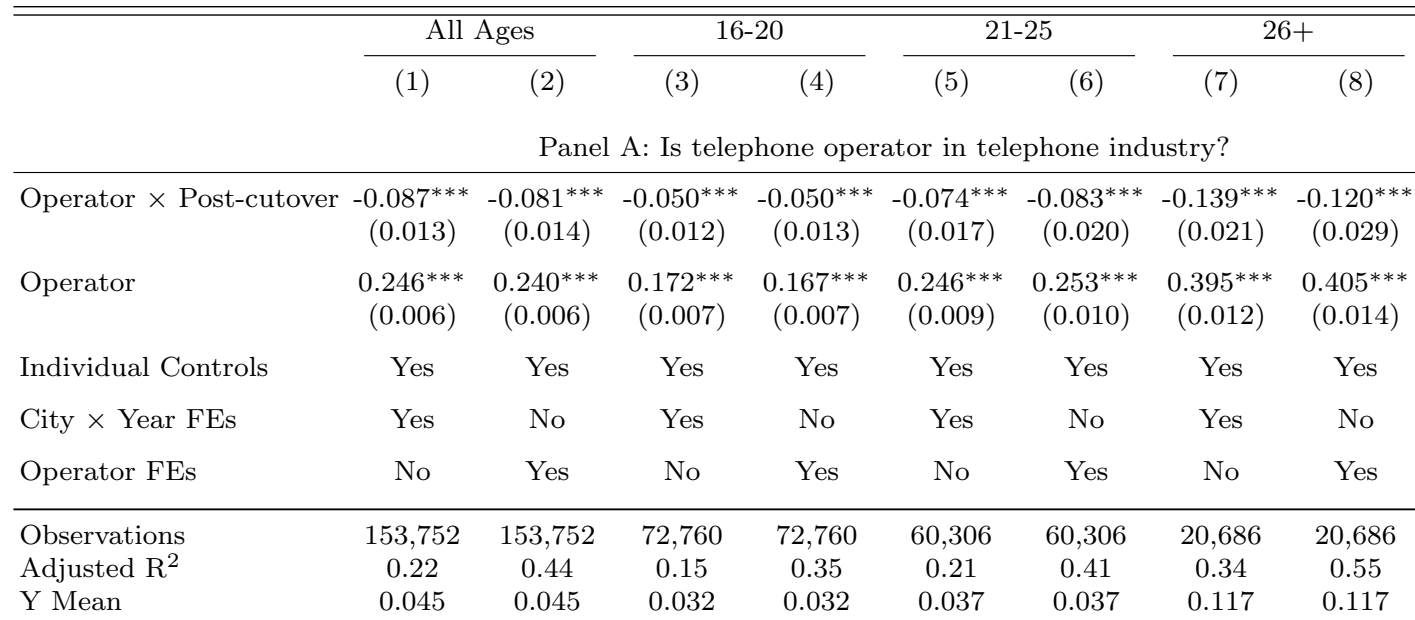

Panel B: Has other job in telephone industry?

\begin{tabular}{|c|c|c|c|c|c|c|c|c|}
\hline Operator $\times$ Post-cutover & $\begin{array}{c}0.010^{* * *} \\
(0.003)\end{array}$ & $\begin{array}{l}0.010^{* *} \\
(0.004)\end{array}$ & $\begin{array}{c}0.010^{* * *} \\
(0.004)\end{array}$ & $\begin{array}{c}0.014^{* * *} \\
(0.005)\end{array}$ & $\begin{array}{c}0.005 \\
(0.005)\end{array}$ & $\begin{array}{c}0.004 \\
(0.005)\end{array}$ & $\begin{array}{l}0.017^{*} \\
(0.010)\end{array}$ & $\begin{array}{l}0.023^{*} \\
(0.013)\end{array}$ \\
\hline Operator & $\begin{array}{c}0.019^{* * *} \\
(0.002)\end{array}$ & $\begin{array}{c}0.018^{* * *} \\
(0.002)\end{array}$ & $\begin{array}{c}0.012^{* * *} \\
(0.002)\end{array}$ & $\begin{array}{c}0.011^{* * *} \\
(0.002)\end{array}$ & $\begin{array}{c}0.020^{* * *} \\
(0.002)\end{array}$ & $\begin{array}{c}0.020^{* * *} \\
(0.003)\end{array}$ & $\begin{array}{c}0.034^{* * *} \\
(0.004)\end{array}$ & $\begin{array}{c}0.030^{* * *} \\
(0.005)\end{array}$ \\
\hline Individual Controls & Yes & Yes & Yes & Yes & Yes & Yes & Yes & Yes \\
\hline City $\times$ Year FEs & Yes & No & Yes & No & Yes & No & Yes & No \\
\hline Operator FEs & No & Yes & No & Yes & No & Yes & No & Yes \\
\hline $\begin{array}{l}\text { Observations } \\
\text { Adjusted R } \\
\text { Y Mean }\end{array}$ & $\begin{array}{c}153,752 \\
0.03 \\
0.007\end{array}$ & $\begin{array}{c}153,752 \\
0.28 \\
0.007\end{array}$ & $\begin{array}{c}72,760 \\
0.02 \\
0.006\end{array}$ & $\begin{array}{c}72,760 \\
0.21 \\
0.006\end{array}$ & $\begin{array}{c}60,306 \\
0.02 \\
0.006\end{array}$ & $\begin{array}{c}60,306 \\
0.24 \\
0.006\end{array}$ & $\begin{array}{c}20,686 \\
0.04 \\
0.014\end{array}$ & $\begin{array}{c}20,686 \\
0.41 \\
0.014\end{array}$ \\
\hline \multicolumn{9}{|c|}{ Panel C: Is telephone operator in other industry? } \\
\hline Operator $\times$ Post-cutover & $\begin{array}{c}0.004 \\
(0.004)\end{array}$ & $\begin{array}{c}0.003 \\
(0.005)\end{array}$ & $\begin{array}{c}0.003 \\
(0.006)\end{array}$ & $\begin{array}{c}0.005 \\
(0.006)\end{array}$ & $\begin{array}{l}0.009^{*} \\
(0.005)\end{array}$ & $\begin{array}{l}0.012^{*} \\
(0.006)\end{array}$ & $\begin{array}{c}0.008 \\
(0.009)\end{array}$ & $\begin{array}{c}0.005 \\
(0.010)\end{array}$ \\
\hline Operator & $\begin{array}{c}0.023^{* * *} \\
(0.002)\end{array}$ & $\begin{array}{c}0.023^{* * *} \\
(0.002)\end{array}$ & $\begin{array}{c}0.017^{* * *} \\
(0.002)\end{array}$ & $\begin{array}{c}0.016^{* * *} \\
(0.002)\end{array}$ & $\begin{array}{c}0.021^{* * *} \\
(0.002)\end{array}$ & $\begin{array}{c}0.019^{* * *} \\
(0.003)\end{array}$ & $\begin{array}{c}0.037^{* * *} \\
(0.004)\end{array}$ & $\begin{array}{c}0.037^{* * *} \\
(0.006)\end{array}$ \\
\hline Individual Controls & Yes & Yes & Yes & Yes & Yes & Yes & Yes & Yes \\
\hline City $\times$ Year FEs & Yes & No & Yes & No & Yes & No & Yes & No \\
\hline Operator FEs & No & Yes & No & Yes & No & Yes & No & Yes \\
\hline Observations & 153,752 & 153,752 & 72,760 & 72,760 & 60,306 & 60,306 & 20,686 & 20,686 \\
\hline Adjusted $\mathrm{R}^{2}$ & 0.04 & 0.32 & 0.06 & 0.27 & 0.05 & 0.31 & 0.07 & 0.47 \\
\hline Y Mean & 0.005 & 0.005 & 0.004 & 0.004 & 0.005 & 0.005 & 0.013 & 0.013 \\
\hline
\end{tabular}

Notes: Table reports effect of cutovers on decade-later outcomes of women who reported being telephone operators in the telephone industry in a given census year, as a function of whether their city had its first cutover in the intervening decade, relative to a matched control group. Sample restricted to women in small city sample (population $\leq 100 \mathrm{k}$ in 1920 ) in the base year. Individual controls include fixed effects for age, birthplace, race, and marital status, all measured in the base year. Operator fixed effects apply to each operator and the associated control women. Following Bailey et al. (2017), we use inverse propensity weights to adjust for observable differences between matched and unmatched persons in our linked sample. *,**,*** represent significance at the 0.1 , 0.05 , and 0.01 levels, respectively. SEs clustered by city in parentheses. 
Table 7: Effects of dial cutovers on the probability of working, getting married, or having children

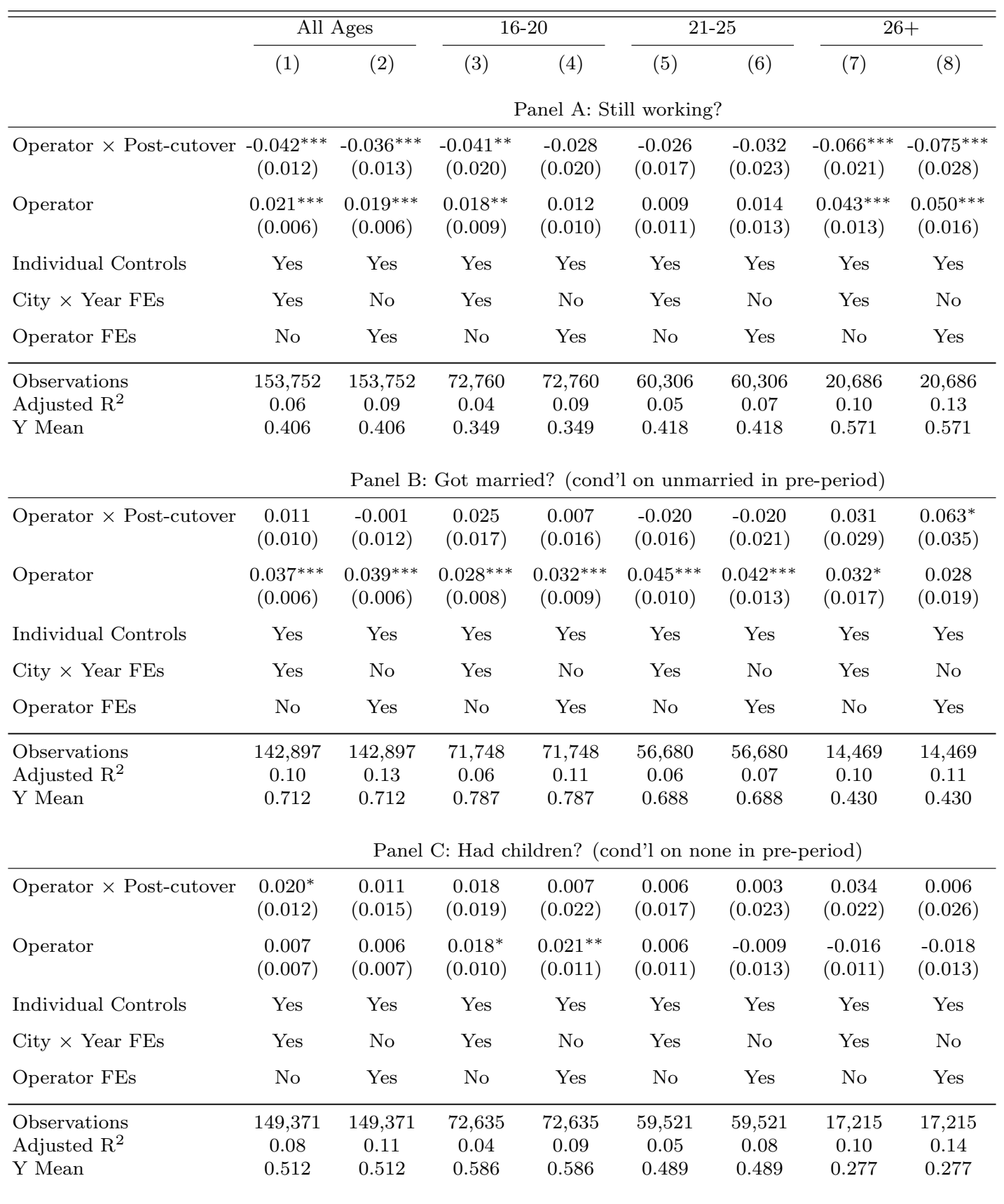

Notes: Table reports effect of cutovers on decade-later outcomes of women who reported being telephone operators in the telephone industry in a given census year, as a function of whether their city had its first cutover in the intervening decade, relative to a matched control group. Sample restricted to women in small city sample (population $\leq 100 \mathrm{k}$ in 1920) in the base year. Individual controls include fixed effects for age, birthplace, race, and marital status, all measured in the base year. Operator fixed effects apply to each operator and the associated control women. Following Bailey et al. (2017), we use inverse propensity weights to adjust for observable differences between matched and unmatched persons in our linked sample. ${ }^{*}, * *, * * *$ represent significance at the 0.1 , 0.05 , and 0.01 levels, respectively. SEs clustered by city in parentheses. 
Table 8: Effects of dial cutovers on the probability of persisting in the same occupation/industry and future occupation scores

\begin{tabular}{|c|c|c|c|c|c|c|c|c|}
\hline & \multicolumn{2}{|c|}{ All Ages } & \multicolumn{2}{|c|}{$16-20$} & \multicolumn{2}{|c|}{$21-25$} & \multicolumn{2}{|c|}{$26+$} \\
\hline & $(1)$ & $(2)$ & $(3)$ & $(4)$ & $(5)$ & (6) & (7) & $(8)$ \\
\hline & \multicolumn{8}{|c|}{ Panel A: Still working in same occupation and industry? (cond'l on still working) } \\
\hline Operator $\times$ Post-cutover & $\begin{array}{c}-0.109^{* * *} \\
(0.020)\end{array}$ & $\begin{array}{c}-0.107^{* * *} \\
(0.023)\end{array}$ & $\begin{array}{c}-0.121^{* * *} \\
(0.028)\end{array}$ & $\begin{array}{c}-0.126^{* * *} \\
(0.034)\end{array}$ & $\begin{array}{c}-0.099^{* * *} \\
(0.033)\end{array}$ & $\begin{array}{c}-0.156^{* * *} \\
(0.038)\end{array}$ & $\begin{array}{c}-0.125^{* * *} \\
(0.033)\end{array}$ & $\begin{array}{l}-0.085 \\
(0.056)\end{array}$ \\
\hline Operator & $\begin{array}{c}0.319^{* * *} \\
(0.010)\end{array}$ & $\begin{array}{c}0.324^{* * *} \\
(0.012)\end{array}$ & $\begin{array}{c}0.329^{* * *} \\
(0.015)\end{array}$ & $\begin{array}{c}0.336^{* * *} \\
(0.019)\end{array}$ & $\begin{array}{c}0.318^{* * *} \\
(0.017)\end{array}$ & $\begin{array}{c}0.340^{* * *} \\
(0.021)\end{array}$ & $\begin{array}{c}0.339^{* * *} \\
(0.018)\end{array}$ & $\begin{array}{c}0.341^{* * *} \\
(0.022)\end{array}$ \\
\hline Individual Controls & Yes & Yes & Yes & Yes & Yes & Yes & Yes & Yes \\
\hline City $\times$ Year FEs & Yes & No & Yes & No & Yes & No & Yes & No \\
\hline Operator FEs & No & Yes & No & Yes & No & Yes & No & Yes \\
\hline $\begin{array}{l}\text { Observations } \\
\text { Adjusted } \mathrm{R}^{2} \\
\text { Y Mean }\end{array}$ & $\begin{array}{c}62,395 \\
0.13 \\
0.278\end{array}$ & $\begin{array}{c}62,395 \\
0.17 \\
0.278\end{array}$ & $\begin{array}{c}25,401 \\
0.13 \\
0.209\end{array}$ & $\begin{array}{c}25,401 \\
0.20 \\
0.209\end{array}$ & $\begin{array}{c}25,188 \\
0.11 \\
0.292\end{array}$ & $\begin{array}{c}25,188 \\
0.11 \\
0.292\end{array}$ & $\begin{array}{c}11,806 \\
0.15 \\
0.394\end{array}$ & $\begin{array}{c}11,806 \\
0.17 \\
0.394\end{array}$ \\
\hline Y Mean & \multicolumn{8}{|c|}{ Panel B: Log occupation score } \\
\hline Operator $\times$ Post-cutover & $\begin{array}{c}-0.056^{* * *} \\
(0.010)\end{array}$ & $\begin{array}{c}-0.056^{* * *} \\
(0.014)\end{array}$ & $\begin{array}{c}-0.061^{* * *} \\
(0.017)\end{array}$ & $\begin{array}{c}-0.061^{* *} \\
(0.025)\end{array}$ & $\begin{array}{c}-0.066^{* * *} \\
(0.018)\end{array}$ & $\begin{array}{c}-0.066^{* *} \\
(0.026)\end{array}$ & $\begin{array}{c}-0.041^{* *} \\
(0.016)\end{array}$ & $\begin{array}{l}-0.026 \\
(0.025)\end{array}$ \\
\hline Operator & $\begin{array}{c}0.076^{* * *} \\
(0.007)\end{array}$ & $\begin{array}{c}0.080^{* * *} \\
(0.008)\end{array}$ & $\begin{array}{c}0.107^{* * *} \\
(0.010)\end{array}$ & $\begin{array}{c}0.118^{* * *} \\
(0.014)\end{array}$ & $\begin{array}{c}0.058^{* * *} \\
(0.010)\end{array}$ & $\begin{array}{c}0.066^{* * *} \\
(0.011)\end{array}$ & $\begin{array}{c}0.082^{* * *} \\
(0.012)\end{array}$ & $\begin{array}{c}0.085^{* * *} \\
(0.014)\end{array}$ \\
\hline Individual Controls & Yes & Yes & Yes & Yes & Yes & Yes & Yes & Yes \\
\hline City $\times$ Year FEs & Yes & No & Yes & No & Yes & No & Yes & No \\
\hline Operator FEs & No & Yes & No & Yes & No & Yes & No & Yes \\
\hline $\begin{array}{l}\text { Observations } \\
\text { Adjusted } \mathrm{R}^{2} \\
\text { Y Mean }\end{array}$ & $\begin{array}{c}56,184 \\
0.10 \\
2.071\end{array}$ & $\begin{array}{c}56,184 \\
0.12 \\
2.071\end{array}$ & $\begin{array}{c}22,271 \\
0.17 \\
2.032\end{array}$ & $\begin{array}{c}22,271 \\
0.17 \\
2.032\end{array}$ & $\begin{array}{c}22,974 \\
0.12 \\
2.099\end{array}$ & $\begin{array}{c}22,974 \\
0.11 \\
2.099\end{array}$ & $\begin{array}{c}10,939 \\
0.14 \\
2.095\end{array}$ & $\begin{array}{c}10,939 \\
0.09 \\
2.095\end{array}$ \\
\hline \multicolumn{9}{|c|}{ Panel C: Decline in occupation score decile } \\
\hline Operator $\times$ Post-cutover & $\begin{array}{c}0.105^{* * *} \\
(0.018)\end{array}$ & $\begin{array}{c}0.101^{* * *} \\
(0.022)\end{array}$ & $\begin{array}{c}0.074^{* * *} \\
(0.024)\end{array}$ & $\begin{array}{l}0.062^{*} \\
(0.032)\end{array}$ & $\begin{array}{c}0.125^{* * *} \\
(0.029)\end{array}$ & $\begin{array}{c}0.186^{* * *} \\
(0.044)\end{array}$ & $\begin{array}{c}0.090^{* * *} \\
(0.029)\end{array}$ & $\begin{array}{c}0.061 \\
(0.039)\end{array}$ \\
\hline Operator & $\begin{array}{c}0.014 \\
(0.009)\end{array}$ & $\begin{array}{c}0.001 \\
(0.011)\end{array}$ & $\begin{array}{c}0.063^{* * *} \\
(0.015)\end{array}$ & $\begin{array}{c}0.053^{* * *} \\
(0.020)\end{array}$ & $\begin{array}{l}-0.003 \\
(0.016)\end{array}$ & $\begin{array}{l}-0.010 \\
(0.020)\end{array}$ & $\begin{array}{l}-0.025 \\
(0.016)\end{array}$ & $\begin{array}{c}-0.051^{* * *} \\
(0.019)\end{array}$ \\
\hline Individual Controls & Yes & Yes & Yes & Yes & Yes & Yes & Yes & Yes \\
\hline City $\times$ Year FEs & Yes & No & Yes & No & Yes & No & Yes & No \\
\hline Operator FEs & No & Yes & No & Yes & No & Yes & No & Yes \\
\hline Observations & 47,736 & 47,736 & 18,446 & 18,446 & 19,612 & 19,612 & 9,678 & 9,678 \\
\hline Adjusted $\mathrm{R}^{2}$ & 0.04 & 0.08 & 0.08 & 0.14 & 0.07 & 0.08 & 0.02 & 0.08 \\
\hline Y Mean & 0.217 & 0.217 & 0.232 & 0.232 & 0.215 & 0.215 & 0.192 & 0.192 \\
\hline
\end{tabular}

Notes: Table reports effect of cutovers on decade-later outcomes of women who reported being telephone operators in the telephone industry in a given census year, as a function of whether their city had its first cutover in the intervening decade, relative to a matched control group. Sample restricted to women in small city sample (population $\leq 100 \mathrm{k}$ in 1920 ) in the base year. Individual controls include fixed effects for age, birthplace, race, and marital status, all measured in the base year. Operator fixed effects apply to each operator and the associated control women. Following Bailey et al. (2017), we use inverse propensity weights to adjust for observable differences between matched and unmatched persons in our linked sample. ${ }^{*},{ }^{* *}, * * *$ represent significance at the 0.1 , 0.05 , and 0.01 levels, respectively. SEs clustered by city in parentheses. 
Figure 1: Percent of Bell system on dial, 1913-1972

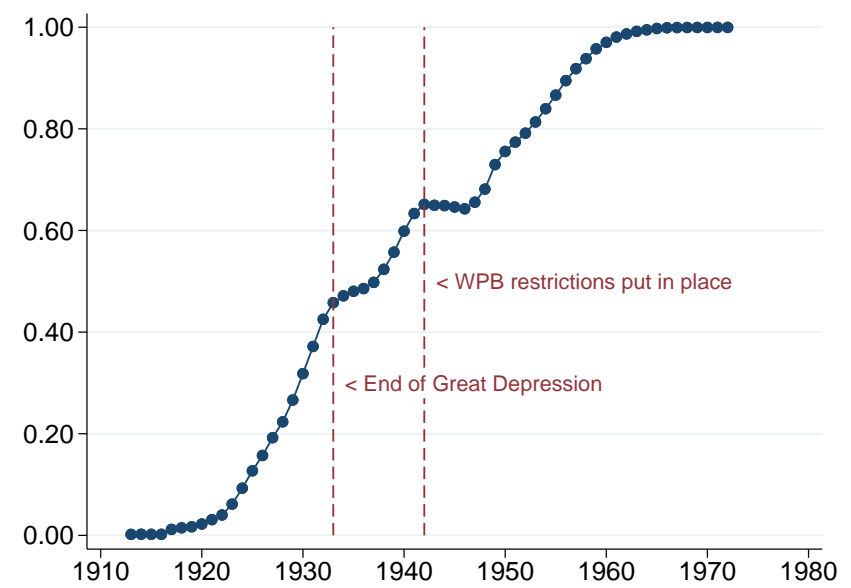

Notes: Figure shows the fraction of Bell system telephones with mechanical operation (i.e., dial) over time. Data from "Bell System Distributions of Company Telephones," AT\&T Archives and History Center, box 85-04-03-02. Note that adoption investments declined during the Great Depression, leading to a slowdown in the late 1930s, and War Production Board restrictions on the use of copper during World War II effectively halted installations for the duration of the war.

Figure 2: Cities in data with cutovers by 1940

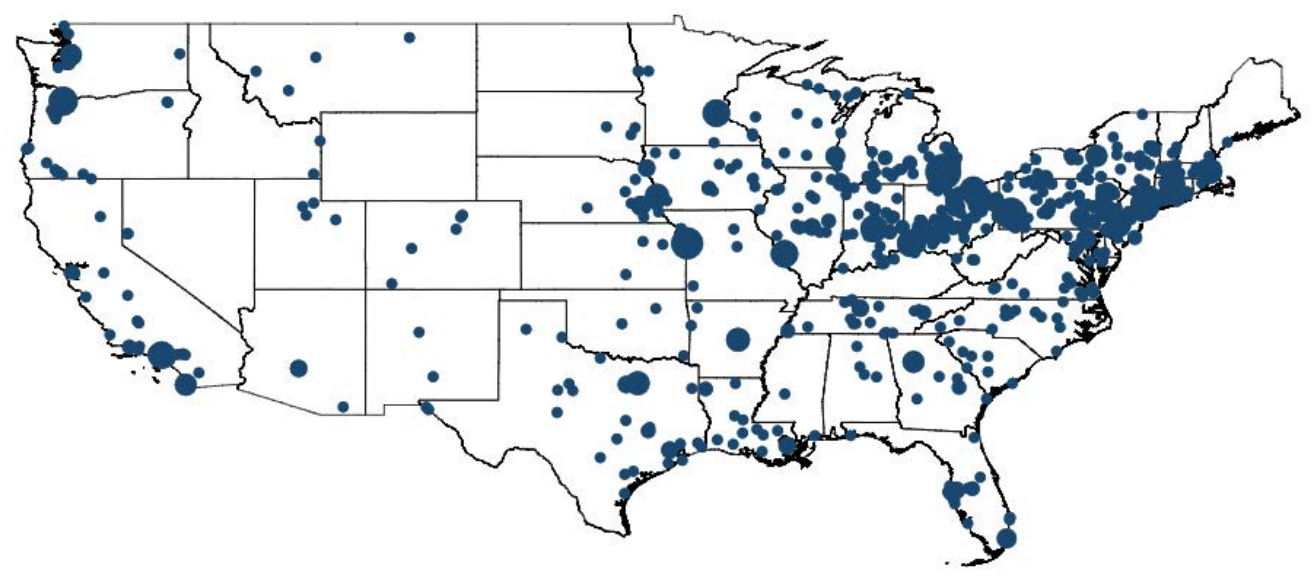

Notes: Figure maps the cities with a dial cutover in the AT\&T and newspapers data through 1940. Bubble sizes are proportional to the \# of reported cutovers through 1940. 
Figure 3: Effect of dial cutovers on the log number of young, white, American-born women who are telephone operators in the telephone industry (event study, 10- and 2-yr intervals)

Panel (A)

Log \# of tel. operators (10-yr intervals)

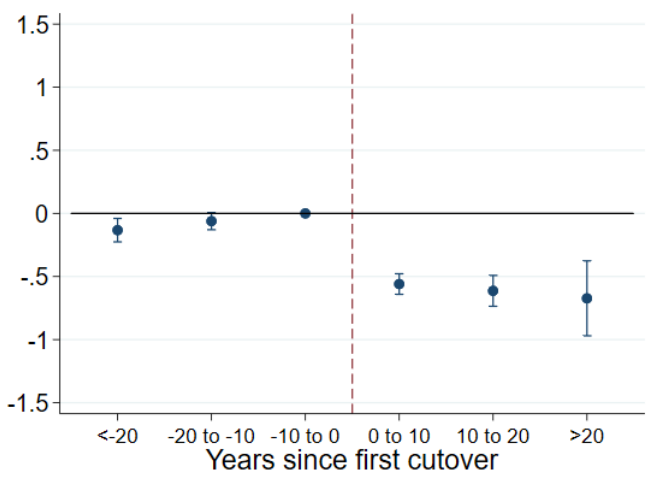

Panel (B)

$\log \#$ of tel. operators (2-yr intervals)

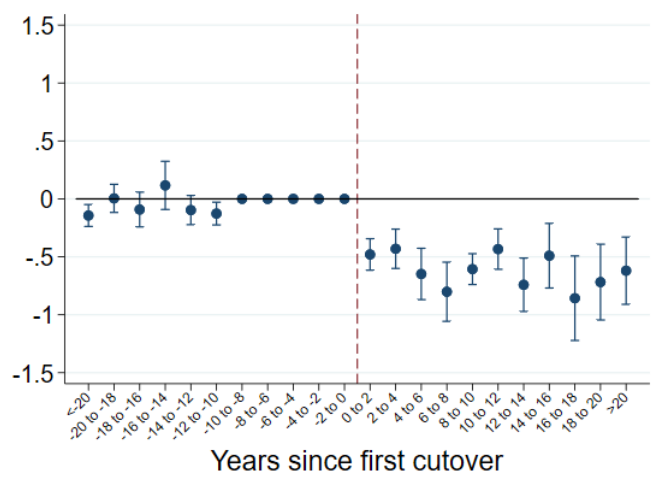

Notes: Figure shows event study estimates of the effects of local dial adoption on the $(\log )$ number of young, white, American-born women in successive cohorts who are telephone operators in the telephone industry $(+1)$, for the small city sample (population $\leq 100 \mathrm{k}$ in 1920), with 10- and 2-year event windows. When event windows are narrower than the 10-year frequency at which outcomes are measured, each bin contains different cities (every fifth bin represents the same set of cities). In estimating these event studies, we aggregate women across ages to the city level, because age-level observations have many zeros both before and after cutovers, which are computed as unchanged and will cause these effects to be underestimated. Error bars represent $95 \%$ confidence intervals, computed from SEs clustered at the city level.

Figure 4: Effect of dial cutovers on the percent of working young, white, American-born women who are telephone operators in the telephone industry (event study and DID by age)

Panel (A)

Percent who are tel. operators (2-yr intervals)

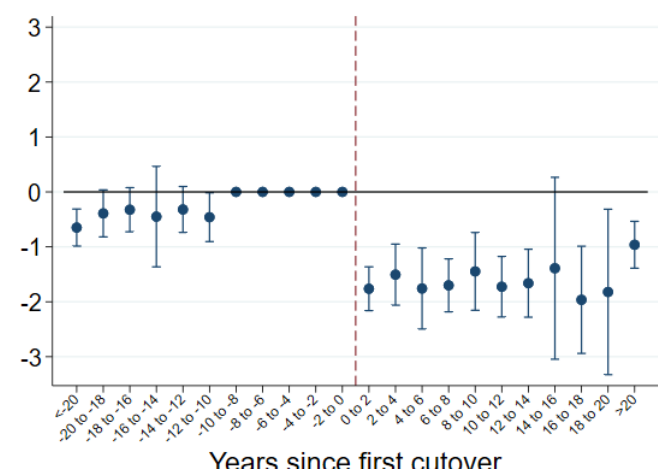

Panel (B)

Percent who are tel. operators (DID by age)

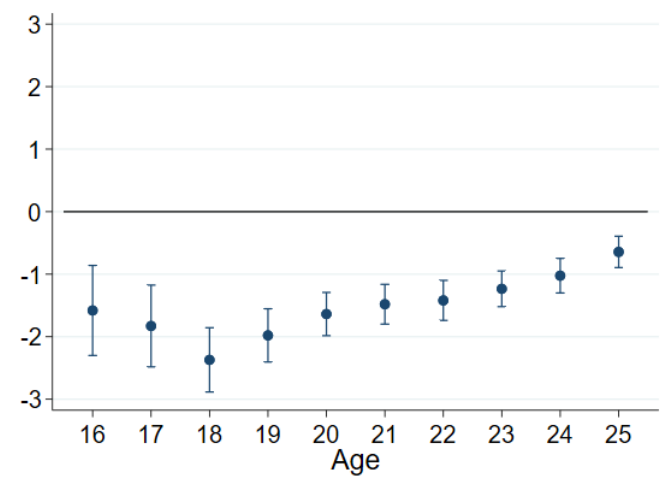

Notes: Figure shows event study and difference-in-difference estimates (by age) of the effects of local dial adoption on the percent of working young, white, American-born women in successive cohorts who are telephone operators in the telephone industry, for the small city sample (population $\leq 100 \mathrm{k}$ in 1920). Error bars represent $95 \%$ confidence intervals, computed from SEs clustered at the city level. 
Figure 5: Effect of dial cutovers on the percent of working young, white, American-born women with other jobs in the telephone industry or who are telephone operators in other industries

Panel (A)

Other jobs in the tel. industry (2-yr intervals)

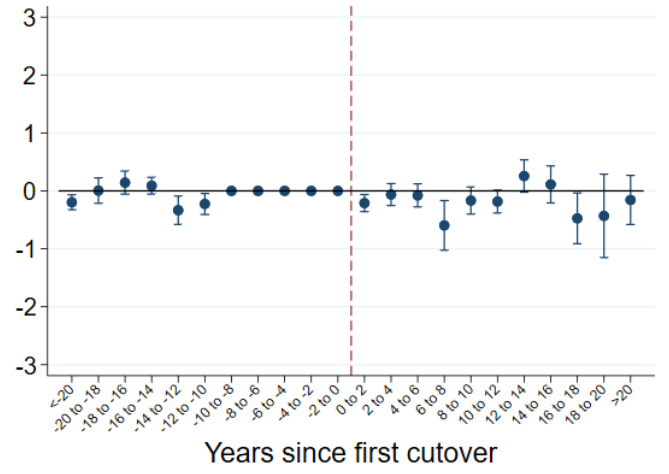

Panel (C)

Other jobs in the tel. industry (DID by age)

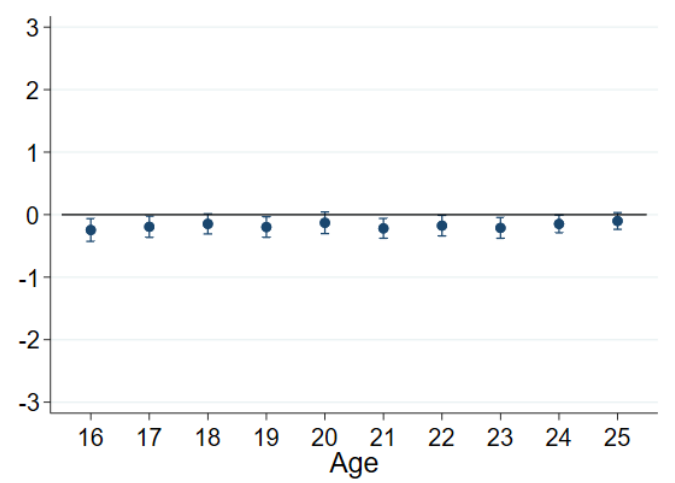

Panel (B)

Tel. operator in other industries (2-yr intervals)

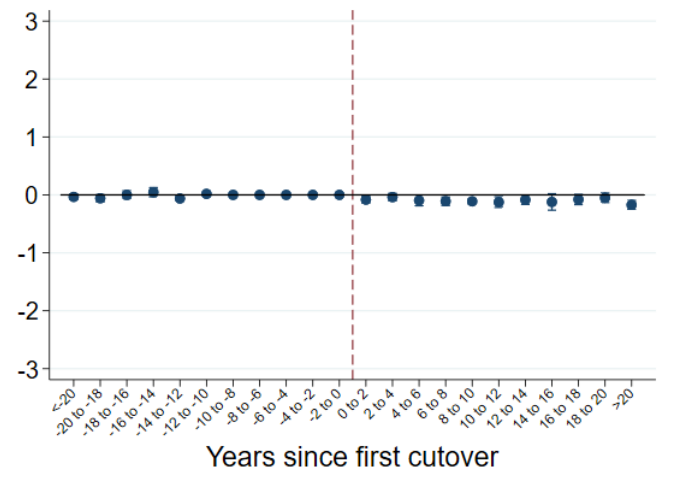

Panel (D)

Tel. operator in other industries (DID by age)



Notes: Upper panels show event study estimates of the effects of local dial adoption on the percent of working young, white, American-born women in successive cohorts who have other jobs in the telephone industry (left) and who are telephone operators in other industries (right), for the small city sample (population $\leq 100 \mathrm{k}$ in 1920). Because event windows are narrower than the 10-year frequency at which outcomes are measured, each bin contains different cities (every fifth bin represents the same set of cities). Lower panels show the associated difference-in-differences estimates, by age. We plot the estimates on the same scale (-3 to 3 p.p.) as the previous figures to ease comparison. Error bars represent $95 \%$ confidence intervals, computed from SEs clustered at the city level. 


\section{Online Appendix}

\section{A Historical Background}

This appendix provides supplementary material to accompany the discussion of U.S. telephone industry history, mechanical switching, and the labor market for young women in Section 1. Table A.1 provides descriptive statistics on the U.S. telephone industry from 1902 to 1932. Figures A.1 and A.2 reproduce two tables from BLS (1932), a government study of the effects of dial on operator employment. Figure A.3 shows example newspaper headlines from articles describing dial cutovers and their effects on young women.

Table A.1: U.S. telephone industry, 1902-1932

\begin{tabular}{lrrrrrrr}
\hline & 1902 & 1907 & 1912 & 1917 & 1922 & 1927 & 1932 \\
\cline { 2 - 7 } & & & & & & & \\
Growth of industry & & & & & & & \\
\hline Miles of wire (1000s) & 4,900 & 12,999 & 20,248 & 28,827 & 37,266 & 63,836 & 87,678 \\
Telephones (1000s) & 2,371 & 6,119 & 8,730 & 11,717 & 14,347 & 18,523 & 17,424 \\
Telephone calls (MMs) & 5,071 & 11,373 & 13,736 & 21,846 & 24,648 & 31,614 & 30,048 \\
Telephone calls (per capita) & 64 & 131 & 144 & 212 & 224 & 266 & 241 \\
Employees & 78,752 & 144,169 & 183,361 & 262,629 & 312,015 & 375,272 & 334,085 \\
Male & & & & 91,510 & 104,433 & 131,802 & 128,677 \\
Female & & & & 171,119 & 207,582 & 243,470 & 205,408 \\
& & & & & & & \\
Labor productivity & 15.53 & 12.68 & 13.35 & 12.02 & 12.66 & 11.87 & 11.12 \\
\hline Employees per MM calls & & & & 4.19 & 4.24 & 4.17 & 4.28 \\
Male & & & & 7.83 & 8.42 & 7.70 & 6.84 \\
Female & & & & & & & \\
Market share & $56 \%$ & $51 \%$ & $58 \%$ & $63 \%$ & $66 \%$ & $74 \%$ & $79 \%$ \\
\hline AT\&T share & & & & & & & \\
& & & & & & & \\
\end{tabular}

Notes: Data from U.S. Census of Electrical Industries, 1907-1932. Enumeration covered all Bell and independent operating companies. Call volume and employment reported for 1912 is restricted to companies with $>\$ 5,000$ in income (in 1912 dollars) and is thus slightly understated. Operating revenue figures in 1902 are for all companies; in 1907-1917, for companies with $>\$ 5,000$ income; and in 1922-1932, for companies with $>\$ 10,000$ income. 
Figure A.1: BLS (1932) Table 1, "Telephones, Telephone Calls, and Personnel of a Single-Office Exchange Now 98 Percent Dial"

\begin{tabular}{|c|c|c|c|c|c|c|}
\hline Item & 1925 & 1926 & 1927 & 1928 & 1929 & 1030 \\
\hline $\begin{array}{l}\text { Telephones: } \\
\text { Ylanual. } \\
\text { Dlal....... }\end{array}$ & 18,644 & 20,042 & $\begin{array}{r}380 \\
20,880\end{array}$ & 22,178 & $\begin{array}{r}487 \\
22,945\end{array}$ & $\begin{array}{r}466 \\
22,450\end{array}$ \\
\hline $\begin{array}{l}\text { A verage number of calls jer monti: } \\
\text { Incal exchanga...... } \\
\text { Toll. }\end{array}$ & $\begin{array}{r}3,368,080 \\
60,321\end{array}$ & $\begin{array}{r}3,575,102 \\
65,302\end{array}$ & $\begin{array}{r}3,438,496 \\
73,381\end{array}$ & $\begin{array}{r}4,195,446 \\
87,540\end{array}$ & $\begin{array}{r}3,953,536 \\
83,007\end{array}$ & $\begin{array}{r}4,019,404 \\
93,177\end{array}$ \\
\hline 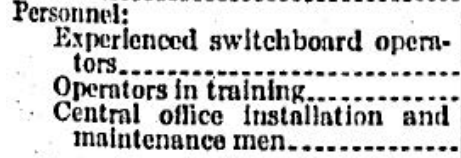 & $\begin{array}{r}214 \\
74 \\
13\end{array}$ & $\begin{array}{r}244 \\
35 \\
13\end{array}$ & $\begin{array}{r}186 \\
1 \\
20\end{array}$ & $\begin{array}{r}157 \\
0 \\
10\end{array}$ & $\begin{array}{r}123 \\
0 \\
18\end{array}$ & $\begin{array}{r}120 \\
4 \\
\quad 25\end{array}$ \\
\hline $\begin{array}{l}\text { All employees (all classes): } \\
\text { Male } \\
\text { Female........... }\end{array}$ & $\begin{array}{r}102 \\
307\end{array}$ & $\begin{array}{r}155 \\
207\end{array}$ & $\begin{array}{r}147 \\
\quad 213\end{array}$ & $\begin{array}{ll}115 \\
179\end{array}$ & $\begin{array}{r}\quad 123 \\
\therefore \quad 166\end{array}$ & $\begin{array}{r}113 \\
\quad \quad 160\end{array}$ \\
\hline Total........ & 400 & 452 & 300 & 291 & 280 & 273 \\
\hline
\end{tabular}

Notes: Figure reproduces Table 1 from BLS (1932), describing changes in employment at a single anonymous exchange which converted from manual to mechanical operation in 1927.

Figure A.2: BLS (1932) Table 2, "Changes in Employment Opportunities for Operators"

\begin{tabular}{|c|c|c|c|c|c|c|c|}
\hline 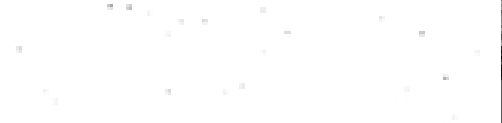 & $\begin{array}{l}\text { Per ceat } \\
\text { of ellal }\end{array}$ & I'er cent & Num & of $e$ & atx & $\begin{array}{c}\text { Loss } \\
\text { mer } \\
\text { tur } \\
\text { of }\end{array}$ & $\begin{array}{l}\text { Dlos:- } \\
\text { por: } \\
\text { for } \\
\text { rs }\end{array}$ \\
\hline$+\cdots$ & $\begin{array}{l}\text { nfter } \\
\text { elianko } \\
\text { to difal } \\
\text { system }\end{array}$ & $\begin{array}{l}\text { olls dur- } \\
\text { ing tran- } \\
\text { sittion } \\
\text { netiod }\end{array}$ & $\begin{array}{l}\text { Tholoro } \\
\text { chanko } \\
\text { to dilal } \\
\text { system }\end{array}$ & $\begin{array}{l}\text { After } \\
\text { chango } \\
\text { to dial } \\
\text { system }\end{array}$ & $\begin{array}{l}\text { If opera- } \\
\text { tors } \\
\text { hind in- } \\
\text { creased } \\
\text { in sonne } \\
\text { ratlo as } \\
\text { calls }\end{array}$ & $\begin{array}{l}\text { Fstl- } \\
\text { mated } \\
\text { num- } \\
\text { her }\end{array}$ & $\begin{array}{l}\text { ler } \\
\text { cent }\end{array}$ \\
\hline 0. & $\begin{array}{r}84.4 \\
90.7 \\
100.0 \\
100.0 \\
11.3\end{array}$ & \begin{tabular}{r|}
114.7 \\
10.0 \\
53.1 \\
134.2 \\
171.4
\end{tabular} & $\begin{array}{r}33 \\
60 \\
33 \\
12 \\
110\end{array}$ & $\begin{array}{r}15 \\
27 \\
16 \\
21 \\
270\end{array}$ & $\begin{array}{r}23 \\
67 \\
51 \\
98 \\
323\end{array}$ & $\begin{array}{r}13 \\
40 \\
35 \\
74 \\
83\end{array}$ & $\begin{array}{r}40.4 \\
50.7 \\
686 \\
175.5 \\
16.4\end{array}$ \\
\hline 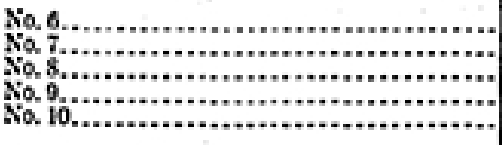 & $\begin{array}{r}100.0 \\
72.5 \\
100.0 \\
100.0 \\
100.0\end{array}$ & $\begin{array}{l}13.8 \\
20.2 \\
18.0 \\
60.6 \\
30.7\end{array}$ & $\begin{array}{r}106 \\
59 \\
169 \\
154 \\
228\end{array}$ & $\begin{array}{r}63 \\
75 \\
80 \\
94 \\
114\end{array}$ & $\begin{array}{l}180 \\
125 \\
250 \\
247 \\
312\end{array}$ & $\begin{array}{r}120 \\
50 \\
170 \\
153 \\
108\end{array}$ & $\begin{array}{l}60.7 \\
40.0 \\
68.0 \\
61.9 \\
63.5\end{array}$ \\
\hline 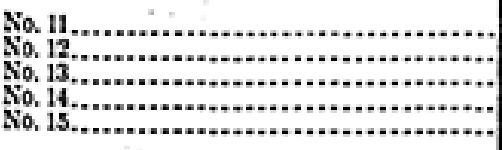 & $\begin{array}{r}100.0 \\
100.0 \\
100.0 \\
08.0 \\
20.0\end{array}$ & $\begin{array}{r}24.0 \\
114.0 \\
33.8 \\
10.0 \\
31.6\end{array}$ & $\begin{array}{l}105 \\
127 \\
213 \\
258 \\
155\end{array}$ & $\begin{array}{r}15 \\
16 \\
05 \\
124 \\
111\end{array}$ & $\begin{array}{l}205 \\
272 \\
275 \\
315 \\
612\end{array}$ & $\begin{array}{l}100 \\
253 \\
100 \\
221 \\
201\end{array}$ & $\begin{array}{r}927 \\
302.0 \\
60.7 \\
64.1 \\
81.0\end{array}$ \\
\hline 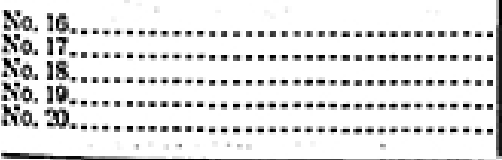 & $\begin{array}{l}100.0 \\
100.0 \\
100.0 \\
70.0 \\
18.0\end{array}$ & $\begin{array}{r}10.4 \\
23.0 \\
12.1 \\
30.5 \\
18.3\end{array}$ & $\begin{array}{r}232 \\
456 \\
501 \\
740 \\
2705\end{array}$ & $\begin{array}{r}17 \\
182 \\
310 \\
800 \\
1,056\end{array}$ & $\begin{array}{r}340 \\
301 \\
603 \\
1,114 \\
3,200\end{array}$ & $\begin{array}{r}323 \\
370 \\
353 \\
554 \\
1,510\end{array}$ & $\begin{array}{r}105.0 \\
67.6 \\
63.2 \\
\quad 49.7 \\
483\end{array}$ \\
\hline
\end{tabular}

Decteaso.

Iarko displacoment due to small proportlon of toll calls.

Larze displecement duo to speclaltred nature of busloces.

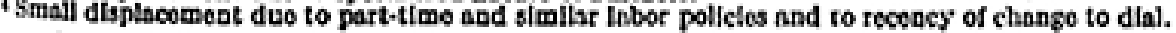

Notes: Figure reproduces Table 2 from BLS (1932), describing changes in employment at 18 surveyed exchanges which converted from manual to mechanical operation. 
Figure A.3: Sampling of newspaper headlines, 1925 to 1940

\section{Telephone Dial Usurps Jobs \\ By Frederic J. Haskin}

Syndicated article, published in newspapers nationwide in 1932

\section{HELLO GIRL SAYS GOODBYE FOREVER AND CITY "DIALS"}

\begin{tabular}{|l|}
\hline Employed 120 Girls \\
There were approximately 120 \\
girls employed by the Bell Tele- \\
phone company as operators prior \\
to today. In a few weeks, but half \\
that number will be on the payroll.
\end{tabular}

Enquirer and Evening News, Battle Creek, MI, 1927
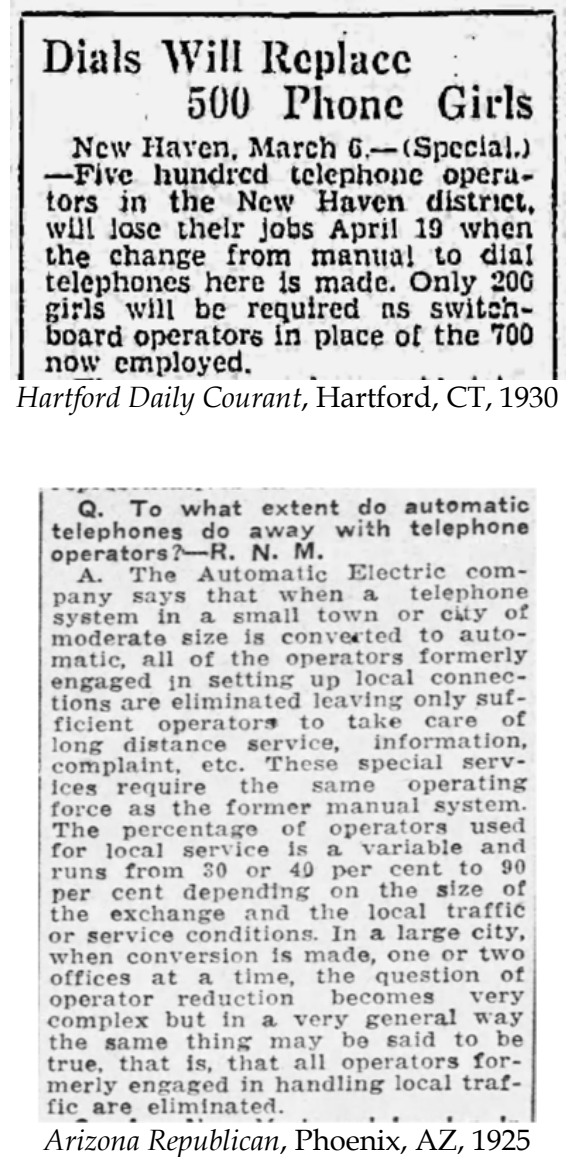

Q. To what extent do automatic telephones do away with telephone A. The Automatic Electric company says that when a telephone moderate size is converted to automatic, all of the operators formerly engaged in setting up local conneconters to take care of ong distance service, information, These special serv. ce is a variable and com 30 or 40 per cent to 90 on the size of local traftic when conversion is made, one or two offices at a time, the question of complex but in a very general way the same thing may be said to be

Arizona Republicàn, Phoenix, AZ, 1925

\section{PHONE GIRLS TO CONTINUE JOBS \\ Change-Over to Dials Will Not Cause Unemploy- ment, Says Manager \\ Operation of a dial system at the proposed new exchange building of the Mountain States Tel. \& Tel Co. will not result in layoff of many telephone switchboard oper- ators and may even bring about added employment, Frank D. Saw- yer, district manager of the com- pany, informed Mayor Fred $M$. A.bbott today. \\ Ogden Standard-Examiner, Ogden, UT, 1940}

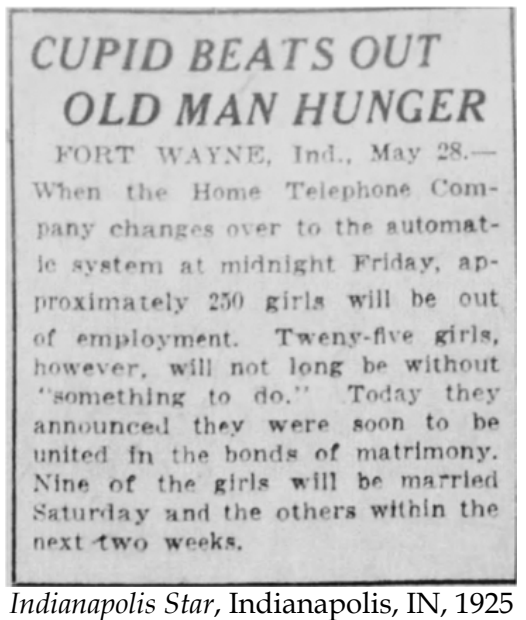

Notes: Figure reproduces newspaper headlines and/or content from the following articles: "Telephone Dial Usurps Jobs" (syndicated); "Hello Girl Says Goodbye Forever and City 'Dials,'" The Enquirer and Evening News (Battle Creek, MI), September 4, 1927; "Dials Will Replace 500 Phone Girls," The Hartford Daily Courant (Hartford, CT), March 7, 1930; "To what extent do automatic telephones do away with telephone operators?" The Arizona Republican (Phoenix, AZ), July 5, 1925; "Phone Girls to Continue Jobs," The Ogden Standard-Examiner (Ogden, UT), January 25, 1940; "Cupid Beats Out Old Man Hunger," The Indianapolis Star (Indianapolis, IN), May 29, 1925. All articles accessed from Newspapers.com. 
Figure A.4: Newspaper reports of telephone rate changes around cutovers, 1925 to 1940
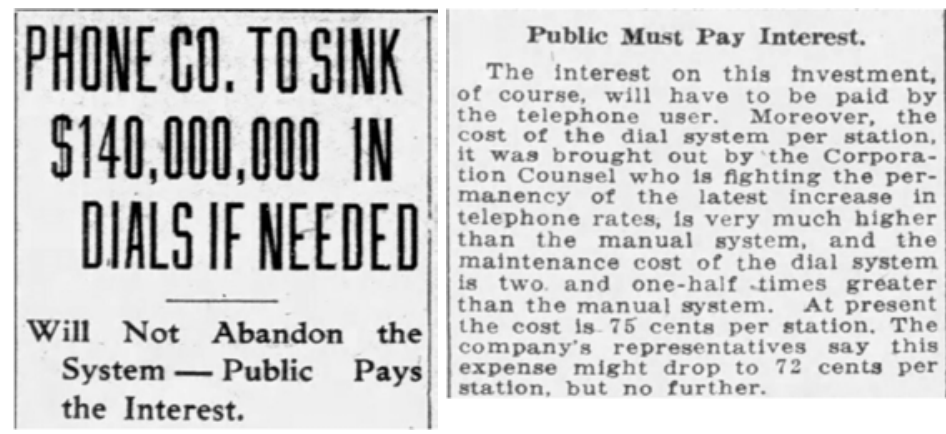
It was made very clear by the com-
pany's offlcers and lawyers that un-
der no circumstances would the dial
system program be abandoned,
although the automatic "ringer" is
proving most unsatisfactory to the
publlc, and the reason given for the
stand taken by the telephone com-
pany in this matter is that because
of the enormous growth of the num-
ber of telephone users in the city
and the further tremendous increase
in the number of stations and users
anticipated for the next few years
the manual system must be aban-
doned entirely and the automatic
substituted, If the public wants good
service. Even now, the company
maintains, it has too many tele-
phones to handle without mechani-
cal ald.

The Brooklyn Daily Eagle, Brooklyn, NY, 1925

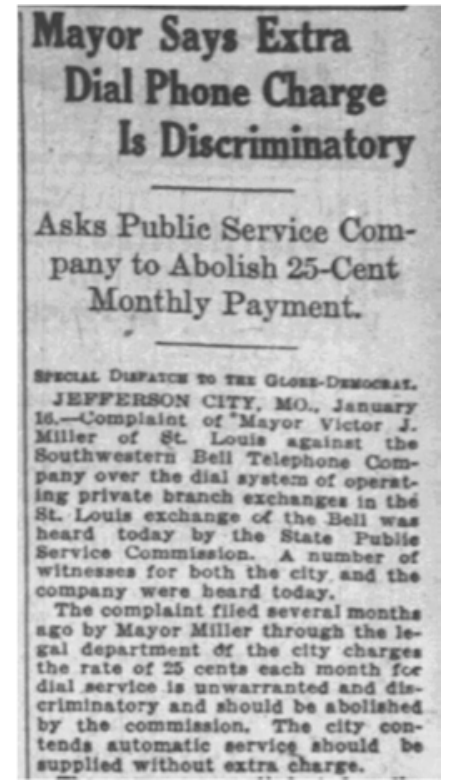



Public Service Commission Turns Down Complaint on Monthly Fee of 25 Cents Per Phone in Private Boards.

LEVY WAS OPPOSED ON BASIS IT DISCRIMINATED

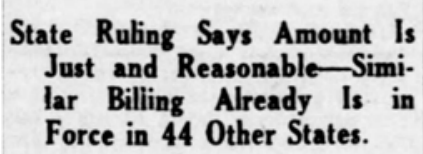

St. Louis Globe Democrat, St. Louis, MO, 1928;

St. Louis Star and Times, St. Louis, MO, 1929 
Figure A.4: Summary of select OSRD research programs (cont'd)

\section{Dial Telephone System Is To Be Installed In Tyler}

New Rates Planned In sareeing to instali the dial stem in Tyler, the elephone comny officials are asking authority the City Commission to put a w rate schedule inio effect, which II call for an increase in the teleone rates, but which will make - rates here on about an even $r$ with those charged in other ies where the dial lelephone sys$\mathrm{n}$ is in operation.

Where the present rate for onee business telephones is now $\mathbf{8 5}$ r minth, the telephone company oposes to increase tinis rate to $\$ 6$ - month. For one-party residence es, the present raie is $\$ 2.50$ per inth and under the new proposed (1) system rate it would be $\$ 3$ - month.
NOW, THEREFORE, BE IT ORDAINED BY THE COMMISSION OF THE CITY OF TYLER:

"1. That the commission looks with favor upon any sound project or plan having for its purpose the upbullding of the cliy or the improvement of conditions in the city. and hereby endorses the plan of the Southwestern Bell Telephone Company to enlarge and improve its property and service in Tyler by the construction and in.tallation. as aforesajd, of a new modern dial telephone plant and system.

\footnotetext{
The Tyler Courier-Times, Tyler, TX, 1939
}

2. That when the new buildi and system have been cumpleted ai are placed in operation, the cor pany may place into eliect a sche ule of rates providing for an i crease in the present one-party bus ness rate of $\$ 1$; in the vresent on party residence rate of $50 \mathrm{c}$, in $\mathrm{tl}$ present two-party residence rate $25 \mathrm{c}$; in the rate for business sem public service for messages over $\mathrm{tl}$ guarantee of $1 / \mathrm{c}$, and in the rate $f$ private branch exchainge trunks \$1.50. All other rates and charg now being made by the compar shall continue in cffect witho change.

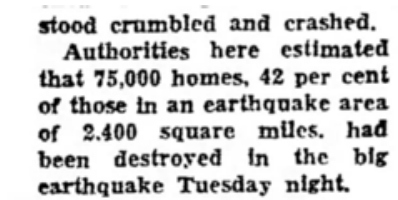

Dial Phone Change Approved By Board

Engineers for the state utilities commission reported favorably today for rate increaces and installation of automatic dial equipment

The Cochocton Tribune, Coshocton, $\mathrm{OH}, 1939$

\begin{abstract}
in nine communities, including West Lafayette and Conesville, served by the Ohio Bell Telephone Co.

Local officials and cttizens have 30 days to file objections. The engineers said telephone subscribers in the communities have agreed to the higher rates if the automatic equipment is installed.

Other communities affected are Fletcher, Slineville, Lena. Chesterland, Bloomingville, Castalia ant Christianburg.
\end{abstract}

Notes: Figure reproduces newspaper headlines and/or content from the following articles: "Phone Co. to Sink $\$ 140,000,000$ in Dials If Needed," The Brooklyn Daily Eagle (Battle Creek, MI), November 22, 1925; "Mayor Says Extra Dial Phone Charge Is Discriminatory," The St. Louis Globe-Democrat (St. Louis, MO), January 17, 1928; "City Loses Its Fight on Dial Phone Charge" The St. Louis Star and Times (St. Luis, MO), July 18, 1929; "Dial Phone Change Approved By Board," The Coshocton Tribune (Coshocton, OH), January 30, 1939; "Dial Telephone System Is To Be Installed In Tyler" The Tyler Courier-Times (Tyler, TX), September 24, 1939. All articles accessed from Newspapers.com. 


\section{Employment of young women}

We can also characterize the nature of work for young women in the period we study, vis-à-vis occupation employment and wage profiles, especially as we think about which occupations women might enter when telephone operation is obsolete. Table A.2 lists the most common occupations for for young, white, American-born women from 1910 to 1940, sorted by rank in 1920, where we see that "telephone operators" was the 6th most-common job for this group in 1920, dropping to 11th by 1940, presumably as a result of the diffusion of mechanical switching.

Table A.2: Top occupations for white, American-born women age 16 to 25, 1910-1940

\begin{tabular}{lcccc}
\hline \hline & \multicolumn{4}{c}{ Rank } \\
\cline { 2 - 5 } Occupation & 1910 & 1920 & 1930 & 1940 \\
\hline Operative and kindred workers & 1 & 1 & 2 & 1 \\
Stenographers, typists, and secretaries & 4 & 2 & 1 & 2 \\
Salesmen and sales clerks & 2 & 3 & 3 & 3 \\
Clerical and kindred workers & 10 & 4 & 4 & 5 \\
Teachers & 5 & 5 & 5 & 9 \\
Telephone operators & 8 & 6 & 7 & 11 \\
Bookkeepers & 7 & 7 & 8 & 7 \\
Private household workers & 3 & 8 & 6 & 4 \\
Laborers & 13 & 9 & 12 & 12 \\
Waiters and waitresses & 12 & 10 & 9 & 6 \\
\hline
\end{tabular}

Notes: Table ranks the top 10 occupations employing white, American-born women age 16-25 in the U.S. in 1920, and shows their ranks in other years.

We use historical survey data on salaries of clerical workers to identify clerical occupations with a similar earnings profiles to telephone operators, which might therefore be natural substitutes. In the 1920s, the National Industrial Conference Board (NICB) surveyed employers in large U.S. cities for the job titles and salaries of clerical workers, with survey returns covering 18 cities, 416 firms, and 25,879 employees. The published results (NICB 1926) report salary distributions for 20 different job titles - separately for males and females, and often separately for junior and senior employees - with one of the worker categories being "Switchboard operators". 1

We identified three surveyed occupations with similar female earnings profiles to telephone operators: "Office labor-saving machine operators", "Junior stenographers", and "Experienced typists", which had median and average earnings of around $\$ 21-22$ per week. Table A.3 shows the earnings profile for women in each occupation, and an imputed median (see table notes). These occupations map directly to 1950 occupation codes 341 ("Office machine operators") and 350 ("Stenographers, typists, and secretaries"), which are thus two of the occupations we study in Section 5 when we examine the post-cutover occupations of young women.

\footnotetext{
${ }^{1}$ We thank Claudia Goldin for pointing us to and sharing these records.
} 
Table A.3: NICB (1926) Salary Distributions for Select Clerical Occupations

\begin{tabular}{crr}
\multicolumn{4}{c}{ Switchboard operators } \\
\hline Range & Count & Cum. pct. \\
\hline$\leq 16.50$ & 30 & $5 \%$ \\
$16.51-18.00$ & 77 & $16 \%$ \\
$18.01-19.50$ & 51 & $24 \%$ \\
$19.51-21.00$ & 155 & $47 \%$ \\
$21.01-22.50$ & 57 & $56 \%$ \\
$22.51-25.00$ & 111 & $73 \%$ \\
$25.01-27.50$ & 66 & $83 \%$ \\
$\geq 27.51$ & 116 & $100 \%$ \\
\hline
\end{tabular}

\begin{tabular}{crr}
\multicolumn{3}{c}{ Office Machine Operators } \\
\hline Range & Count & Cum. pct. \\
\hline$\leq 15.00$ & 235 & $10 \%$ \\
$15.01-17.00$ & 190 & $18 \%$ \\
$17.01-19.00$ & 235 & $28 \%$ \\
$19.01-21.00$ & 363 & $44 \%$ \\
$21.01-23.50$ & 461 & $63 \%$ \\
$23.51-26.00$ & 376 & $79 \%$ \\
$26.01-30.00$ & 373 & $95 \%$ \\
$\geq 30.01$ & 116 & $100 \%$ \\
\hline \multicolumn{2}{c}{ Imputed median: 22.71 }
\end{tabular}

Junior Stenographers Experienced Typists

\begin{tabular}{crr}
\hline Range & Count & Cum. pct. \\
\hline$\leq 17.50$ & 191 & $20 \%$ \\
$17.51-19.00$ & 104 & $31 \%$ \\
$19.01-20.50$ & 97 & $41 \%$ \\
$20.51-22.00$ & 123 & $54 \%$ \\
$22.01-23.50$ & 151 & $69 \%$ \\
$23.51-25.00$ & 78 & $77 \%$ \\
$25.01-26.50$ & 97 & $88 \%$ \\
$\geq 26.51$ & 120 & $100 \%$ \\
\hline
\end{tabular}

Imputed median: 20.97

\begin{tabular}{crr}
\multicolumn{3}{c}{ Experienced Typists } \\
\hline Range & Count & Cum. pct. \\
\hline$\leq 17.50$ & 263 & $23 \%$ \\
$17.51-19.00$ & 105 & $33 \%$ \\
$19.01-20.50$ & 196 & $50 \%$ \\
$20.51-22.00$ & 149 & $63 \%$ \\
$22.01-23.50$ & 153 & $77 \%$ \\
$23.51-25.00$ & 89 & $84 \%$ \\
$25.01-27.50$ & 96 & $93 \%$ \\
$\geq 27.51$ & 81 & $100 \%$ \\
\hline \multicolumn{3}{c}{ Imputed median: 20.50}
\end{tabular}

Notes: Table reports salary distribution for female switchboard operators, office machine operators, junior stenographers, and experienced typists from NICB (1926). Medians imputed assuming a uniform distribution in each bin in which the median salary occurs (i.e., as a weighted average of the lower and upper bounds of the bin in which the true median falls). 


\section{B Data Appendix}

\section{B.1 Data on dial cutover location and timing}

We collect data on the local adoption of mechanical call switching (dial) from two sources: records at the AT\&T archives which report dial penetration in cities with population $>50,000$ in the 1930s, and local newspaper reports, which cover cities large and small across the country.

To understand the cutover data collection it is useful to first recall the process by which cutovers took place. Although the AT\&T corporate office (specifically, AT\&T's chief engineer) gave general guidance to the regional operating subsidiaries on the adoption of dial-including information on the performance of dial vs. manual operation in different-sized markets and under different operating conditions - the decision to convert any single telephone exchange from manual to dial was made by the management of the operating companies themselves. This decision would set in motion a multi-year planning and installation process: exchange buildings had to be expanded or built, new switching equipment had to be installed, and new telephone directories and dial telephone sets had to be distributed to subscribers, who in turn had to be taught how to use them when dial service began. Judging from the newspaper reporting which we describe below, the date that telephone service would convert to dial was fixed in advance, but sometimes experienced (usually modest) delays. On the designated day - usually at midnight on a Saturday, when call volumes were lowest - technicians would physically cut the wires out of the manual switchboards, and connect them to the mechanical equipment (hence the term "cutover"). The actual cutting-over took only a few minutes, after which local calls were mechanically operated. In small cities and rural areas with at most a few telephone exchanges, these would typically all be cut over together. In larger cities with many to hundreds of telephone exchanges (New York had hundreds), these conversions effectively took place one exchange/neighborhood at a time, such that in these cities, telephone service was automated in a more piecemeal fashion over years or decades.

\section{Data from AT\&T's corporate archives}

Because AT\&T cutover decisions were decentralized, there is no single source at the AT\&T archives documenting the place and time of all cutovers in the Bell system. ${ }^{2}$ However, in the course of reviewing documents at the AT\&T corporate archives (Warren, NJ), we discovered a three-page document compiled in the late 1930s which lists all cities in the U.S. and Canada with population $>50,000$, along with the date of that city's first cutover to dial and the percent of subscribers on dial as of December 31, 1937 (Figure B.1). ${ }^{3}$ For cities which were less than 100\% dial in 1937, we manually search Google and historical newspapers for reports of cutovers between 1937 and 1940, and update the percent dial to 1940 values based on these results.

We use distinct estimation strategies for studying the effects of dial in small versus large cities, which we cut at a 1920 population of 100,000, with an event study strategy for small cities (which typically had one-shot cutovers) in the paper and a long-differences strategy for larger cities (which were converted to dial in a more graduated, piecemeal fashion) in the appendix. Figures B.2 below provides suggestive evidence that this was indeed the case: the figures show that smaller cities in the AT\&T data (with population $\leq 100 \mathrm{k}$ ) were nearly all $100 \%$ dial by 1940 , irrespective of the date of their first cutover - suggesting these were one-shot events.

\footnotetext{
${ }^{2}$ According to a call with Sheldon Hochheiser, AT\&T corporate historian, on March 1, 2017, the decision and pace of dial adoption was decided by management of the individual regional operating companies, not AT\&T corporate.

${ }^{3}$ This document was found in AT\&T Archives and History Center box 106-10-02-07.
} 
Figure B.1: AT\&T data on the adoption of dial in cities of population $>50,000$

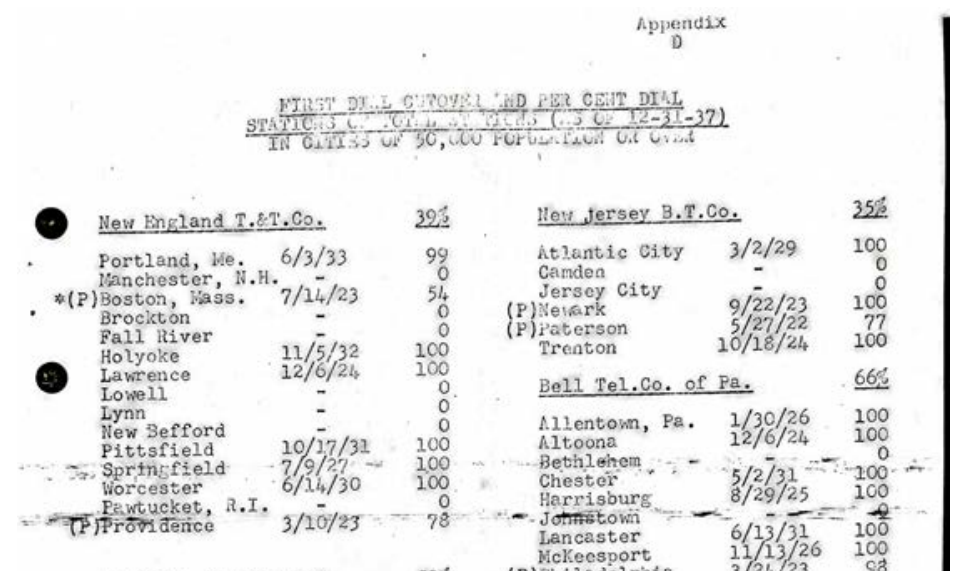

Notes: Figure shows an extracted table from the source data on dial installation in large cities from the AT\&T Archives and History Center (box 106-10-02-07).

Figure B.2: AT\&T city-level data: Fraction dial in 1940 vs. first cutover date

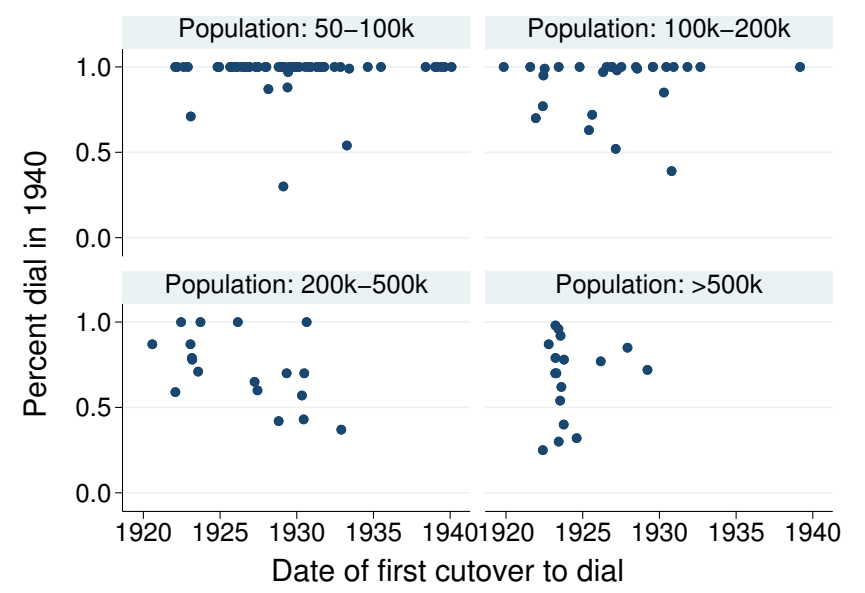

Notes: Figure plots a city's fraction dial in 1940 against the date of the city's first cutover to dial, for cities in the AT\&T data, group by their 1920 population. The figure illustrates that smaller large cities $(\leq 100 \mathrm{k}$ population) with cutovers were nearly all $100 \%$ dial, irrespective of the first cutover date, suggesting that they were single-cutover cities. In larger cities (200-500k), the fraction dial in 1940 varies with how recently cutovers began, and in the largest cities $(>500 \mathrm{k})$, which nearly all began cutting over to dial before 1925 , they are unrelated.

\section{Data from historical newspapers}

We supplement the large-city AT\&T data with a more comprehensive data collection effort from historical newspapers. Dial cutovers were locally-notable events and often reported on in the days before and after the change, and also sometimes months or even years in advance or later - not only because readers needed to know when to start using their dial telephone sets, but also out of public 
curiosity or celebration, as well as due to public concern over the fate of soon-to-be disemployed telephone operators, which was itself the focus of many articles.

We searched three online digitized newspaper collections for reports of cutovers and had assistants read through search hits to identify articles which reported cutovers, and for each record the cutover city, date, and number or percent of affected subscribers. Because these data are at the core of the paper, we will describe the data collection in substantial detail.

\section{Round 1: July-August 2017}

Data collection efforts began in the summer of 2017 and were initially focused on reviewing articles between 1917 and 1940 at Newspapers.com, which hosts the largest digitized, searchable historical newspaper collection available. ${ }^{4}$ After testing several potential Boolean search terms, we settled on two preferred search terms, which we label "ST1" and "ST2" below:

$$
\begin{aligned}
& \text { (ST1) telephone ("dial" or "automatic") ("cutover" or "cut over" or } \\
& \text { "changeover" or "manual") ("office" or "exchange") } \\
& \text { (ST2) telephone ("dial" or "automatic") ("cutover" or "cut over" or } \\
& \text { "changeover" or "manual") "midnight" }
\end{aligned}
$$

Whereas ST2 is a more targeted search (due to the requirement of the word "midnight") and is designed to minimize false positives, ST1 casts a wider net and is designed to minimize false negatives. Between the two, we believe we can identify nearly all cutovers reported in the Newspapers.com collection. When these searches were conducted in July 2017, ST2 returned 4173 results, and ST1 returned 36072 results, of which 33060 were additional to those of ST2.

We had research assistants read all articles in the ST2 search results and the top 25\% of the ST1 results ${ }^{5}$ and asked them to determine whether the article does in fact describe a cutover, and if so, to record (i) the cities affected (sometimes several neighboring small towns are cut over at once, or served jointly by a single exchange); (ii) the date, including whether past or future (planned); (iii) the number or percent of subscribers affected, if reported (rarely); and (iv) any additional notes that may be relevant to measurement or interpretation (for example, occasionally an article reports on a cutover at a large firm or other organization that operates its own private, internal switchboard, rather than at the local telephone service provider). Whenever a research assistant flagged an article as describing a cutover or potentially describing a cutover, we manually reviewed their data entry to ensure the accuracy of the entered data.

We find newspaper reporting on both past and future cutovers characterized with varying degrees of specificity: many articles report exact dates, but some - especially articles that reference cutovers in passing, but are focused on other telephone company news - describe only the month and year (e.g., "last month"), season and year ("next fall"), year alone ("towards the end of this year"), or are non-specific (e.g., "nearing completion", proposed but not yet planned, or no timing reported; in the cases where an article describes a cutover without providing any information on its timing, we nevertheless infer whether that timing is past or future based on the verb tense in the article).

\footnotetext{
${ }^{4}$ The search window was chosen on the grounds that (i) AT\&T records indicate that the firm only began dial cutovers in the late 1910s, and (ii) we have outcome data through 1940.

${ }^{5}$ The search results are listed in order of "relevance", however determined by the website. Reassuringly, the rate of verified cutovers in these search results declines rapidly in the search rank: by the time we get a quarter of a way down the ST1 results list, only around 5 out of every 100 search results is a true description of a cutover, and these are often redundant to earlier reports, or lacking information on timing and unusable.
} 
In many cases, we find multiple reports of the same cutover, and we use these to cross-validate and refine our timing measures where possible. We take these data and aggregate up to the city and month: given that we study census-measured outcomes at decadal frequency, monthly variation in cutover timing should be sufficient for the purposes of this paper.

It is important to attempt to include cutovers even with imprecisely-reported timing: dropping these cutovers would bias our results towards zero, as the control group (of cities not cut over by 1940) would then have treated locations in it. Moreover, with outcomes at only decadal frequency, a bit of measurement error on the precise timing is acceptable in specifications that measure treatment as $\mathbb{1}$ (Post-cutover) (but specifications measuring the time since a cutover would be more sensitive to this type of measurement error). When a cutover is reported with an "approximate" date, we thus treat it as the true date. We otherwise use the article language (e.g., "recent", "soon", "ongoing", mentions of specific calendar seasons) to approximate the month and year.

When an article provides only the year and no more precise information can be inferred from other reports, we do the following: if the year is in the past or present (relative to the article), we assign the cutover to July of that year (the midpoint). Although this may introduce measurement error, this error will not be material to this paper unless the year is a Census year, and there are only two such cases in the data (one of which is Detroit, a large city, which we exclude from our event study on the grounds of its size anyway). If the year is in the future, the cutover itself is uncertain, let alone the timing, and we treat it as planned but undated.

Round 2: July-August 2019

In the summer of 2019, we undertook a second round of newspaper-based data collection to capture new results from Newspapers.com, whose collection of digitized newspapers had more than doubled, and to expand our data collection effort to the two next-largest digital newspaper repositories (NewspaperArchive.com and GenealogyBank.com), which may cover different cities or time periods. In July 2019, we repeated our ST1 and ST2 searches for the 1917-1940 period on Newspapers.com, and also performed searches on these two additional sites. ${ }^{6}$

When these searches were conducted on Newspapers.com in June 2019, ST2 returned 6666 results, of which 2490 were new since 2017, and 2280 of these unique newspaper issues (in the second round of data collection, we noticed that sometimes the search returns multiple hits from the same newspaper on the same day, and we had assistants read each newspaper issue only once, to reduce duplicated efforts). ST1 returned 55312, of which 39889 were also not already collected in 2017 or covered by ST2, 36502 of these from unique issues, and 3512 in the top $25 \%$ of ST1 search results. These results (2280 for ST2, 3512 for ST1) were then manually reviewed by research assistants. Similarly: on GenealogyBank.com, ST2 returned 2609 results, of which 2497 were new since 2017, and 2309 of these unique issues; ST1 returned 21171, of which 18143 were also not already collected in 2017 or covered by ST2, 16304 of these unique issues, and 4021 in the top 25\% of ST1 search results. On NewspaperArchive.com, ST2 returned 2100 results, of which 1512 were new since 2017, and 1189 of these unique issues; ST1 returned 1520 (see previous footnote as to why this number is lower than that for ST2), of which 828 were also not already collected in 2017 or covered by ST2, 513 of these unique issues. The table below summarizes this information:

\footnotetext{
${ }^{6}$ Note that NewspaperArchive.com does not support Boolean search. In this case, we searched each non-Boolean permutation of each search term. For this data source we skipped the following permutations of ST1: "telephone dial manual office" / "telephone dial manual exchange" / "telephone automatic manual office" / "telephone automatic manual exchange", due to the size of the results list and the high rate of false positives. Having omitted these results, we review all other ST1 results from NewspaperArchive.com (rather than just the top 25\%). We believe most true positives in these search results will be picked up this way.
} 


\begin{tabular}{lllcc|c} 
& & & & \multicolumn{3}{c}{$\begin{array}{c}\text { ST1 } \\
\text { (not in }\end{array}$} & \\
& & & ST2 & ST2) & Total \\
\hline \multirow{2}{*}{ Round 1 (2017) } & \multirow{2}{*}{ Newspapers.com } & All results & 4,173 & 33,060 & 37,233 \\
& & Reviewed & 4,173 & 8,265 & 12,438 \\
\hline \multirow{2}{*}{ Round 2 (2019) } & \multirow{2}{*}{ Newspapers.com } & New results & 2,490 & 36,502 & 38,782 \\
\cline { 2 - 6 } & \multirow{2}{*}{ NewspaperArchive.com } & Reviewed & 2,280 & 3,512 & 5,792 \\
\cline { 2 - 6 } & & All results & 2,100 & 1,520 & 3,620 \\
& \multirow{2}{*}{ GenealogyBank.com } & Reviewed & 1,189 & 513 & 1,702 \\
\hline & \multirow{2}{*}{ Total } & Reviewed & 2,609 & 21,171 & 23,780 \\
& & All results & 11,372 & 92,253 & 103,415 \\
& & Reviewed & 9,951 & 16,311 & 26,262
\end{tabular}

Results

In total, we find 3,945 reports of cutovers in the continental U.S., with 3,859 describing non-private branch exchange (PBX) cutovers in 887 distinct cities and towns. With respect to the precision of the timing information, these reports break down as follows:

\begin{tabular}{clcc}
\hline \hline & & \multicolumn{2}{c}{ Articles } \\
Category & Label & Count & Percent \\
\hline 1 & Exact date provided & 2,171 & 56.2 \\
2 & Date inferred from coarse information + other reports & 1,150 & 29.8 \\
3 & Month and year provided or approximated & 308 & 8.0 \\
4 & Year provided, past or present & 25 & 0.7 \\
5 & Year provided, future & 9 & 0.2 \\
6 & No timing information provided & 196 & 5.1 \\
\hline Total & & 3,859 & 100 \\
\hline \hline
\end{tabular}

Of the 887 cities with cutovers, 798 have at least one cutover in the newspapers data with exact or approximate timing (categories 1-4 above), whereas 89 only have cutovers without reliable timing information. To be conservative, we drop these cities from the analysis in Sections 4 to 6 of the paper, because we cannot know for certain when the shock occurred - or, for reports of future cutovers, if it even occurred at all. For the remaining cities: although a handful (43) have $\geq 1$ reports of a cutover that we are unable to date, (i) most of these are large cities excluded from the event study sample, and (ii) we find that the majority (70\%) have their earliest known cutover in the 1920 s, and the vast majority (98\%) by 1933, providing confidence that we can accurately measure cities' earliest cutovers, which is the relevant margin for this paper.

We aggregate these data up to the city $\mathrm{x}$ month level, identifying months in which each city was reported to have experienced a dial cutover, and henceforth we call each such city-month a "cutover" (we assume that when there are multiple reported cutovers in a given city in the same month, these are part of the same event - although there are few such cases in the data, as we have previously harmonized cutover dates in the raw data).

There are 1,047 cutovers with known timing across the 798 cities in our final sample (an average of 1.3 per city, with a median of 1 , 90th percentile of 2 , and max of 15), and 904 that take place between the 1910 and 1940 Censuses (April 1910 and April 1940), the period studied in this paper. ${ }^{7}$

\footnotetext{
${ }^{7}$ Note that of the 1,047 cutovers with known timing from the Newspapers data, 26 cutovers (2.5\%) took place before the first cutover in the AT\&T data (in November 1919), ostensibly having been executed by independent (non-AT\&T) telephone service providers - which we confirm by manual review. Additional comparisons between AT\&T and Newspapers data are provided in the next subsection below.
} 
Among these, the average and median cutover took place in 1931. Figure B.3 below maps these cutovers, illustrating their expanding geographic incidence - which is the variation at the heart of this paper. Figure B.4 shows a binned scatterplot of a city's number of cutovers in the Newspapers data against 1920 log population, with a line at 100k population (our threshold for the event study sample). This figure reinforces the evidence that smaller cities typically have only one or at most two cutovers in our data, consistent with these locations being served by only one or a few telephone exchanges, which could be simultaneously converted to dial.

Figure B.3: Newspapers city-level data: Expanding geography of dial, 1915 to 1940
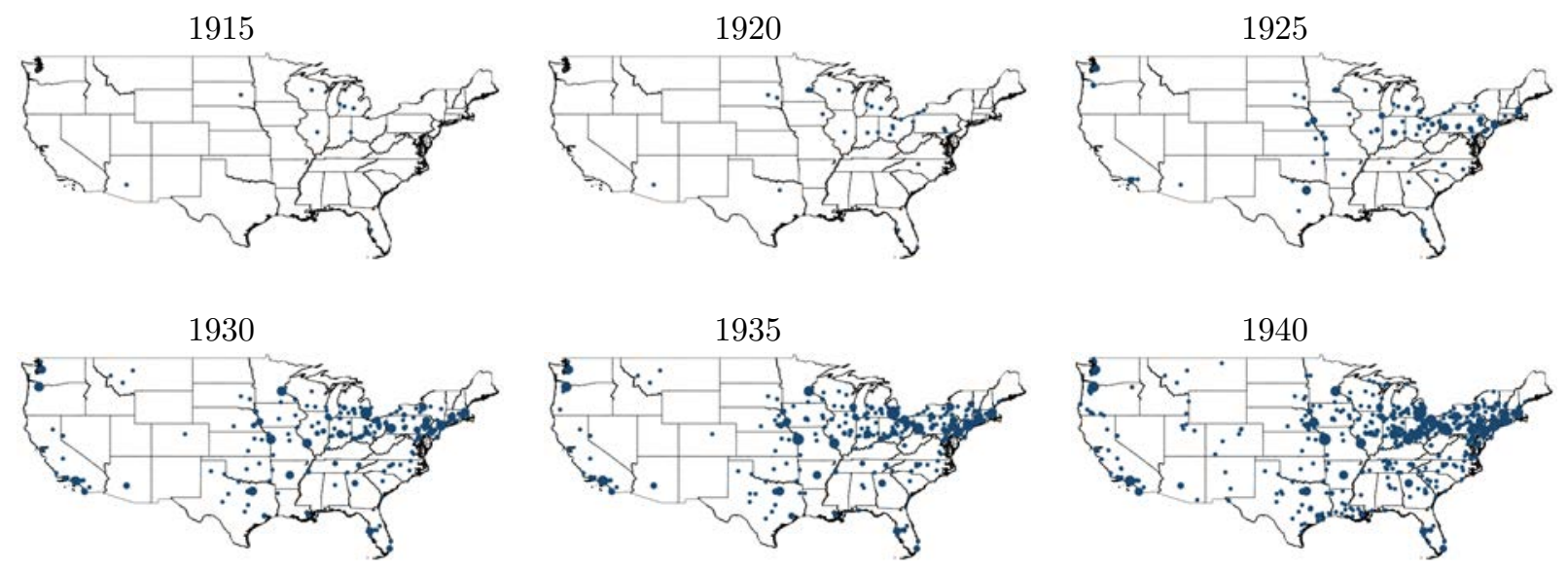

Notes: Figure maps cities with a dial cutover in the newspaper data through the year shown in each panel. Bubble sizes are proportional to the cumulative \# of reported cutovers in the given city through the given year.

Figure B.4: Newspapers city-level data: Number of reported cutovers vs. 1920 population

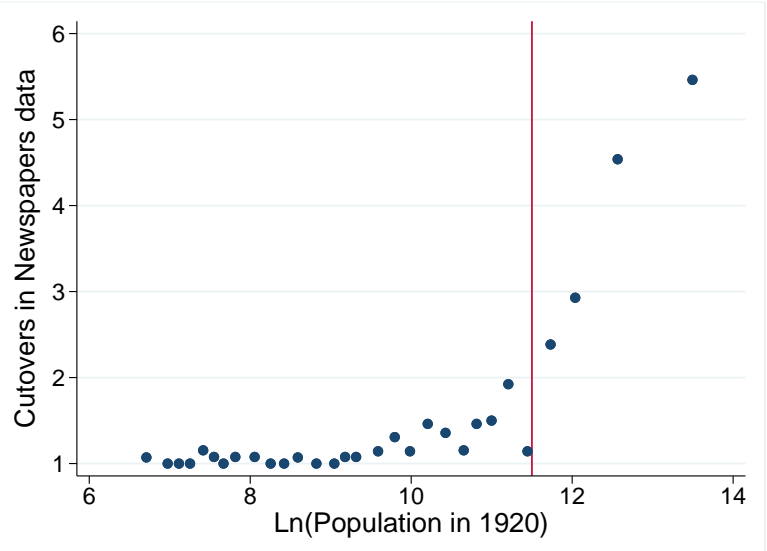

Notes: Figure shows a binned scatterplot of cities' number of reported cutovers, measured as the number of distinct months between 1919 and 1940 with a cutover reported in our Newspaper data, against log 1920 population, with a line drawn at $100 \mathrm{k}$ population (the $\log$ of which is $\approx 11.5$ ). The figure illustrates that smaller cities typically have only one or at most two cutovers in our data, suggesting that they were single-cutover cities. Larger cities have several cutovers in our data. 


\section{Comparison of AT\&T and Newspapers data}

We can also cross-validate the AT\&T and Newspapers data against each other, by comparing the timing of the earliest cutover reported in newspapers versus in the AT\&T administrative data for all cities appearing in both sources. Figure B.5 shows this comparison, plotting individual cities' earliest newspaper-reported cutover (vertical axis) against earliest AT\&T-reported cutover (horizontal axis). Each point represents a city and is labeled with its state's abbreviation, and the dashed red line is the 45-degree line. Dates coincide across the two sources for the vast majority of cities, providing reassurance on the quality of the newspaper data. For the handful of cities where newspapers report a cutover preceding those in the AT\&T data by more than a month (below the 45-degree line), we revisited the reporting articles and determined that either (i) these were performed by independent (non-AT\&T) companies (13 cases), or (ii) these were preliminary cutovers affecting a very small portion of the population (1 case).

Figure B.5: Timing of cities' first cutover in AT\&T data vs. newspaper data

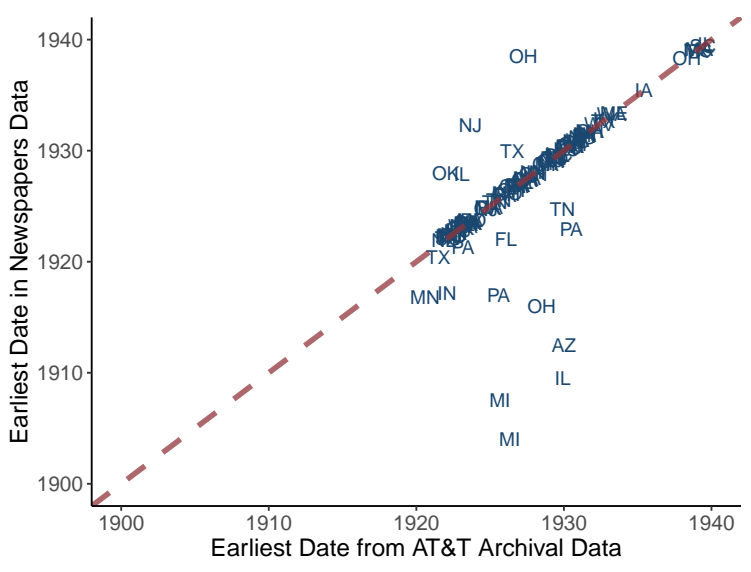

Notes: Figure plots cities' earliest observed cutover date in newspapers data versus AT\&T data, for cities in both data sources, and the 45-degree line in red. Each city is labeled with its state abbreviation. Figure is presented to illustrate the degree of agreement between the AT\&T and newspapers data. Nearly all cutovers identified in the newspaper data collection that preceded AT\&T-reported cutovers were performed by independent (non-AT\&T) telephone companies.

\section{B.2 Complete-count Census data}

Taken decennially, the US Federal Census enumerates the entire population and contains a wealth of economic, social, and demographic information. We draw on the recently digitized complete count census data from IPUMS (Ruggles et al. 2019) for the censuses in 1900, 1910, 1920, 1930, and $1940 .{ }^{8}$ That the data is complete count means simply that all individuals enumerated - the complete count of people in the US in each census year - has been transcribed and coded by IPUMS. This enables us to count not just the number of telephone operators in the telephone industry in each city, but the number who are 17, white, born in Massachusetts, and single, if we wanted that level of granularity. In this appendix subsection, we describe our aggregation procedures-

\footnotetext{
${ }^{8}$ We stop in 1940 because the census is privacy-restricted for 72 years after it is taken and so 1940 is the most recent census IPUMS has and could transcribe and digitize in full.
} 
particularly which individuals we include in which samples - as well as other controls variables we build with the complete count data.

\section{Aggregation of complete count individual-level data}

\section{Unit of observation}

We restrict attention to the adult (16+) non-farm population with non-farm occupations, in the continental U.S. only (lower 48 states plus District of Columbia). Our primary dataset aggregates these individuals in the complete count data up to the level of:

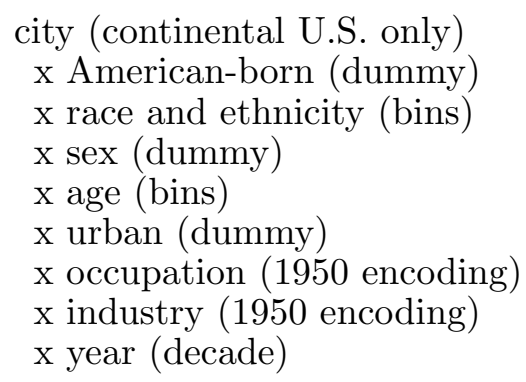

where these variables are defined as follows:

- American-born: indicates whether an individual was born in a U.S. state or territory

- Race/ethnicity: bins for (i) white/non-Hispanic, (ii) white/Hispanic, (iii) black, (iv) Native American, (v) Asian, (vi) mixed, and (vii) other

- Sex: indicates whether individual is male or female

- Age: 5-year bins for individuals age 16-20 to 56-60, and 61+

- Urban: indicates whether individual's household was urban (vs. rural)

- Occupation: 1950 occupation codes (283 categories)

- Industry: 1950 industry codes (162 categories)

We also prepare derivative datasets that (i) further aggregate up to dummies for telephone operators and the telephone industry (rather than separate bins for each occupation and industry), and (ii) aggregate up all occupations and industries. To study effects of dial on the youngest ages, we also prepare variants of these datasets where age is measured in individual years for ages 16-25.

In addition to these city $\mathrm{x}$ demographic bin $\mathrm{x}$ year datasets, we prepared separate datasets of (i) all individuals reporting as telephone operators (occ1950=370), and (ii) all individuals reporting as working in the telephone industry (ind1950=578).

\section{Sampled cities}

The raw complete count data include each individual's household's state and county, and city where relevant. The IPUMS data includes not only a raw city string (as originally reported on Census manuscripts) but also a standardized city, to account for the fact that city spellings may change or be reported slightly differently for different households or in different years. However, this standardized city was not always provided, or was sometimes provided where the raw city was missing, and we determined that additional harmonization was needed.

We begin by combining the list of raw city strings and IPUMS-standardized cities from all years 1910-1940 (note that these can vary: some smaller cities are not found in every year of the IPUMS data). Having done so, we then manually examine (i) cities in the same state that start with the same three letters, (ii) cities in the same county that sort adjacently and have a Levenshtein edit 
distance of $\leq 4$, and/or (iii) cities in the same county that sort within 30 positions of each other and have an edit distance $\leq 2$, to find spelling variants that appear to be the same city. We use the results of this effort to build a crosswalk from the raw and IPUMS-standardized city names to our manually, fully-harmonized city names. We apply this crosswalk to both the raw city strings and IPUMS-standardized city names, which will also now match when both are provided. We take either of these measures, when available, as an individual's (household's) true city.

From this effort, we produce a list of unique, harmonized cities by year. We then identify all such cities which (i) are observed every year from 1910 to 1940, and (ii) have a population of $\geq 2,000$ in 1920, as measured by aggregating up individuals in the IPUMS data. This yields a balanced panel of 3,027 cities, which comprise the sample for this paper. Within this sample, the median 1920 city population is 4,346 ; the 95 th percentile is 48,414 . Of these 3,027 cities, 415 are identified in our cutover data, and 384 with exact or approximate cutover timing.

This characterizes our base city sample, but we later exclude several of these cities from our empirical analysis. Specifically, we remove 14 cities with a population $\leq 500$ in 1910, to eliminate those where inference is made difficult by small samples - though this is unlikely to affect our analysis, which is weighted on population. We also winsorize 56 cities where the IPUMS data report large, sharp drop-offs in the fraction of the population (notably, prime-age males) with an occupation. Figure B.6 illustrates some examples, several of which are neighboring cities where these outlier values occur in the same year, suggesting it is due to enumeration anomalies. We identify outlier cities as those where employment growth in any year is below the 1st percentile or above the 99th percentile, or where the ratio of the average employment rate in $t-10$ and $t+10$ to that in year $t$ is above the 99th percentile. To be conservative and err towards precise measurement, we additionally drop 31 cities where newspapers report a cutover but without indicating when it took place, as well as New York City boroughs, since it is often difficult to discern from newspapers articles in which borough a cutover took place, and because there were many more cutovers in the very large New York City system than in other cities. In total, this results in 105 cities being excluded from the original city sample in preparation for analysis.

Figure B.6: Examples of cities with outlier changes in the population with an occupation

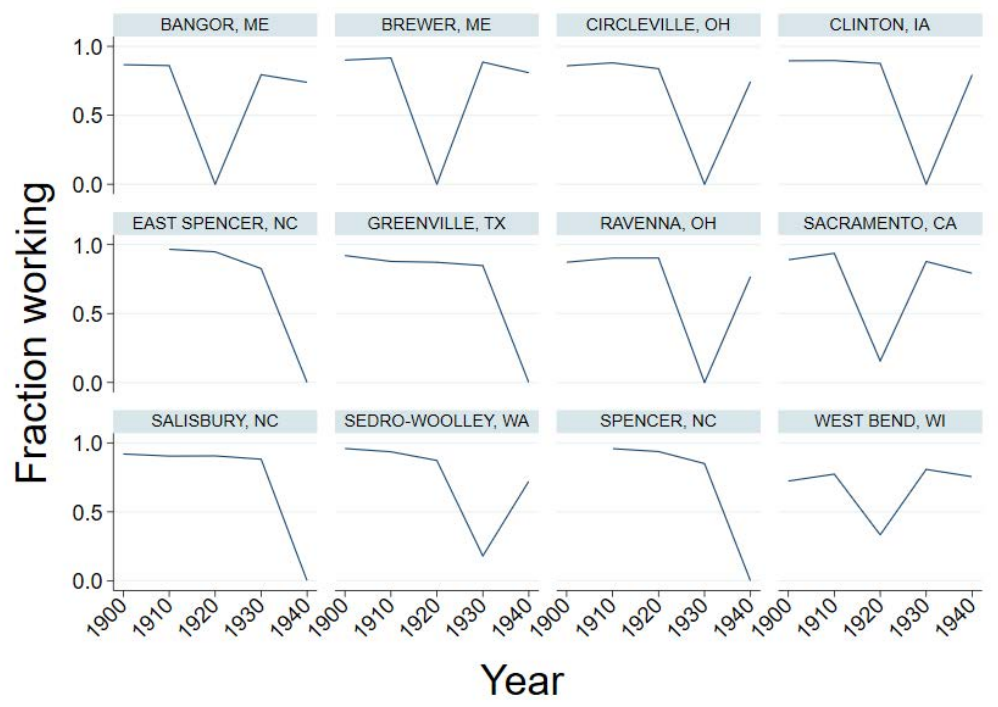




\section{Other remarks}

We also collect 1920 to 1940 city populations from Census publications for validation and independent use. From the 1930 Census, we retrieve 1920 and 1930 populations for all cities with >1,000 people in 1930, and from the 1940 Census, 1930 and 1940 population for all cities with >1,000 people in 1940. We then merge these data to build the panel (retaining 1930 values from the 1940 Census, rather than the 1930 Census, where conflicts arise).

\section{B.3 Creating our Linked Sample of Female Telephone Operators}

In addition to studying future cohorts, we study the effects of automating telephone operation on the telephone operators themselves. To do this, we have to follow operators over time, tracing their careers and lives from when they were employed as operators in the telephone industry to after the cutover shocks. If the operators had been men, this task would be relatively straightforward and we could rely on one of the commonly used census linking strategies in the economic history literature. ${ }^{9}$ However, as we showed in Table 2, the vast majority of operators in 1920 and 1930 were young women. While the demographic profile of operators makes them an interesting set of workers to study, it also makes them impossible to link across censuses in traditional ways. Census linking is commonly performed on "stable" features enumerated in the census, most importantly names. However, young female operators may marry and then change their names upon marriage between the census we see them as an operator and the next census where we would like to find them. Because census records do not attach unmarried names to married records, such name changes would make linking impossible without additional data or information.

To create our individual-level longitudinal data on telephone operators, we turn to an alternative source of linked data, the FamilySearch public family history tree (Price et al. 2019). In this appendix, we describe in detail our precise procedure to link telephone operators via the FamilySearch tree and how we weight our final sample to ensure our results are internally valid to all telephone operators in this period and not just those more likely to be on the tree. In the penultimate subsection of the appendix, highlighting the novelty of using the FamilySearch tree to created linked data for empirical analysis in this paper and future research, we ask and answer the question of which individual features make someone more or less likely to be on the tree.

When we analyze the effects of cutovers on telephone operators, we compare the operators to control women. To serve as a control woman for a given operator, the control must match the operator in the initial census (1920 or 1930, the census in which the operators were employed as telephone operators in the telephone industry) on sex, race, Hispanic ethnicity, marital status, whether or not she has any children, whether or not she is US-born, whether or not her mother is US-born, whether or not her father is US-born, and is within 5 years younger or older of the operator. In addition, we match controls on precise geography, zooming in on the enumeration district. In the 1920 and 1930 census, enumeration districts are census-constructed geographies that contain about 1000 people all living in close proximity, akin to a neighborhood in most cities. The final key matching variable is employment status: we only compare telephone operators to other women who were also employed in the initial census. As we note in the paper, we identified 21 controls for each operator. We then followed the same genealogical linking strategy for the control women as for the operators, locating them on FamilySearch and, if possible, tracing them forward to the following census. Ultimately, we linked nearly 5 controls per operator. However, to reduce data collection time, we attempted to

\footnotetext{
${ }^{9}$ For an overview of automated census linking, see Abramitzky et al. (2021).
} 
link control women forward only after we had linked the operators and we only attempted to link the control women for operators we linked ahead to the following census. This reduced the number of control women we had to attempt to link dramatically, from more than 4.2 million to about 460 thousand, and with no empirical downside because the control observations for unmatched operators would not be included in our analysis. Because this procedure determined entry into the sample, we focus our description of our linking and our analysis of who is on the tree on the operators. Later in this appendix we describe the control sample in more detail.

\section{B.3.1 The Procedure to Link Telephone Operators}

To link the women in our sample, we develop and implement a novel linking procedure, making use of a popular genealogy platform and the "work" of many expert family historians (both professional genealogists and hobbyists) linking the women in their family trees across censuses, marriage events, migration events, and more. In this subsection, we describe our linking pipeline and the matched data, echoing information from the main paper with additional details. In Figure B.7 we illustrate our procedure as it compares to traditional linking methods, and in Figure B.8 we document the specifics of our approach at each of the steps described below.

Figure B.7: FamilySearch-based versus Traditional Linking Procedures

\section{Our FamilySearch-Based Linking Procedure}

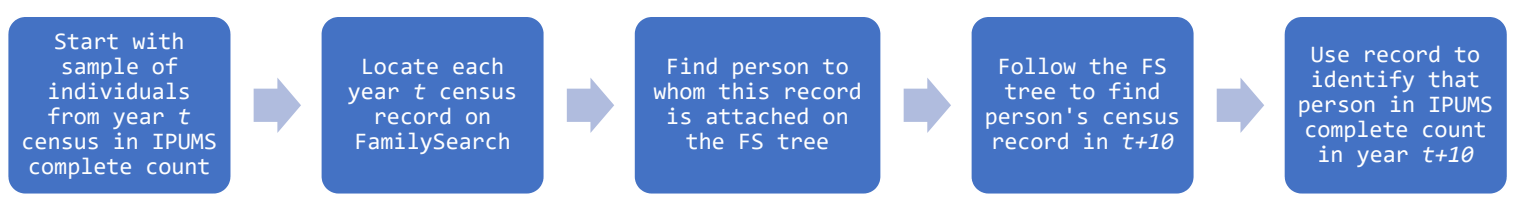

Traditional Linking Procedure
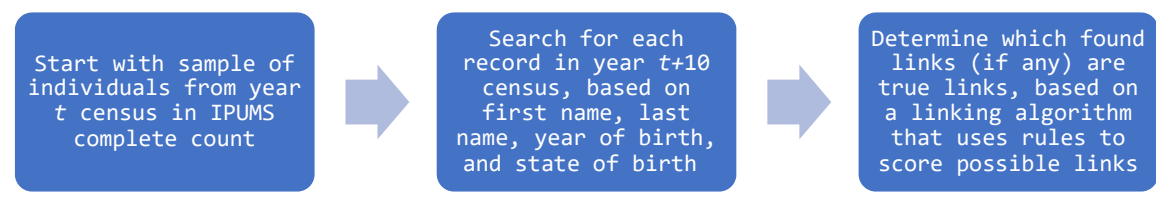

We begin by reproducing our description of the linking procedure from Section 2. We link in the following four steps. First, we identify all women working as telephone operators in the telephone industry in the 1920 and 1930 complete count census data (Ruggles 2002). After limiting to women in our focal cities, we have 96,183 women in 1920 and 61,110 women in $1930 .{ }^{10}$ Second, we look for each telephone operator on FamilySearch, a public genealogy platform with an open wiki-style

\footnotetext{
${ }^{10}$ Note that this sample omits a small number of male operators from our analysis as well as a small number of operators younger than 16 or older than 60. Only operators in cities with cutovers after 1920 are included. We further limit to operators in cities with population $\leq 100,000$ in 1920 , where cutovers were typically one-shot events, matching the sample we use when we study the next generation of potential operators (see Section 4 ). For the 1930 sample, we further restrict the sample by filtering out cities with cutovers before 1930, as these women are selected on being operators after their city was cut over to dial service.
} 
Figure B.8: Sampling at Each Stage of the FamilySearch-based Procedure

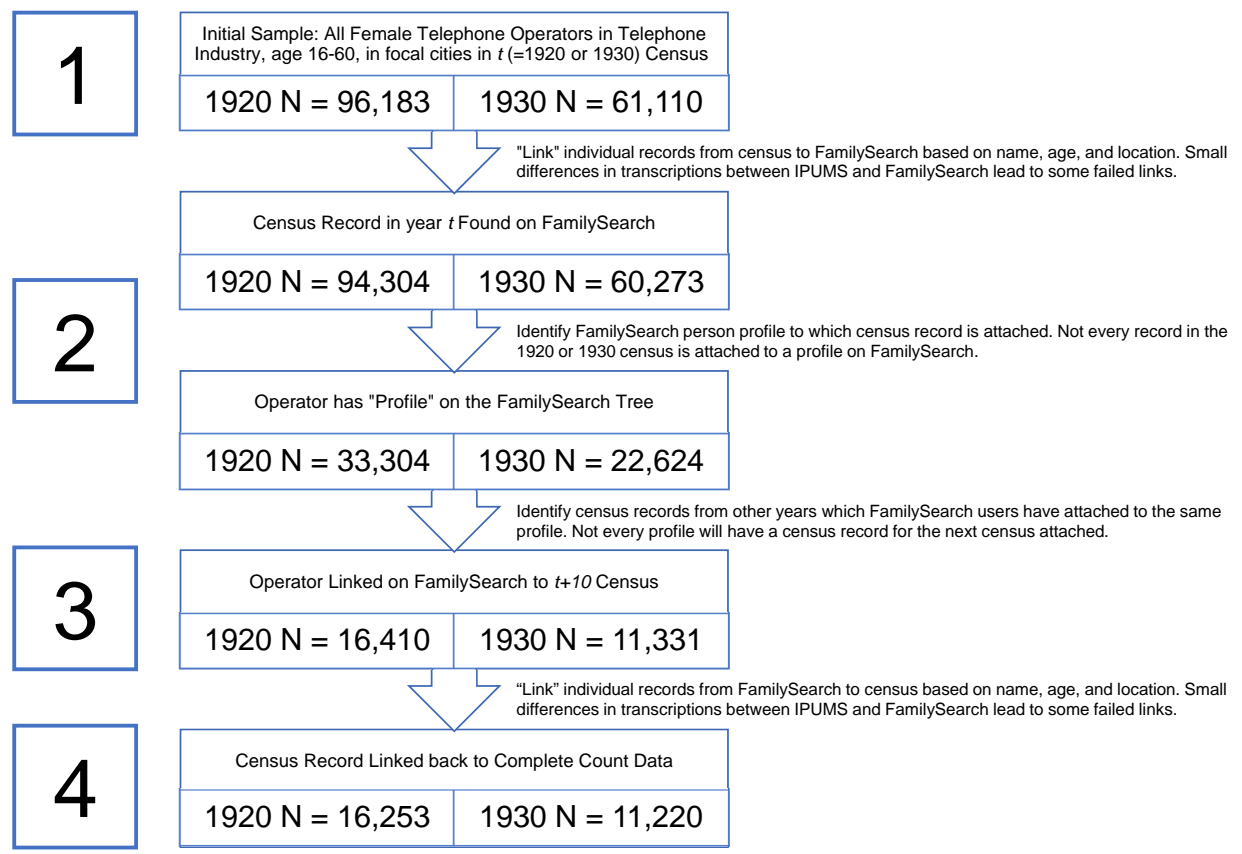

family tree (Price et al. 2019), where users create pages for deceased individuals - usually their own ancestors but not always - and attach links to historical records, including entries from Federal Censuses, marriage records, and birth certificates. We search FamilySearch in our base years by name, age, sex, location, and state of birth. Because the 1920 and 1930 census transcriptions in the IPUMS complete count data are based on the same original manuscripts as those on FamilySearch and we can use names, addresses, and other characteristics to link them, matching is straightforward. However, not all telephone operators have a page on FamilySearch. We are able to find $34.6 \%$ of operators in 1920 and $37.0 \%$ in 1930 with a FamilySearch page. ${ }^{11}$

Third, we query the FamilySearch tree for links to the next census. That is, we begin with the set of operators who were attached to the tree in year $t \in\{1920,1930\}$, the census in which they were an operator. We check whether or not each operator's profile on FamilySearch has been linked to a record from the census in $t+10$. Conditional on being on the tree, $49.3 \%$ of records in our sample from 1920 are linked ahead to the 1930 census and 50.1\% of 1930 records are linked to 1940 .

Finally, for the set of operators with FamilySearch records attached to censuses in $t$ and $t+10$, we use census record metadata - reel, page, and line number - to make links back to the complete count, restricted use IPUMS data. This process yields a sample of 16,253 operators linked from 1920 to 1930 and another 11,220 linked from 1930 to 1940. For all of these operators, we observe the full set of census covariates in $t$ and $t+10$, allowing us to study what happens to operators a

\footnotetext{
${ }^{11}$ Whether or not an operator - or anyone else - is attached to the FamilySearch tree is inevitably nonrandom. Pages are built, and records attached, by people working on family history today, and the FamilySearch platform is affiliated with the Church of Jesus Christ of Latter-day Saints. As long as the bias in who is likely or not likely to be on the tree is uncorrelated with the timing of cutovers, our event study strategy - comparing operators across cities and before and after cutovers - should produce an unbiased estimate of the cutover treatment effect. Later in this appendix, we describe in more detail what predicts whether or not an operator is on the tree and shows that match rates are not a function of our treatment.
} 
decade later, including their occupation, industry, marital status, and fertility.

An example can clarify why linking women is difficult, and why the FamilySearch data can help. Suppose we start with a telephone operator in 1920 in New York named Daisy Fay. We see in the 1920 census that Daisy was born in 1902 in Kentucky. With traditional census linking methods like Abramitzky et al. (2021) or Ferrie (1996), we would search for records in the 1930 Census with the name Daisy Fay, born in 1902 in Kentucky, likely with some tolerance for transcription errors or enumeration errors in these fields. However, if Daisy marries Tom Buchanan in 1922, we would have no way of knowing that Daisy Fay is likely known as Daisy Buchanan in 1930. Worse, if another woman named Daisy born in Kentucky around 1902 marries and takes a surname of Fay, we could falsely match two women who are not the same person. With our FamilySearch-based approach, we instead search for Daisy Fay on FamilySearch in 1920. If her 1920 record is attached to a page, we consider her on the tree. We then look to see if a FamilySearch user has also attached her to the census in 1930, possibly triangulating with knowledge of her name after marriage or her marriage date, either from personal knowledge or an attached marriage or birth certificate (or in Daisy's case, a prominent work of American literature). If she is linked to both the 1920 and 1930 censuses, she will make our sample.

\section{B.3.2 Inverse Propensity Weights}

The set of operators that we can link using the FamilySearch data from 1920 to 1930 (or 1930 to 1940) is inevitably not random. To account for any potential unrepresentativeness of our final sample, we follow Bailey et al. (2017) and use inverse propensity weights (IPW) to adjust for observable differences between telephone operators in our initial sample and those we are able to match to the following census via the FamilySearch tree. ${ }^{12}$

Bailey et al. (2017) construct these weights in two steps, per footnote 33 of that paper:

1. Run a probit regression of link status (i.e., whether an individual is matched) on the following variables: an indicator for middle name; length of first, middle, and last names; polynomials in day of birth and age; an index for how common the first and last names are; whether or not one has siblings and number of siblings; and length of the names of one's parents.

2. Compute inverse propensity scores as $\frac{1-p}{p} \frac{m}{1-m}$, where $p$ is the predicted likelihood of being matched based on the probit coefficients and $m$ is the actual match rate.

Starting with the census attributes we observe about the telephone operators in our initial sample, we follow a similar procedure to predict which women are linked and which are not. As we emphasized in the previous section, there are three reasons an operator might not reach our final sample. ${ }^{13}$ The IPWs account for any differential propensity to stay in or leave the sample being driven at any stage in the linking process.

We adapt the reweighting procedure to match our setting as follows:

\footnotetext{
${ }^{12}$ Concerns about whether or not the final analysis sample is representative of the underlying population is not unique to our setting, nor to genealogy-based linking (versus hand or automated linking). All historical samples built with census linking could potentially be subject to concerns about unrepresentativeness, as linking is a function of names, ages, and other individual characteristics - features which might correlate both with being link-able and with other empirically-relevant observed or unobserved individual attributes.

${ }^{13}$ The reasons why an operator may not reach our final sample are: 1 . The operator does not have a page on the FamilySearch tree to begin with; 2. The operator's record in the following census is not attached to her page on the tree; 3 . The metadata in the tree or in the IPUMS complete count census indicates that the same person is not referenced in the same reel $\mathrm{x}$ page $\mathrm{x}$ line of each source (errors), although this last issue is very rare.
} 
1. We control for age and age-squared. However, we cannot include polynomials for the day of birth, as day of birth is not recorded in either the 1920 or 1930 censuses.

2. We include two indicators for middle names/initials, one for the presence of a middle name and one for the presence of a middle initial.

3. We control for first and last name length, separately. We do not control for parents' name length as we rarely observe our operators living with their parents, unlike the Bailey et al. (2017) example which linked children to their adult-selves.

4. We control for both the commonness of first and last name, measured as the log of the number of people in the 1900, 1910, and 1920 censuses with that first or last name.

5. We control for whether or not the operator is married or single, whether or not the operator has children, and household size, all measured in the initial census. These are similar, in spirit, to the Bailey et al. (2017) controls for siblings.

6. We include a full set of indicators for the operator's role within the household (head of household, spouse, daughter, boarder, etc).

7. We include a full set of indicators for birthplace (state of birth for the American-born, and country of birth for the few foreign-born).

8. We include a full set of indicators for current state and size of place, where size of place refers to the city or town of residence in the census year.

9. We control for race and Hispanic status.

In Table B.1, we present the coefficients from the probit regression for our linked samples, with the weight-generating function for the link for the full sample in the first column, from 1920 to 1930 in the second column, and from 1930 to 1940 in the third column. We omit the many fixed effects - for state of birth, state of residence, household role, and size of place - and report coefficients directly from the probit model. We see that operators with more common first names are less likely to be linked, so we will use the IPWs to up-weight the women with common names whom we do link so that our final analysis sample is comparable to our initial sample. On the other hand, we see that operators with children or in larger households are more likely to be linked, perhaps because they have larger families with more descendants researching genealogy today. We see matching is less likely for non-white and Hispanic women, a common result in the linking literature that may be exacerbated by the demographics of the FamilySearch userbase.

\section{B.3.3 Who is on the FamilySearch Tree?}

While the weighting scheme described in the previous section addresses the potential unrepresentativeness of our sample built with genealogical links, because this paper is among the first to use the FamilySearch tree links for empirical analysis ${ }^{14}$ we also want to explore in more detail the representativeness of the tree. We do so in this section, tracing out which operators in our initial sample are more or less likely to be on the tree. We find that being on the tree is far from random

\footnotetext{
${ }^{14}$ We are not the first to propose using the FamilySearch data. Price et al. (2019) introduce the FamilySearch tree data to the economics literature, but their focus is on building a new method to link census data using the FamilySearch tree as training data rather than using the links themselves. In addition, Price et al. (2020) use linked data trained with the FamilySearch tree and Michelman et al. (2020) use a focused set of FamilySearch links, supplemented by additional hand-linking, to trace elite college graduates in the 1920s and 1930s. Lleras-Muney et al. (2020) study the correlation between longevity and education using FamilySearch links as well.
} 
Table B.1: Probit Model of Operator Linking to Build Inverse Propensity Weights

\begin{tabular}{|c|c|c|c|}
\hline & \multicolumn{3}{|c|}{ Telephone Operators } \\
\hline & Linked & Linked 1920-1930 & Linked 1930-1940 \\
\hline & (1) & $(2)$ & $(3)$ \\
\hline Age & $\begin{array}{l}-0.003 \\
(0.007)\end{array}$ & $\begin{array}{c}-0.017^{* * *} \\
(0.006)\end{array}$ & $\begin{array}{c}0.022^{* * *} \\
(0.005)\end{array}$ \\
\hline Age-Squared/100 & $\begin{array}{l}-0.000 \\
(0.012)\end{array}$ & $\begin{array}{l}0.018^{*} \\
(0.010)\end{array}$ & $\begin{array}{c}-0.037^{* * *} \\
(0.009)\end{array}$ \\
\hline Middle Name & $\begin{array}{l}0.114^{*} \\
(0.061)\end{array}$ & $\begin{array}{l}0.131^{* *} \\
(0.056)\end{array}$ & $\begin{array}{c}0.107 \\
(0.072)\end{array}$ \\
\hline Middle Initial & $\begin{array}{c}0.176^{* * *} \\
(0.010)\end{array}$ & $\begin{array}{c}0.197^{* * *} \\
(0.016)\end{array}$ & $\begin{array}{c}0.147^{* * *} \\
(0.017)\end{array}$ \\
\hline Middle Name and Initial & $\begin{array}{c}-0.536^{* *} \\
(0.221)\end{array}$ & $\begin{array}{c}-1.317^{* *} \\
(0.576)\end{array}$ & $\begin{array}{l}-0.226 \\
(0.309)\end{array}$ \\
\hline First Name Length & $\begin{array}{c}-0.004^{* * *} \\
(0.001)\end{array}$ & $\begin{array}{l}-0.004 \\
(0.004)\end{array}$ & $\begin{array}{l}-0.003 \\
(0.004)\end{array}$ \\
\hline Last Name Length & $\begin{array}{c}-0.003^{* *} \\
(0.001)\end{array}$ & $\begin{array}{l}-0.005 \\
(0.004)\end{array}$ & $\begin{array}{l}-0.000 \\
(0.003)\end{array}$ \\
\hline First Name Commonness & $\begin{array}{c}-0.013^{* * *} \\
(0.002)\end{array}$ & $\begin{array}{c}-0.013^{* * *} \\
(0.002)\end{array}$ & $\begin{array}{c}-0.013^{* * *} \\
(0.003)\end{array}$ \\
\hline Last Name Commonness & $\begin{array}{c}-0.004^{* *} \\
(0.002)\end{array}$ & $\begin{array}{c}-0.004^{* * *} \\
(0.001)\end{array}$ & $\begin{array}{c}-0.004^{* *} \\
(0.002)\end{array}$ \\
\hline Single & $\begin{array}{c}0.032 \\
(0.033)\end{array}$ & $\begin{array}{c}0.038 \\
(0.028)\end{array}$ & $\begin{array}{c}0.023 \\
(0.024)\end{array}$ \\
\hline Has Children & $\begin{array}{l}0.171^{* *} \\
(0.069)\end{array}$ & $\begin{array}{c}0.171^{* * *} \\
(0.028)\end{array}$ & $\begin{array}{c}0.167^{* * *} \\
(0.025)\end{array}$ \\
\hline Family Size & $\begin{array}{c}0.056^{* * *} \\
(0.002)\end{array}$ & $\begin{array}{c}0.056^{* * *} \\
(0.003)\end{array}$ & $\begin{array}{c}0.055^{* * *} \\
(0.004)\end{array}$ \\
\hline Nonwhite & $\begin{array}{c}-0.237^{* * *} \\
(0.057)\end{array}$ & $\begin{array}{c}-0.356^{*} \\
(0.200)\end{array}$ & $\begin{array}{l}-0.196 \\
(0.219)\end{array}$ \\
\hline Hispanic & $\begin{array}{c}-0.174^{* * *} \\
(0.066)\end{array}$ & $\begin{array}{c}-0.170^{*} \\
(0.100)\end{array}$ & $\begin{array}{l}-0.189 \\
(0.131)\end{array}$ \\
\hline Relate FE & Yes & Yes & Yes \\
\hline Birthplace FE & Yes & Yes & Yes \\
\hline Size of Place FE & Yes & Yes & Yes \\
\hline State of Residence FE & Yes & Yes & Yes \\
\hline Year FE & Yes & Yes & Yes \\
\hline Observations & 157,293 & 96,183 & 61,110 \\
\hline
\end{tabular}


on many demographic features - especially state of residence, place of birth, and family size - but unrelated to the treatment in this paper, telephone exchange cutovers.

Of the 157,293 telephone operators we went looking for on the FamilySearch tree, we found 55,928 $(35.6 \%)$ on the tree. As Table B.2 shows, the share-on-the-tree is very similar for operators in 1920 and in 1930. Why are some operators on the tree and others are not? One simple reason is that the operators on the tree were put there by someone, likely a descendant. However, these descendants need not be direct descendants; much of the genealogical work on the tree is done by relatively distant relatives expanding their trees in many directions. An operator could be a grandmother or great grandmother of a FamilySearch user today, but she could also be a distant great aunt or the spouse of a third cousin. We lack specific (private, protected) data from FamilySearch on who is adding each person to the tree and how they are related. But we can investigate which demographic features or other census-enumerated covariates predict which operators or are not on the FamilySearch tree, which is more germane to our analysis.

Table B.2: Share of Operators on the Family Search Tree, 1920-1930

\begin{tabular}{|c|c|c|c|c|c|}
\hline Year & Telephone Operators & On the Tree & Share $(\%)$ & Linked to Next Census & Share $(\%)$ \\
\hline Pooled & 157293 & 55928 & 35.6 & 27473 & 17.5 \\
\hline 1920 & 96183 & 33304 & 34.6 & 16253 & 16.9 \\
\hline 1930 & 61110 & 22624 & 37.0 & 11220 & 18.4 \\
\hline
\end{tabular}

The FamilySearch tree has much more coverage of people who were likely ancestors of today's FamilySearch users. One particularly large user group is members of the Church of Jesus Christ of Latter-day Saints (LDS), as FamilySearch is operated in partnership with the LDS church. We can see this in the maps in Figure B.9 and Figure B.10, where Utah and other Mountain West states stand out in their rates of tree coverage. Tree rates are lowest in Mid-Atlantic states like New York and New Jersey, which have relatively fewer LDS members.

Figure B.9: Share of Telephone Operators on the FamilySearch Tree by State of Birth

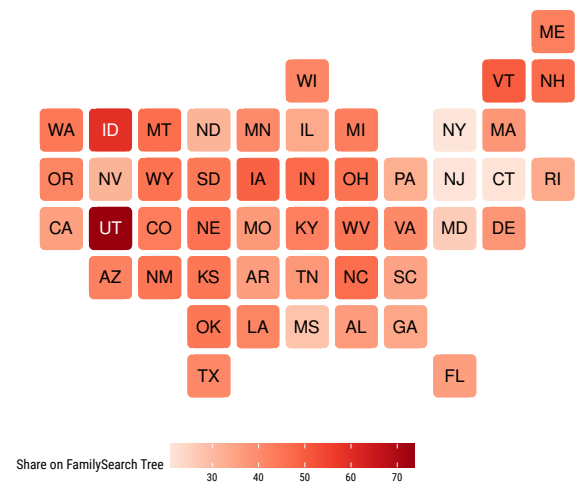

(a) 1920

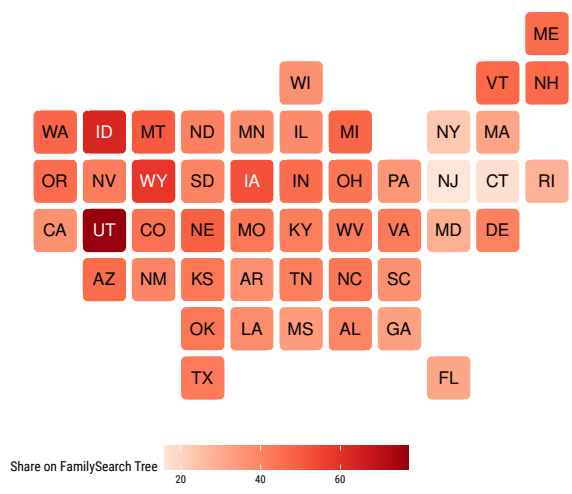

(b) 1930

Note: We map the share of telephone operators who were found on the tree in the same census we identified them as telephone operators in the telephone industry, plotted according to their states of birth in the census. 
Figure B.10: Share of Telephone Operators on the FamilySearch Tree by State of Residence



(a) 1920



(b) 1930

Note: We map the share of telephone operators who were found on the tree in the same census we identified them as telephone operators in the telephone industry, plotted according to their states of residence in the census.

Operators who were younger in the initial census are more likely to be found on the tree, though this relationship is stronger in 1920 than in 1930. We plot the share on the tree by age in Figure B.11. More than 35\% of the youngest operators in 1920 are on the FamilySearch tree, falling to around $27 \%$ around age 30 where the rate plateaus. In 1930, by contrast, tree rates fluctuate around $35 \%$ for most ages, falling a bit for the few operators older than 35 .

Figure B.11: Share of Telephone Operators on the FamilySearch Tree by Age



Note: We plot the share of telephone operators who were found on the tree in the same census we identified them as telephone operators in the telephone industry according to their age in the initial census.

As most people are added to the FamilySearch tree by descendants - and the FamilySearch hints are often based on own name and names of other people in the household - those in larger families are more likely to be on the tree. We plot this relationship in Figure B.12. In both 1920 and 1930, the share of women operators on the tree who were in households alone is quite low $(<10 \%$ in 1920 
and about $12 \%$ in 1930). This rises monotonically with family size in both censuses. ${ }^{15}$

Figure B.12: Share of Telephone Operators on the FamilySearch Tree by Family Size

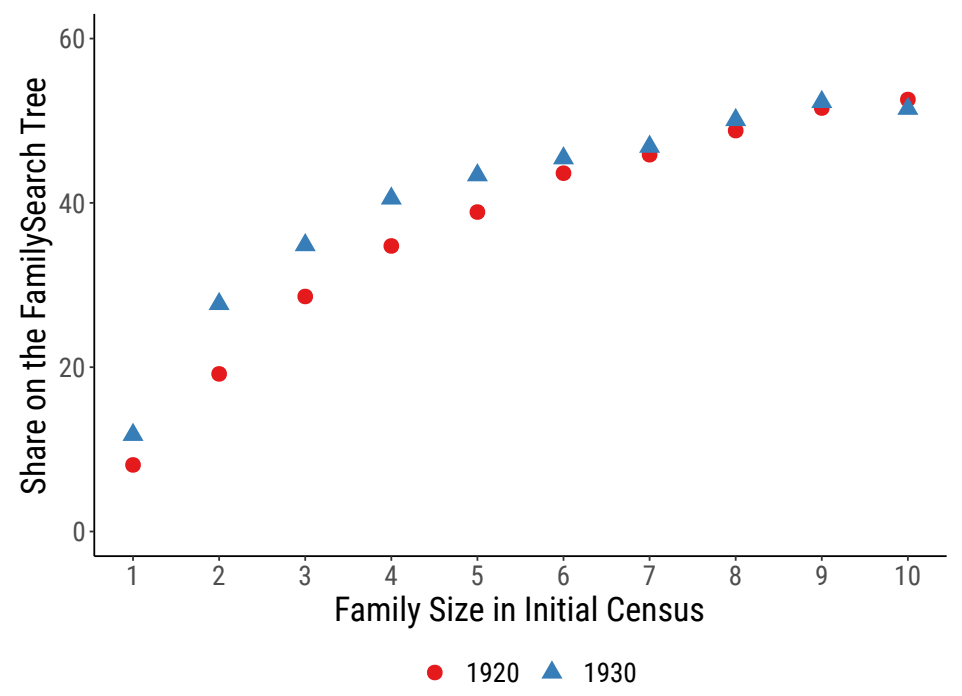

Note: We plot the share of telephone operators who were found on the tree in the same census we identified them as telephone operators in the telephone industry according to the size of their family in their household in the initial census. Specifically, we use the IPUMS variable famsize.

Name commonness is a pervasive challenge for census linking, whether by hand or by automated methods (Abramitzky et al. 2021, Bailey et al. 2017). When there are multiple people with the same name, humans and algorithms can struggle to determine which is the correct person and which is the doppelganger. This challenge affects our tree linking as well. Women with the most common first names are least likely to be on the tree, as we show in Figure B.13a, where we split women into deciles by name commonness. However, the differences are relatively small: women with the least common first names are on the tree in 1920 and 1930 about 37\% of the time, compared to $27 \%$ for women with the most common first names. The pattern among last names is a bit different. Women with incredibly rare last names are very unlikely to be on the tree $(25.8 \%$ in 1920 and $27.9 \%$ in 1930), possibly because such women have been enumerated or transcribed with error. That is, these rare last names may not actually be rare, but rather noise and error, and a name transcribed incorrectly might make it hard to connect it to other records for that person. Otherwise, the relationship between last name commonness and being on the tree is relatively flat, fluctuating between 30 and $40 \%$ in both 1920 and 1930 .

\footnotetext{
${ }^{15}$ We measure family size in the census with the famsize variable from IPUMS, defined as "the number of own family members residing with each individual, including the person her/himself. Persons not living with others related to them by blood, marriage/cohabitating partnership, or adoption are coded 1."
} 
Figure B.13: Share of Telephone Operators on the FamilySearch Tree by Name Commonness

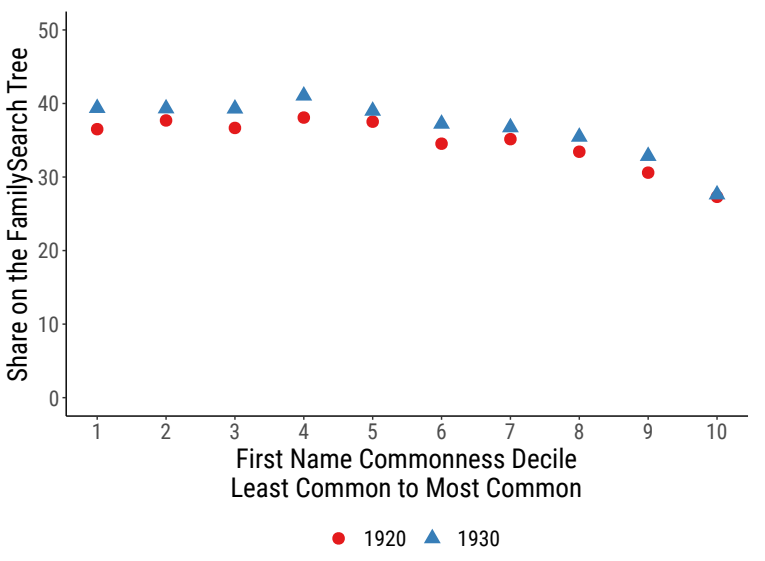

(a) Commonness of First Name

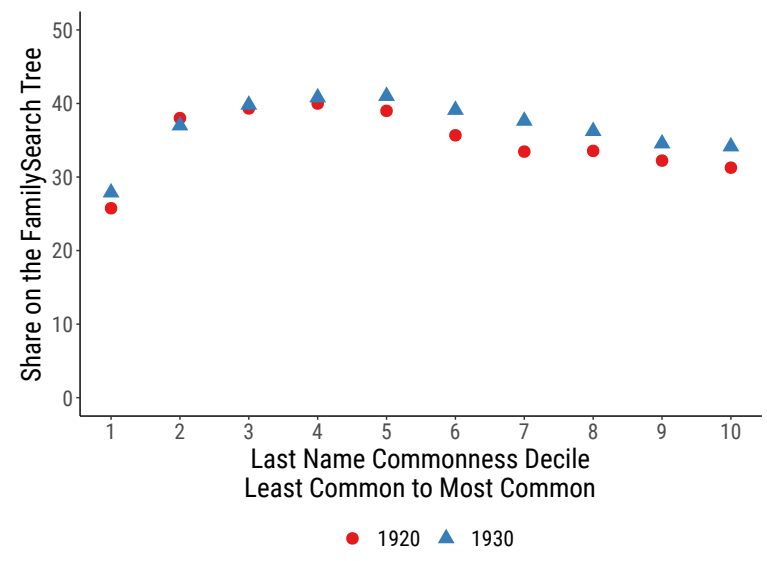

(b) Commonness of Last Name

Note: We plot the share of telephone operators who were found on the tree in the same census we identified them as telephone operators in the telephone industry according to the commonness of their first or last names. Name commonness is calculated using the complete count censuses in 1900, 1910, 1920, and 1930.

Similar to how rare first or last names may help census linkers or genealogists distinguish one person from another, middle names or initials could play a similar role. $28 \%$ of the operators enumerated in the census have a middle initial reported, while only about $1 \%$ have a full middle name. In both cases, these people are more likely to be on the FamilySearch tree, ranging from about $43 \%$ with a middle initial or name down to $32 \%$ without either listed.

Figure B.14: Share of Telephone Operators on the FamilySearch Tree by Middle Name Status

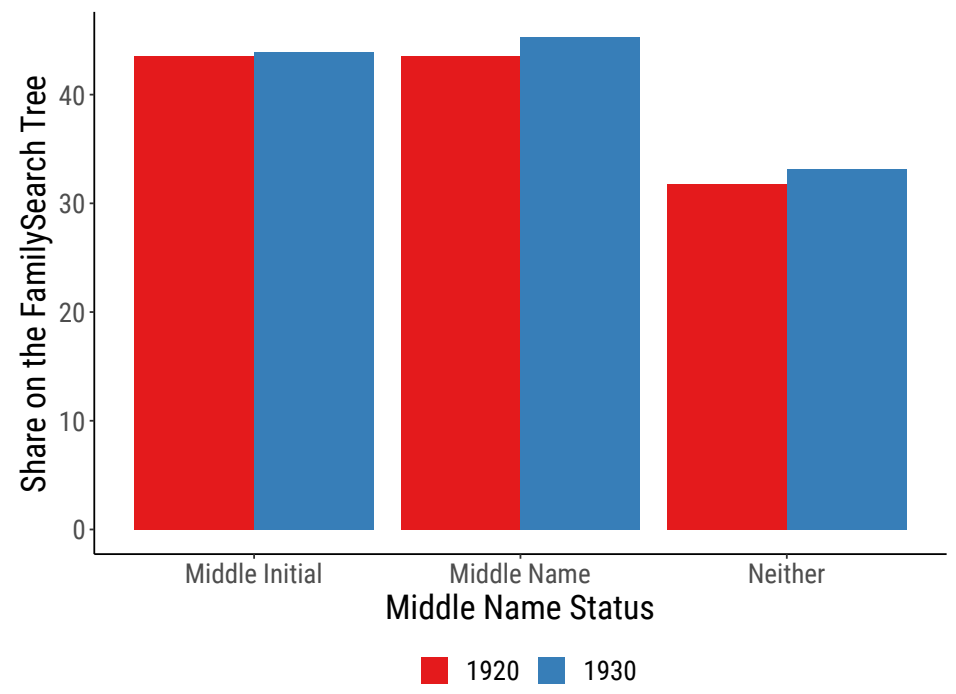

Note: Not every person enumerated in the complete count censuses report a middle name or middle initial. Whether or not someone reports this extra identifying information affects the ease of linking them, census to census or to other records on FamilySearch. We plot the share of telephone operators who were found on the tree in the same census we identified them as telephone operators in the telephone industry according to whether or not they report a middle name or middle initial or neither.

Ultimately, our goal is to estimate the effect of automation on incumbent operators. If operators 
in cities with cutovers over the following decade are differentially likely - either more or less - to be found on the tree, that could cause issues with inference, at a minimum by shifting sample weight across cities which were or were not treated. Is this the case? Can future cutovers predict whether women are on the tree in the census before the cutover? As we show in Table B.3, the answer is no. Having a cutover over the next decade - that is, being in the treated group - does not significantly predict whether we were able to find an operator on the FamilySearch tree (column 1). Moreover, the relative magnitudes of these effects are small: a cutover in the next decade increases the probability a woman is found on the tree by about 0.3 p.p. from a base tree rate of $35.6 \%$.

We also see that having a cutover in the next decade does not predict whether we were ultimately able to link an operator to a record in the next census, as we show in column 2 of Table B.3. Here the relative magnitudes are also small. Conditional on being on the FamilySearch tree, about half of women are found in the next census. A cutover reduces this rate by an insignificant 0.8 p.p.

Table B.3: Cutovers Do Not Predict Operator FamilySearch Tree

\begin{tabular}{|c|c|c|}
\hline & \multirow{2}{*}{$\begin{array}{c}\text { On the FamilySearch Tree } \\
(1)\end{array}$} & \multirow{2}{*}{$\frac{\text { Linked to Next Census }}{(2)}$} \\
\hline & & \\
\hline Cutover Previous Decade & $\begin{array}{c}0.003 \\
(0.007)\end{array}$ & $\begin{array}{c}0.008 \\
(0.007)\end{array}$ \\
\hline City Controls & Yes & Yes \\
\hline Individual Controls & Yes & Yes \\
\hline Year FEs & Yes & Yes \\
\hline State FEs & Yes & Yes \\
\hline Observations & 157,293 & 55,928 \\
\hline $\begin{array}{l}\text { Note: We analyze whethe } \\
\text { 1) or whether or not an } \\
\text { conditional on being on } \\
\text { the empirical strategy fr } \\
\text { includes city by year fix } \\
\text { control women who were } \\
\text { and individual-level con } \\
\text { trols include fixed effect } \\
\text { middle names or initials } \\
\text { first and last name com } \\
\text { of women with occupat } \\
\text { tion, and the share of } \mathrm{p} \\
\text { industry, all measured in }\end{array}$ & $\begin{array}{l}\text { or not an operator is on the } \\
\text { operator is successfully link } \\
\text { he FamilySearch tree (colum } \\
\text { m our the individual-level a } \\
\text { d effects (enabled because v } \\
\text { not operators). Instead, we } \\
\text { rols. All regressions are un } \\
\text { for age, birthplace, race, } \\
\text { all measured in the base y } \\
\text { monness. City controls incl } \\
\text { ons, the black and foreign-b } \\
\text { eople in the city who were } \\
\text { the base year. SEs clustere }\end{array}$ & $\begin{array}{l}\text { amilySearch tree (column } \\
\text { d to the following census } \\
\text { n 2). We cannot replicate } \\
\text { alysis in the paper which } \\
\text { compare operators with } \\
\text { clude a suite of city-level } \\
\text { veighted. Individual con- } \\
\text { arital status, family size, } \\
\text { ar, as well as controls for } \\
\text { de population, the share } \\
\text { orn shares of the popula- } \\
\text { perators in the telephone } \\
\text { by city in parentheses. }\end{array}$ \\
\hline
\end{tabular}

\section{B.3.4 Linking Control Women}

When we analyze the individual-level linked data, we use a differences in differences specification: we compare the outcomes in the following census of telephone operators living in cities with and without cutovers over the following decade, and - to account for any secular trends in the local labor market - we compare operators to other working women living in their neighborhoods. In this section, we detail how we construct this control sample.

For every telephone operator in our sample, we identify a set of women who are "similar" in the complete count census and can serve as a control for her. The size of the complete count census allows us to match on a number of dimensions. Specifically, we focus on women of the same race 
and Hispanic status and within five years of age. We also match on marital status and fertility; if the operator is married, her controls are as well, and if the operator has children, her controls must have children as well. We also use the operator's birthplace and her mother and father's birthplaces to link on nativity; if the operator is US-born, her controls must be US-born, and the same for her mother's US-born status and her father's US-born status. Finally, we match on precise geography, using census enumeration districts. In 1920 and 1930, enumeration districts contained approximately 1000 residents (usually 200 to 300 households) and were geographically compact units that we think of as neighborhoods. Finally, we require control women to have an occupation in the initial census so that we compare telephone operators to other working women.

As we document in Table B.4, we locate approximately 21 control women for each telephone operator in 1920 and 1930. We then follow the linking procedure outlined in Appendix Subsection B.3.1 to locate these control women on FamilySearch and find them in the following census. Of 459,786 matched control women, 191,761 are on the tree (41\% versus $36 \%$ for operators). ${ }^{16} 97,922$ of the control women are attached to records in the following census. These women form our final control set, providing nearly five control observations for every operator observation.

Table B.4: Share of Control Women on the Family Search Tree, 1920-1930

\begin{tabular}{|c|c|c|c|c|c|c|}
\hline \multirow[b]{2}{*}{ Year } & \multicolumn{2}{|c|}{ Control Women } & \multicolumn{2}{|c|}{ On the Tree } & \multicolumn{2}{|c|}{ Linked to Next Census } \\
\hline & Unique & per Operator & Unique & per Operator & Unique & per Operator \\
\hline Pooled & 459786 & 21.4 & 191761 & 9.2 & 97922 & 4.7 \\
\hline 1920 & 273024 & 21.4 & 113990 & 9.2 & 58710 & 4.8 \\
\hline 1930 & 186762 & 21.4 & 77771 & 9.2 & 39212 & 4.6 \\
\hline
\end{tabular}

While we see 4.7 control women per operator on average, there is wide variation in the actual number of control women for each operator in the sample (Figure B.15). In both 1920 and 1930, about three-quarters of our operators have at least one linked control woman. In both years, about $14 \%$ of operators have only one linked control woman and another $10 \%$ have two. At the other end of the range, $16 \%$ of operators are matched to more than ten linked control women.

Figure B.15: Control Women Linked to Next Census per Telephone Operator

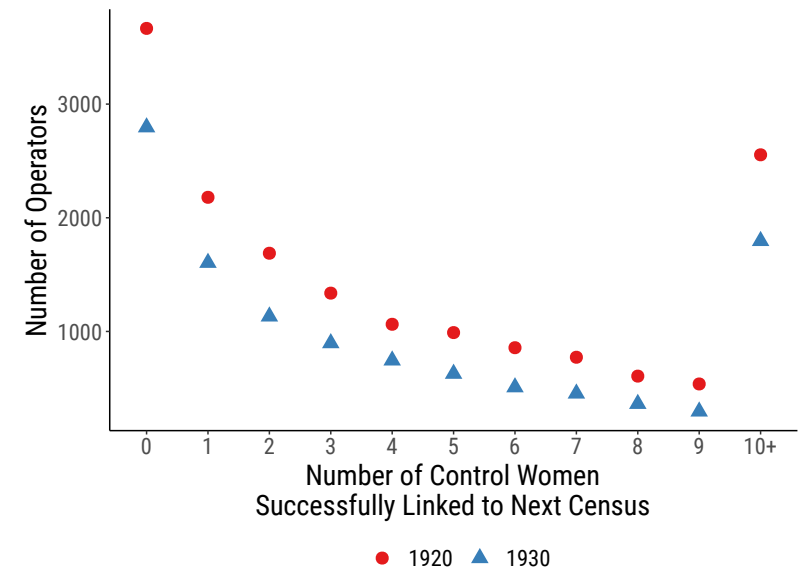

\footnotetext{
${ }^{16}$ Note that compared to the operator sample, a higher share of control women are on the tree. However, this is not surprising, as we have limited our search to the control women of operators whom we already successfully linked. These control women thus come from the same neighborhoods (and age, race, and family nativity, etc.) of linked operators, not random operators, and are selected on being more "linkable".
} 
We do not enforce uniqueness among controls for operators. That is, one control woman could serve as a control for multiple operators in our data, if the operators (and the control) live in the same enumeration district and match on all the required criteria. More than $75 \%$ of control women in 1920 and 1930 are matched to only one operator. Of the controls matched to multiple operators, $17 \%$ are matched to only two operators and only a handful are matched to more than 6 operators (50 in 1920 and 35 in 1930; none matched to more than 8 operators).

\section{B.4 Additional data}

We also collect data from additional sources which have ancillary uses in this paper.

\section{AT\&T data on dial diffusion, 1913-1972}

Archival documents at the AT\&T corporate archives include a two-page report providing the annual time series of the total number of Bell system telephones from 1913 to 1972, and a breakdown by the type of central office, manual versus dial (see "Bell System Distributions of Company Telephones," AT\&T Archives and History Center, box 085-04-03-02). We use these data to chart aggregate dial diffusion within the Bell system (shown in Figure 1).

\section{County- and city-level heterogeneity}

We use a number of additional data sources when we investigate heterogeneity in Appendix C. In addition to the complete count census data, we incorporate data from the Census of Agriculture, to measure county-level household electrification (although technically for farms, we believe it a useful proxy for local electrification generally); from the American Federation of Labor (AFL), to measure city-level AFL organizers (AFL 1919); and from Fishback et al. (2005) on county per-capita retail sales growth from 1929 to 1933, to measure local severity of the Great Depression. When these variables are available only at the county level, we assign to each city in our city sample values of the surrounding county. When cities span county boundaries, we compute weighted averages, weighting by the city population in each associated county. 


\section{Additional Results}

\section{C.1 Characteristics of cities with earlier and later cutovers}

Table C.1 provides mean characteristics of cities by the timing of their first cutover, binning cities into five-year intervals from 1920 to 1940, as well as pre-1920 and post-1940. We measure characteristics in 1910 - or where necessary, circa 1910 - before mechanical switching was widely adopted. Consistent with Table 3 of the paper, we see that cutovers correlate strongly with population, with larger cities being automated sooner, especially in the AT\&T cutover era (post-1920). Cities with earlier cutovers may have had somewhat higher labor force participation among young, white, American-born women (which we denote with the label " $\mathrm{f} / \mathrm{n} / \mathrm{w} / \mathrm{y}$ "), and were also more likely to have had operator unions and strikes pre-1920, but are otherwise demographically similar. ${ }^{17}$ Table 3 of the paper shows that in a multivariate regression, nearly all of the explanatory power loads onto population, with t-stats of around 20. That market size and scale economies explain the adoption of mechanical switching is consistent with our findings in concurrent work exploring the drivers and frictions in AT\&T's automation of the telephone network (Feigenbaum and Gross 2021).

Table C.1: Mean 1910 characteristics of cities by timing of earliest cutover

\begin{tabular}{lcccccc}
\hline \hline Characteristic & pre-1920 & $1921-1925$ & $1926-1930$ & $1931-1935$ & $1936-1940$ & post-1940 \\
\hline Population 16+(1000s) & 38.92 & 116.82 & 43.87 & 18.41 & 9.14 & 4.06 \\
& $(55.49)$ & $(248.98)$ & $(80.23)$ & $(27.30)$ & $(13.33)$ & $(6.68)$ \\
Average age & 27.93 & 27.97 & 28.15 & 28.32 & 27.70 & 27.75 \\
& $(2.07)$ & $(2.06)$ & $(2.31)$ & $(2.38)$ & $(2.80)$ & $(3.15)$ \\
Percent female & 48.46 & 50.08 & 48.94 & 50.08 & 50.03 & 50.34 \\
& $(4.25)$ & $(3.04)$ & $(5.66)$ & $(5.33)$ & $(4.54)$ & $(5.61)$ \\
Percent f/n/w/y & 12.25 & 11.62 & 11.46 & 11.74 & 11.96 & 12.32 \\
& $(2.43)$ & $(2.30)$ & $(2.61)$ & $(2.21)$ & $(2.57)$ & $(2.99)$ \\
Percent working & 60.54 & 60.35 & 60.81 & 59.60 & 58.96 & 57.55 \\
& $(5.27)$ & $(5.05)$ & $(5.69)$ & $(5.64)$ & $(5.83)$ & $(7.28)$ \\
Percent operators & 0.19 & 0.21 & 0.19 & 0.17 & 0.19 & 0.21 \\
& $(0.10)$ & $(0.12)$ & $(0.14)$ & $(0.11)$ & $(0.11)$ & $(0.15)$ \\
F/n/w/y percent working & 41.17 & 40.68 & 40.23 & 44.01 & 36.71 & 35.09 \\
& $(7.79)$ & $(12.09)$ & $(10.32)$ & $(11.86)$ & $(12.31)$ & $(12.12)$ \\
F/n/w/y percent operators & 1.16 & 1.36 & 1.19 & 1.02 & 1.12 & 1.21 \\
& $(0.65)$ & $(1.09)$ & $(0.87)$ & $(0.67)$ & $(0.79)$ & $(0.97)$ \\
Unionized by 1920 & 0.17 & 0.26 & 0.19 & 0.09 & 0.08 & 0.03 \\
& $(0.38)$ & $(0.44)$ & $(0.40)$ & $(0.29)$ & $(0.28)$ & $(0.18)$ \\
Had strike by 1920 & 0.07 & 0.10 & 0.09 & 0.03 & 0.03 & 0.01 \\
& $(0.26)$ & $(0.30)$ & $(0.28)$ & $(0.17)$ & $(0.18)$ & $(0.11)$ \\
\hline Observations & 29 & 62 & 114 & 67 & 60 & 2660 \\
\hline \hline
\end{tabular}

Notes: Table reports mean 1910 characteristics of cities in our primary sample whose first cutover occurred in each of the periods shown (2,992 cities included in this table, omitting 31 cities with cutovers with ambiguous timing and New York City boroughs). Percentages are measured in whole units (out of 100). Population and population percentages reflect the adult population only, and $\mathrm{f} / \mathrm{n} / \mathrm{w} / \mathrm{y}$ is shorthand for female, American-born, white/non-Hispanic, and young (age 16 to 25). Note that the dial era in the AT\&T system began in 1919, such that cutovers pre-1920 are nearly all by independents. The final column consists of cities that do not have a cutover in our data by April 1, 1940.

\footnotetext{
${ }^{17}$ We measure local union chapters using historical issues of the Journal of Electrical Workers and Operators (IBEW 1915) and the Union Telephone Operator (IBEW 1921), the monthly journal of the Telephone Operator Department of the International Brotherhood of Electrical Workers, and strikes using Annual Reports of the U.S. Secretary of Labor (U.S. Department of Labor 1913) and written histories by Norwood (1990) and Segrave (2017).
} 


\section{C.2 Implicit First Stage: Differential effects of cutovers across subpopulations}

Figure C.1 presents event study estimates of the effects of dial cutovers on the percent of different population groups who are telephone operators in the telephone industry, estimated with 10-year intervals. Consistent with the evidence from Table 2 that the majority of operators were young, white, American-born women, we see that the employment share reduction is largest for this group, further motivating our focus on young women throughout the paper.

Figure C.1: Effect of dial cutovers on the percent of different demographic groups who are telephone operators in the telephone industry (event study, 10-yr intervals)



Notes: Figure shows event study estimates of the effects of local dial adoption on the percent of increasingly narrow adult populations (from all adults to young, white, American-born women) in successive cohorts who are telephone operators in the telephone industry, for the small city sample (population $\leq 100 \mathrm{k}$ in 1920). Error bars represent $95 \%$ confidence intervals, computed from SEs clustered at the city level. 


\section{C.3 Pre-treatment balance tests}

Figure C.2: Pre-treatment run-up balance tests for the outcomes studied throughout the paper
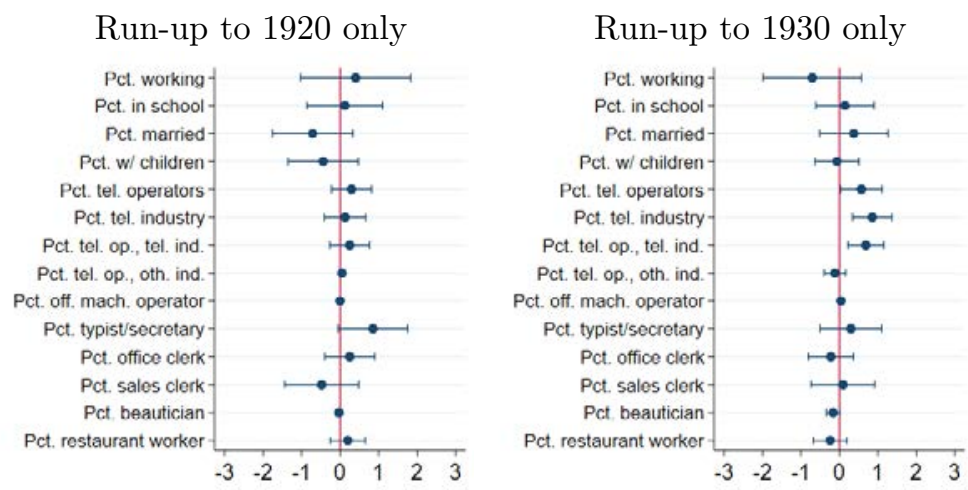

Run-up to 1920 \& 1930 (pooled)

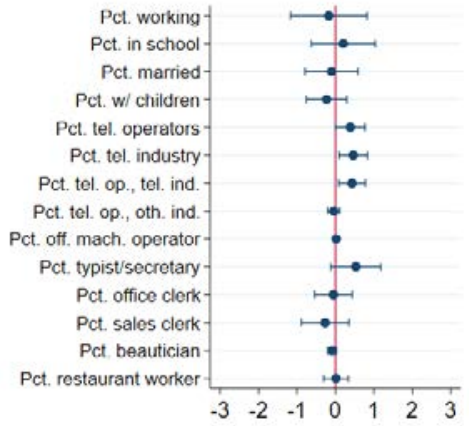

Notes: Figures estimate differences in the prior 10-year changes in each of the variables shown across cities with versus without an imminent cutover. For example, the left panel examines cities which in 1920 had not yet had a cutover in our data, calculates the 1910 to 1920 change in a given outcome $(\Delta Y)$, and estimates the conditional difference in means of $\Delta Y$ between cities which did versus did not have a cutover between 1920 and 1930 , controlling for city size. The middle panel repeats for 1930, and the right panel pools 1920 and 1930 together. All outcomes are measured for young, white, American-born women only. The evidence indicates that most outcomes were not changing differentially (over the prior 10 years) in cities with an impending cutover, with the exception of employment in telephone operation, which was growing prior to cutovers, and possibly employment in secretarial work, which we show in the paper absorbed many of the women who might have otherwise been operators. In all figures, sample restricted to cities with population $\leq 100 \mathrm{k}$ in 1920 . Error bars represent $95 \%$ confidence intervals, computed from SEs clustered at the city level. 


\section{C.4 Event studies for labor market outcomes, by age}

In Figure C.3 and C.4, we show the event study estimates for labor market outcomes of successive cohorts of young, white, American-born women around cutovers, splitting the population into the same age groups as in Tables 4 and 5: 16 to 25, 16 to 20, and 21 to 25 .

Figure C.3: Changes in work, education, marriage, and fertility patterns for young, white, American-born women around cutovers (event study, by age)

Percent working

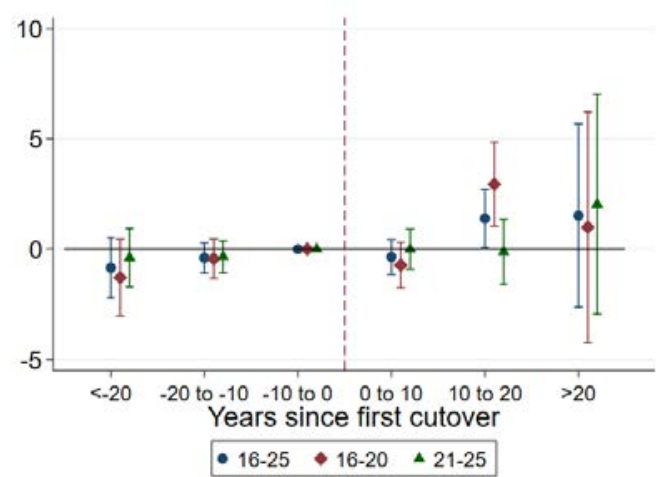

Percent married

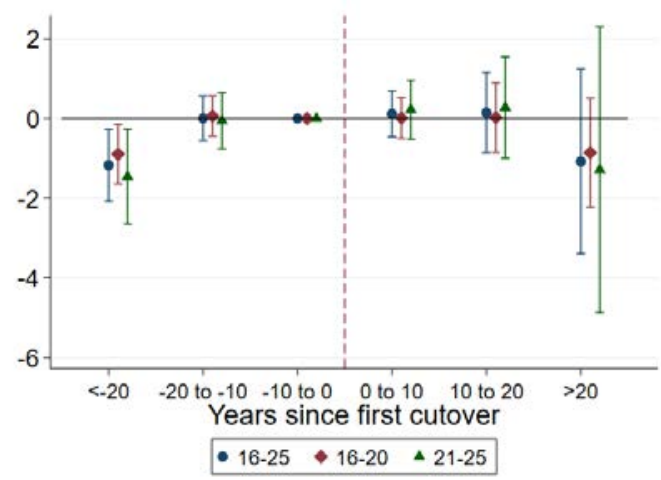

Percent in school

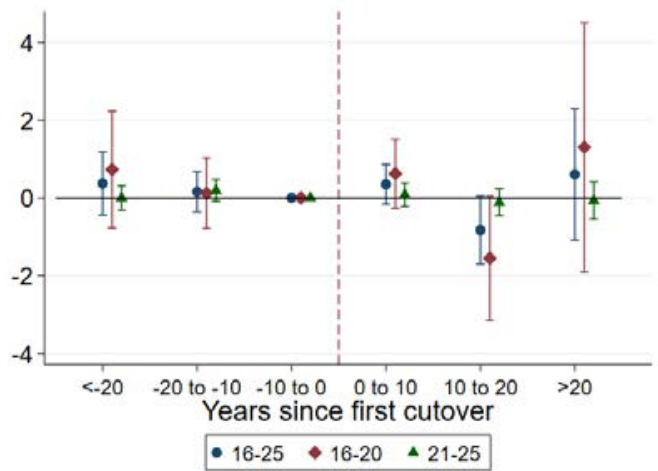

Percent with children

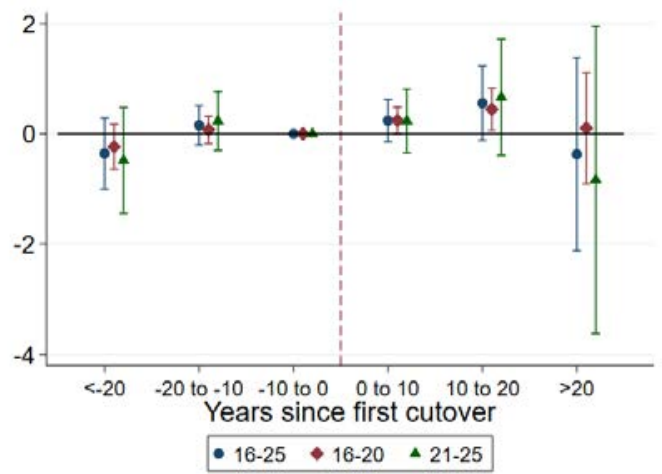

Notes: Figure shows event study estimates, by age, of the effects of local dial adoption on the percent of young, white, American-born women in successive cohorts who are in the labor force, in school, married, and have children, for cities with population $\leq 100 \mathrm{k}$ in 1920 . Error bars represent $95 \%$ confidence intervals, computed from SEs clustered at the city level. 
Figure C.4: Changes in

employment shares in select occupations for young, white, American-born women around cutovers

Percent who are office mach. operators

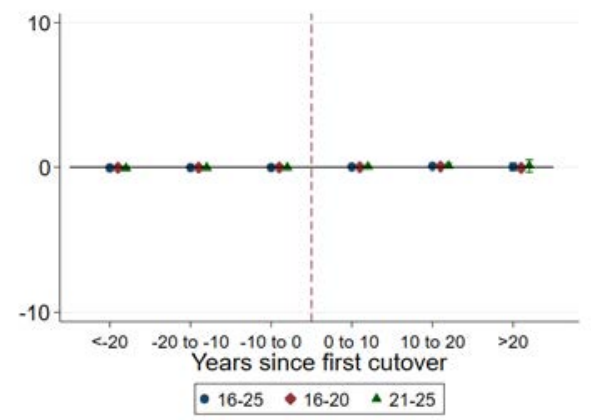

Percent who are office clerks

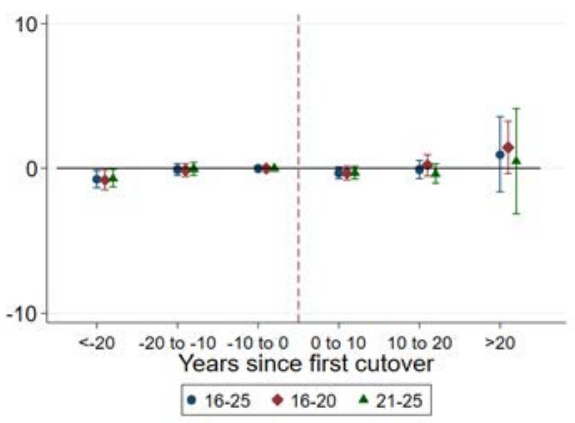

Percent who are beauticians

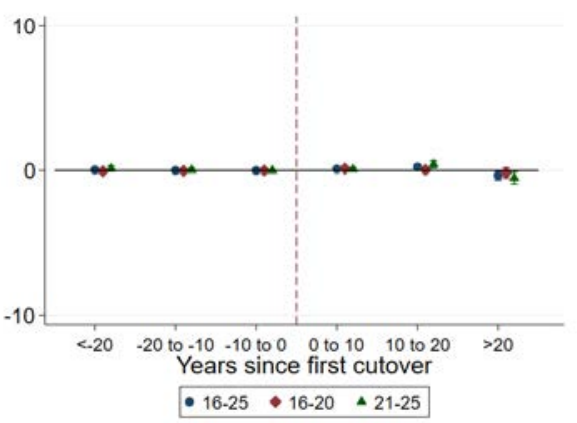

Percent who are typists/stenographers

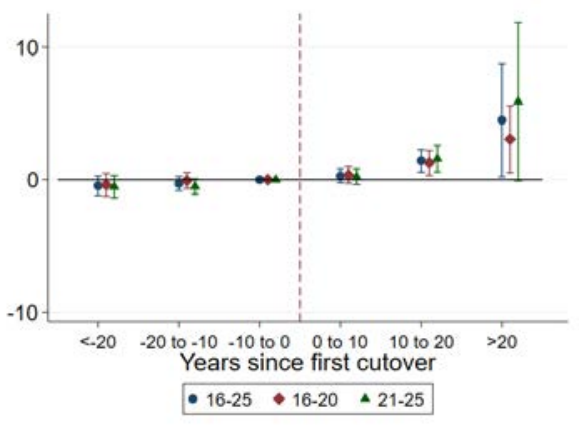

Percent who are sales clerks

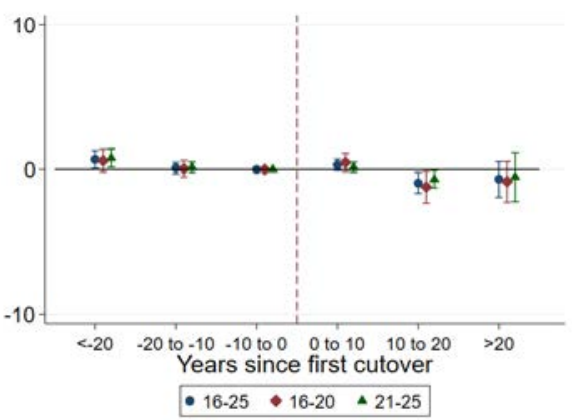

Percent who are waitresses

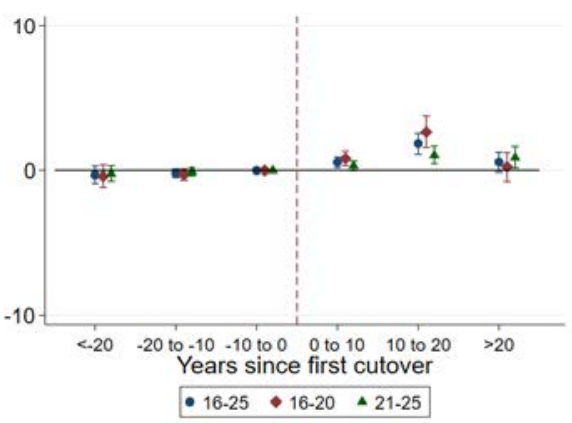

Notes: Figure shows event study estimates, by age, of the effects of local dial adoption on young, white, American-born women's employment shares in select occupations, across successive cohorts, for cities with population $\leq 100 \mathrm{k}$ in 1920 . Error bars represent $95 \%$ confidence intervals, computed from SEs clustered at the city level. 


\section{C.5 Robust event study estimation methods}

Appendix Figure C.5 presents a robustness check on the event study results in Figures 3 and 4 of the paper, evaluating their robustness to alternative event study estimation methods, as suggested by recent developments in applied econometrics. See Section 4.2 for discussion.

Figure C.5: Effect of dial cutovers on the log number of young, white, American-born women and percent of the same who are telephone operators in the telephone industry (robust event study)

Log \# of tel. operators (10-yr intervals)

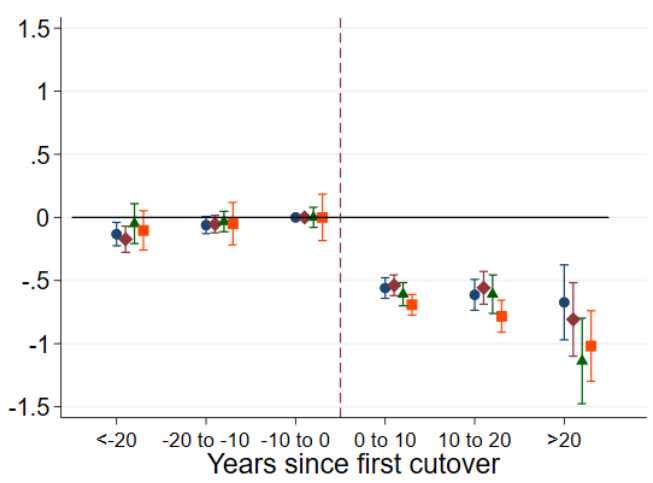

Log \# of tel. operators (2-yr intervals)

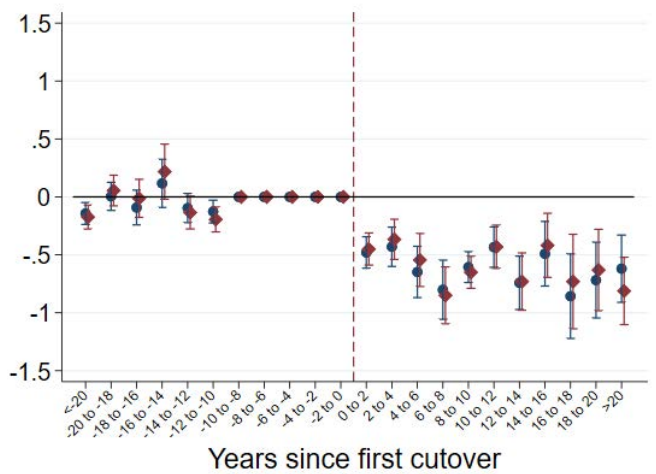

Percent who are tel. operators (10-yr intervals)

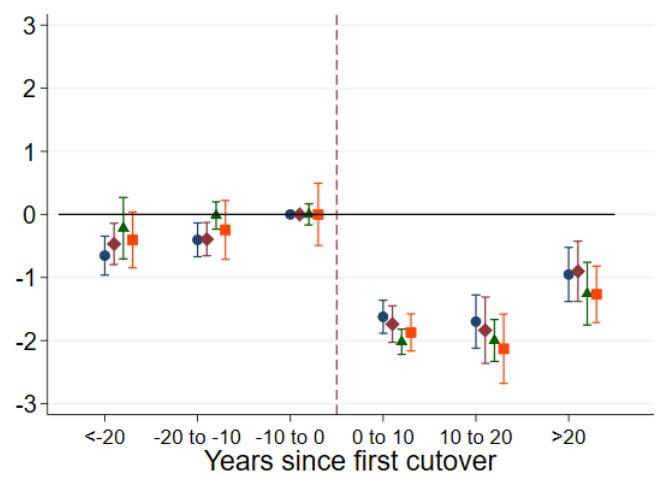

Percent who are tel. operators (2-yr intervals)

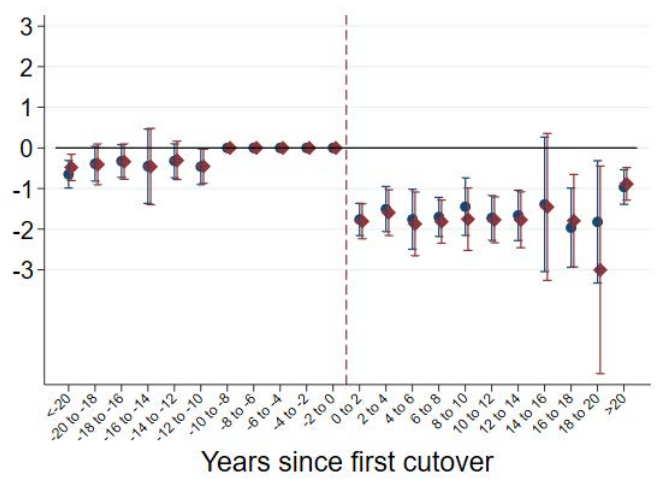

Notes: Left panels show event study estimates of the effects of local dial adoption on the (log) number of young, white, American-born women in successive cohorts who are telephone operators in the telephone industry $(+1)$, for the small city sample (population $\leq 100 \mathrm{k}$ in 1920), with 10- and 2-year event windows. When event windows are narrower than the 10-year frequency at which outcomes are measured, each bin contains different cities (every fifth bin represents the same set of cities). Right panels show event study estimates for the percent of working young, white, American-born women who are the same. The figure provides results by four estimation methods: (i) vanilla OLS (blue circle), (ii) Sun and Abraham (2021) (red diamond), (iii) Callaway and Sant'Anna (2021) (green triangle), and (iv) Borusyak et al. (2021) (orange square). With 2-year intervals, only the first two methods are estimated. Error bars represent $95 \%$ confidence intervals, computed from SEs clustered at the city level. 


\section{C.6 Restricting to cities with continuous newspaper coverage}

Here we present robustness checks restricting the estimation sample to cities with continuous newspaper coverage in our data sources from 1917 to 1940. Figures C.6 to C.7, and Tables C.2 to C.3, are counterparts to Figures 3 to 4 , and Tables 4 to 5 , in the body of the paper.

Figure C.6: Effect of dial cutovers on the log number of young, white, American-born women who are telephone operators in the telephone industry (event study) sample restricted to cities with continuous newspaper coverage from 1917 to 1940

Panel (A)

Log \# of tel. operators (10-yr intervals)

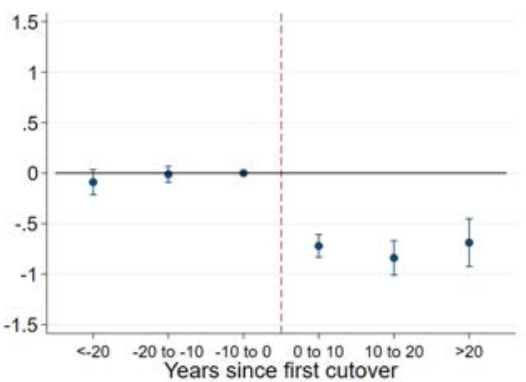

Panel (B)

$\log \#$ of tel. operators (2-yr intervals)

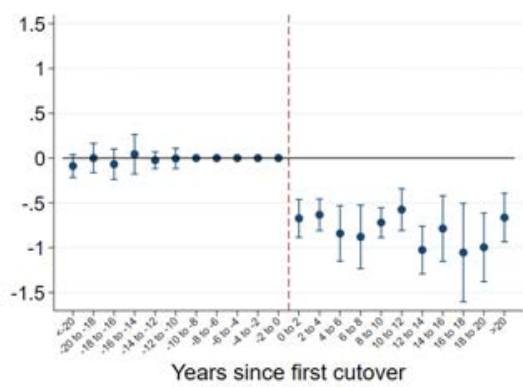

Notes: Figure shows event study estimates of the effects of local dial adoption on the (log) number of young, white, American-born women in successive cohorts who are telephone operators in the telephone industry $(+1)$, for the small city sample (population $\leq 100 \mathrm{k}$ in 1920 ), with 10 - and 2-year event windows. When event windows are narrower than the 10-year frequency at which outcomes are measured, each bin contains different cities (every fifth bin represents the same set of cities). Sample restricted to cities with continuous newspaper coverage from 1917 to 1940. In estimating these event studies, we aggregate women across ages to the city level, because age-level observations have many zeros both before and after cutovers, which are computed as unchanged and will cause these effects to be underestimated. Error bars represent $95 \%$ confidence intervals, computed from SEs clustered at the city level.

Figure C.7: Effect of dial cutovers on the percent of working young, white, American-born women who are telephone operators in the telephone industry (event study and DID by age) sample restricted to cities with continuous newspaper coverage from 1917 to 1940

Panel (A)

Percent who are tel. operators (2-yr intervals)

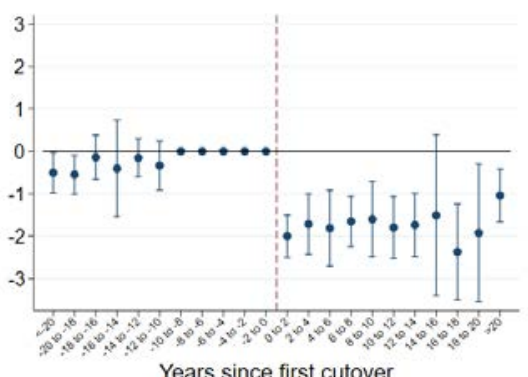

Panel (B) Percent who are tel. operators (DID by age)

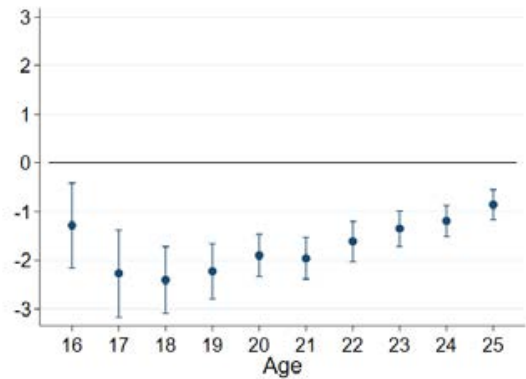

Notes: Figure shows event study and difference-in-difference estimates (by age) of the effects of local dial adoption on the percent of working young, white, American-born women in successive cohorts who are telephone operators in the telephone industry, for the small city sample (population $\leq 100 \mathrm{k}$ in 1920 ). Sample restricted to cities with continuous newspaper coverage from 1917 to 1940 . Error bars represent 95\% confidence intervals, computed from SEs clustered at the city level. 
Figure C.8: Effect of dial cutovers on the percent of working young, white, American-born women with other jobs in the telephone industry or who are telephone operators in other industries sample restricted to cities with continuous newspaper coverage from 1917 to 1940

Panel (A)

Other jobs in the tel. industry (2-yr intervals)

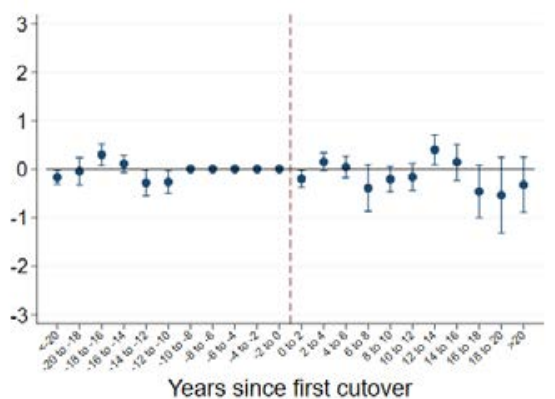

Panel (C)

Other jobs in the tel. industry (DID by age)



Panel (B)

Tel. operator in other industries (2-yr intervals)

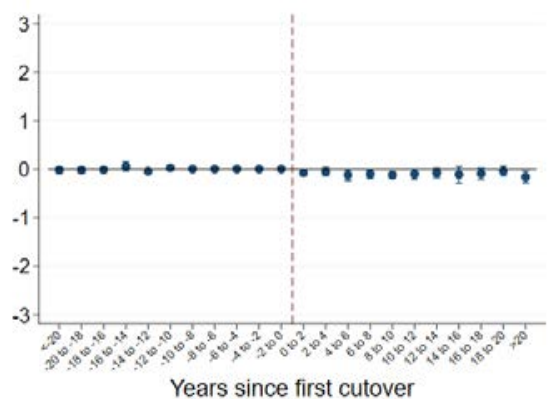

Panel (D)

Tel. operator in other industries (DID by age)

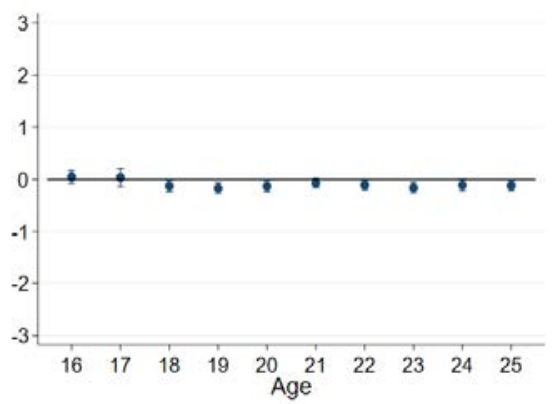

Notes: Upper panels show event study estimates of the effects of local dial adoption on the percent of working young, white, American-born women in successive cohorts who have other jobs in the telephone industry (left) and who are telephone operators in other industries (right), for the small city sample (population $\leq 100 \mathrm{k}$ in 1920). Sample restricted to cities with continuous newspaper coverage from 1917 to 1940. Because event windows are narrower than the 10-year frequency at which outcomes are measured, each bin contains different cities (every fifth bin represents the same set of cities). Lower panels show the associated difference-in-differences estimates, by age. We plot the estimates on the same scale (-3 to 3 p.p.) as the previous figures to ease comparison. Error bars represent $95 \%$ confidence intervals, computed from SEs clustered at the city level. 
Table C.2: Changes in work, education, marriage, and fertility patterns around cutovers sample restricted to cities with continuous newspaper coverage from 1917 to 1940

\begin{tabular}{|c|c|c|c|c|c|}
\hline \multicolumn{6}{|c|}{ Panel A: White, American-born women ages 16 to 25} \\
\hline & \multicolumn{5}{|c|}{ Percent of the group that is: } \\
\hline & Tel. oper. & Working & In school & Married & Has children \\
\hline Post-cutover & $\begin{array}{c}-0.78^{* * *} \\
(0.06)\end{array}$ & $\begin{array}{l}-0.29 \\
(0.58)\end{array}$ & $\begin{array}{l}-0.14 \\
(0.34)\end{array}$ & $\begin{array}{c}0.07 \\
(0.35)\end{array}$ & $\begin{array}{c}0.02 \\
(0.24)\end{array}$ \\
\hline $\mathrm{N}$ & 20664 & 20664 & 20664 & 20664 & 20664 \\
\hline$R^{2}$ & 0.52 & 0.88 & 0.97 & 0.97 & 0.96 \\
\hline Cities & 517 & 517 & 517 & 517 & 517 \\
\hline Cut over & 137 & 137 & 137 & 137 & 137 \\
\hline Y Mean & 1.18 & 41.68 & 20.44 & 35.60 & 19.65 \\
\hline \multicolumn{6}{|c|}{ Panel B: White, American-born women ages 16 to 20} \\
\hline & \multicolumn{5}{|c|}{ Percent of the group that is: } \\
\hline & Tel. oper. & Working & In school & Married & Has children \\
\hline Post-cutover & $\begin{array}{c}-0.85^{* * *} \\
(0.10)\end{array}$ & $\begin{array}{l}-0.31 \\
(0.77)\end{array}$ & $\begin{array}{l}-0.22 \\
(0.61)\end{array}$ & $\begin{array}{l}-0.09 \\
(0.31)\end{array}$ & $\begin{array}{c}0.18 \\
(0.15)\end{array}$ \\
\hline $\mathrm{N}$ & 10332 & 10332 & 10332 & 10332 & 10332 \\
\hline$R^{2}$ & 0.56 & 0.90 & 0.94 & 0.94 & 0.91 \\
\hline Cities & 517 & 517 & 517 & 517 & 517 \\
\hline Cut over & 137 & 137 & 137 & 137 & 137 \\
\hline Y Mean & 1.28 & 38.57 & 37.37 & 17.24 & 7.36 \\
\hline \multicolumn{6}{|c|}{ Panel C: White, American-born women ages 21 to 25} \\
\hline & \multicolumn{5}{|c|}{ Percent of the group that is: } \\
\hline & Tel. oper. & Working & In school & Married & Has children \\
\hline Post-cutover & $\begin{array}{c}-0.71^{* * *} \\
(0.06)\end{array}$ & $\begin{array}{l}-0.28 \\
(0.57)\end{array}$ & $\begin{array}{l}-0.05 \\
(0.17)\end{array}$ & $\begin{array}{c}0.23 \\
(0.44)\end{array}$ & $\begin{array}{l}-0.14 \\
(0.36)\end{array}$ \\
\hline $\mathrm{N}$ & 10332 & 10332 & 10332 & 10332 & 10332 \\
\hline$R^{2}$ & 0.45 & 0.81 & 0.83 & 0.88 & 0.86 \\
\hline Cities & 517 & 517 & 517 & 517 & 517 \\
\hline Cut over & 137 & 137 & 137 & 137 & 137 \\
\hline Y Mean & 1.07 & 44.73 & 3.84 & 53.59 & 31.69 \\
\hline
\end{tabular}

Notes: Tables present difference-in-difference estimates, by age, of the effects of local dial adoption on the percent of young, white, American-born women in successive cohorts who are in the labor force, in school, married, and have children, for cities with population $\leq 100 \mathrm{k}$ in 1920 . Sample restricted to cities with continuous newspaper coverage from 1917 to 1940. The left-most column provides the effect of cutovers on the percent of these women who were telephone operators in the telephone industry, as a reference point. All regressions include city and year fixed effects, and log city size $\mathrm{x}$ year controls. ${ }^{*}, * *, * * *$ represent significance at the $0.1,0.05$, and 0.01 levels, respectively. SEs clustered by city in parentheses. 
Table C.3: Changes in employment shares in select occupations around cutovers sample restricted to cities with continuous newspaper coverage from 1917 to 1940

Panel A: White, American-born women ages 16 to 25

Conditional on working, percent employed as or in

Tel. oper. Off. mach. Typist/secr. Office clerk Sales clerk Beautician Restaurant

\begin{tabular}{lccccccc}
\hline Post-cutover & $-1.71^{* * *}$ & 0.04 & 0.45 & -0.18 & $0.57^{* *}$ & 0.09 & $0.61^{* *}$ \\
& $(0.15)$ & $(0.03)$ & $(0.31)$ & $(0.24)$ & $(0.29)$ & $(0.07)$ & $(0.25)$ \\
\hline $\mathrm{N}$ & 20430 & 20430 & 20430 & 20430 & 20430 & 20430 & 20430 \\
$R^{2}$ & 0.46 & 0.51 & 0.73 & 0.59 & 0.49 & 0.56 & 0.60 \\
Cities & 517 & 517 & 517 & 517 & 517 & 517 & 517 \\
Cut over & 137 & 137 & 137 & 137 & 137 & 137 & 137 \\
Y Mean & 2.84 & 0.16 & 12.69 & 4.59 & 10.23 & 1.04 & 4.38
\end{tabular}

Panel B: White, American-born women ages 16 to 20

Conditional on working, percent employed as or in

Tel. oper. Off. mach. Typist/secr. Office clerk Sales clerk Beautician Restaurant

\begin{tabular}{lccccccc}
\hline Post-cutover & $-2.03^{* * *}$ & 0.02 & 0.58 & -0.24 & $0.73^{*}$ & 0.13 & $0.90^{* * *}$ \\
& $(0.26)$ & $(0.03)$ & $(0.40)$ & $(0.27)$ & $(0.43)$ & $(0.08)$ & $(0.35)$ \\
\hline $\mathrm{N}$ & 10126 & 10126 & 10126 & 10126 & 10126 & 10126 & 10126 \\
$R^{2}$ & 0.48 & 0.47 & 0.72 & 0.55 & 0.50 & 0.44 & 0.56 \\
Cities & 517 & 517 & 517 & 517 & 517 & 517 & 517 \\
Cut over & 137 & 137 & 137 & 137 & 137 & 137 & 137 \\
Y Mean & 3.24 & 0.11 & 10.53 & 4.29 & 11.13 & 0.70 & 4.81
\end{tabular}

Panel C: White, American-born women ages 21 to 25

Conditional on working, percent employed as or in

Tel. oper. Off. mach. Typist/secr. Office clerk Sales clerk Beautician Restaurant

\begin{tabular}{lccccccc}
\hline Post-cutover & $-1.40^{* * *}$ & 0.05 & 0.33 & -0.13 & $0.42^{*}$ & 0.05 & 0.33 \\
& $(0.12)$ & $(0.04)$ & $(0.34)$ & $(0.27)$ & $(0.25)$ & $(0.09)$ & $(0.23)$ \\
\hline $\mathrm{N}$ & 10304 & 10304 & 10304 & 10304 & 10304 & 10304 & 10304 \\
$R^{2}$ & 0.40 & 0.53 & 0.69 & 0.64 & 0.44 & 0.61 & 0.68 \\
Cities & 517 & 517 & 517 & 517 & 517 & 517 & 517 \\
Cut over & 137 & 137 & 137 & 137 & 137 & 137 & 137 \\
Y Mean & 2.44 & 0.20 & 14.80 & 4.89 & 9.36 & 1.37 & 3.96 \\
& & & & & & & \\
\hline \hline
\end{tabular}

Notes: Tables present difference-in-difference estimates, by age, of the effects of local dial adoption on young, white, American-born women's employment shares in select occupations, across successive cohorts, for cities with population $\leq 100 \mathrm{k}$ in 1920 . Sample restricted to cities with continuous newspaper coverage from 1917 to 1940 . The left-most column provides the effect of cutovers on the percent of these women who were telephone operators in the telephone industry, as a reference point. The other occupations across columns are: (i) office machine operators, (ii) typists, stenographers, and secretaries, (iii) other office clerks, (iv) sales clerks, (v) beauty parlor workers, and (vi) restaurant workers. All regressions include city and year fixed effects, and log city size x year controls. *, **, *** represent significance at the $0.1,0.05$, and 0.01 levels, respectively. SEs clustered by city in parentheses. 


\section{C.7 Long-differences strategy with "Large City" sample}

In the body of the paper, we focus our attention on "small" cities (those with population $\leq 100,000$ in 1920), where cutovers were typically one-time events. As a robustness check, we also examine the 160 "large" cities in the AT\&T sample which merge to our focal city sample (=164 U.S. cities in AT\&T data, less four New York City boroughs) - where automation typically took place gradually, as individual exchanges were converted to mechanical operation one or two at a time. Although this sample is not suitable for event studies, we can use AT\&T's data on the intensity of local dial adoption to estimate its effects on young women, and the results are statistically and quantitatively similar to those for smaller cities in the body of the paper.

Specifically, we relate the AT\&T data on the fraction of a city's subscribers with dial service as of 1940 to 1920-to-1940 long-differenced outcomes, as follows:

$$
\Delta_{1920,1940} Y_{i}=\beta \cdot \text { Fraction dial in } 1940_{i}+X_{i} \phi+\varepsilon_{i}
$$

Results from these regressions are presented below, in a format analogous to the by-age differencein-difference results in the paper. Figure C.9 estimates the effects on the percent of young, white, American-born women who are telephone operators in the telephone industry (for comparison to Figure 4 in the body of the paper). Tables C.4 and C.5 estimate effects on the percent of women who are working, in school, married, have children, and are in assorted occupations (for comparison to Tables 4 and 5 in the body of the paper). 
Figure C.9: Effect of dial cutovers on the pct. of working young, white, American-born women in a given city who are telephone operators in the telephone industry (long differences, by age) sample restricted to cities in the ATET large-city data whose first cutover occurred post-1920

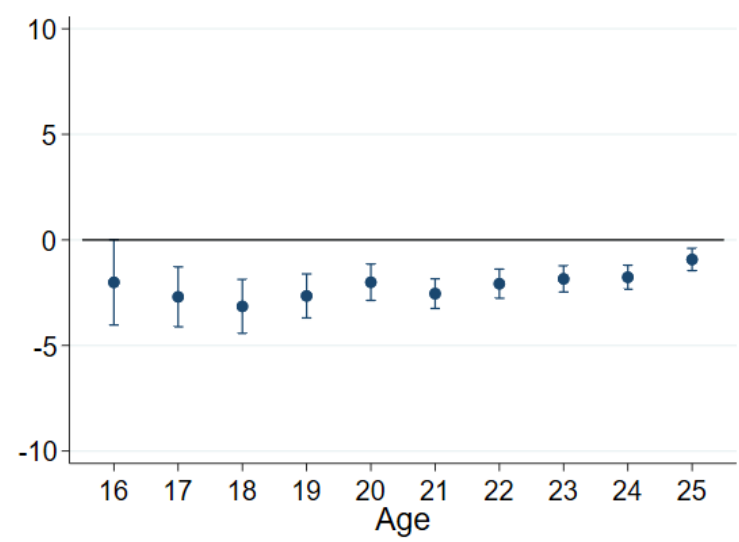

Notes: Figure shows 1920 to 1940 long difference estimates, by age, of the effects of local dial adoption (measured as the fraction of a city on dial as of the 1940 Census [April 1940]) on the percent of working young, white, American-born women who are telephone operators in the telephone industry. Sample restricted to cities in the AT\&T data whose first cutover occurred after the 1920 Census (January 1920). Error bars represent $95 \%$ confidence intervals, computed from robust SEs.

Figure C.10: Effect of dial cutovers on the pct. of working young, white, American-born women with other jobs in the telephone industry or who are telephone operators in other industries sample restricted to cities in the ATET large-city data whose first cutover occurred post-1920

Other jobs in the telephone industry

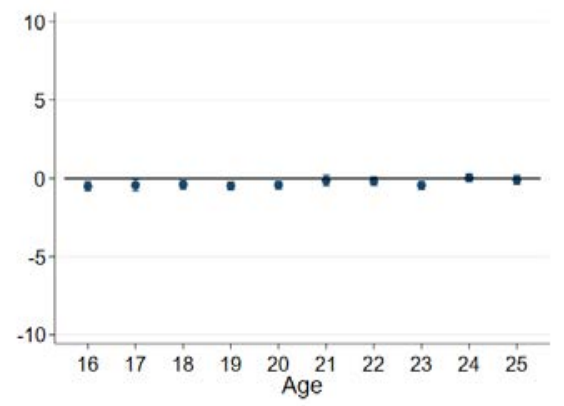

Tel. operator in other industries

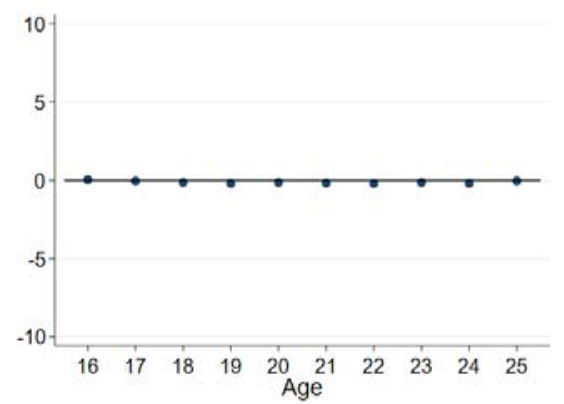

Notes: Figure shows 1920 to 1940 long differences estimates, by age, of the effects of local dial adoption (measured as the fraction of a city on dial as of the 1940 Census [April 1940]) on the percent of working young, white, American-born women in successive cohorts who have other jobs in the telephone industry (left) and who are telephone operators in other industries (right). Sample restricted to cities in the AT\&T data whose first cutover occurred after the 1920 Census (January 1920). We plot the estimates on the same scale (-10 to 10 p.p.) as the previous figures to ease comparison. Error bars represent $95 \%$ confidence intervals, computed from robust SEs. 
Table C.4: Changes in work, education, marriage, and fertility patterns around cutovers sample restricted to cities in the ATET large-city data whose first cutover occurred post-1920

\begin{tabular}{|c|c|c|c|c|c|}
\hline \multicolumn{6}{|c|}{ Panel A: White, American-born women ages 16 to 25} \\
\hline & \multicolumn{5}{|c|}{ Percent of the group that is: } \\
\hline & Tel. oper. & Working & In school & Married & Has children \\
\hline Percent dial in 1940 & $\begin{array}{c}-0.84^{* * *} \\
(0.15)\end{array}$ & $\begin{array}{c}0.43 \\
(1.17)\end{array}$ & $\begin{array}{c}-1.47^{* *} \\
(0.64)\end{array}$ & $\begin{array}{l}-1.66 \\
(1.17)\end{array}$ & $\begin{array}{c}0.00 \\
(0.72)\end{array}$ \\
\hline $\mathrm{N}$ & 1580 & 1580 & 1580 & 1580 & 1580 \\
\hline$R^{2}$ & 0.45 & 0.85 & 0.88 & 0.28 & 0.06 \\
\hline Y Mean & -1.64 & -8.75 & 9.14 & -0.27 & -0.91 \\
\hline \multicolumn{6}{|c|}{ Panel B: White, American-born women ages 16 to 20} \\
\hline & \multicolumn{5}{|c|}{ Percent of the group that is: } \\
\hline & Tel. oper. & Working & In school & Married & Has children \\
\hline Percent dial in 1940 & $\begin{array}{c}-0.83^{* * *} \\
(0.23)\end{array}$ & $\begin{array}{c}1.90 \\
(1.81) \\
\end{array}$ & $\begin{array}{c}-2.78^{* *} \\
(1.20) \\
\end{array}$ & $\begin{array}{l}-1.15 \\
(0.93) \\
\end{array}$ & $\begin{array}{l}-0.08 \\
(0.42) \\
\end{array}$ \\
\hline $\mathrm{N}$ & 790 & 790 & 790 & 790 & 790 \\
\hline$R^{2}$ & 0.20 & 0.76 & 0.81 & 0.09 & 0.10 \\
\hline Y Mean & -2.38 & -22.86 & 17.66 & -2.52 & -0.55 \\
\hline \multicolumn{6}{|c|}{ Panel C: White, American-born women ages 21 to 25} \\
\hline & \multicolumn{5}{|c|}{ Percent of the group that is: } \\
\hline & Tel. oper. & Working & In school & Married & Has children \\
\hline Percent dial in 1940 & $\begin{array}{c}-0.85^{* * *} \\
(0.13)\end{array}$ & $\begin{array}{l}-0.95 \\
(1.31)\end{array}$ & $\begin{array}{c}-0.24 \\
(0.23)\end{array}$ & $\begin{array}{l}-2.14 \\
(1.45)\end{array}$ & $\begin{array}{c}0.08 \\
(1.05)\end{array}$ \\
\hline $\mathrm{N}$ & 790 & 790 & 790 & 790 & 790 \\
\hline$R^{2}$ & 0.23 & 0.11 & 0.30 & 0.16 & 0.03 \\
\hline Y Mean & -0.96 & 4.23 & 1.30 & 1.80 & -1.25 \\
\hline
\end{tabular}

Notes: Tables present long differences estimates, by age, of the effects of local dial adoption (measured as the fraction of a city on dial as of the 1940 Census [April 1940]) on the percent of young, white, American-born women in successive cohorts who are in the labor force, in school, married, and have children. Sample restricted to cities in the AT\&T data whose first cutover occurred after the 1920 Census (January 1920). The left-most column provides the effect of cutovers on the percent of these women who were telephone operators in the telephone industry, as a reference point. All regressions include log city size controls. *, **, *** represent significance at the $0.1,0.05$, and 0.01 levels, respectively. Robust SEs in parentheses. 
Table C.5: Changes in employment shares in select occupations around cutovers sample restricted to cities in the ATEST large-city data whose first cutover occurred post-1920

Panel A: White, American-born women ages 16 to 25

Conditional on working, percent employed as or in

Tel. oper. Off. mach. Typist/secr. Office clerk Sales clerk Beautician Restaurant

\begin{tabular}{lccccccc}
\hline Percent dial in 1940 & $-2.16^{* * *}$ & 0.06 & 1.64 & 0.19 & -0.17 & $0.27^{*}$ & $\begin{array}{c}1.87^{* * *} \\
(0.60)\end{array}$ \\
\hline $\mathrm{N}$ & $(0.34)$ & $(0.11)$ & $(1.25)$ & $(0.68)$ & $(0.58)$ & $(0.14)$ & 1580 \\
$R^{2}$ & 1580 & 1580 & 1580 & 1580 & 1580 & 1580 & 0.09 \\
Y Mean & 0.29 & 0.33 & 0.31 & 0.03 & 0.24 & 0.32 & 5.37
\end{tabular}

Panel B: White, American-born women ages 16 to 20

Conditional on working, percent employed as or in

Tel. oper. Off. mach. Typist/secr. Office clerk Sales clerk Beautician Restaurant

\begin{tabular}{lccccccc}
\hline Percent dial in 1940 & $-2.51^{* * *}$ & 0.06 & 2.28 & 0.47 & -0.57 & 0.13 & $\begin{array}{c}2.10^{* *} \\
(0.84)\end{array}$ \\
& $(0.56)$ & $(0.08)$ & $(1.39)$ & $(0.72)$ & $(0.85)$ & $(0.10)$ & 790 \\
$\mathrm{~N}$ & 790 & 790 & 790 & 790 & 790 & 790 & 0.06 \\
$R^{2}$ & 0.13 & 0.31 & 0.17 & 0.05 & 0.28 & 0.27 & 6.04 \\
Y Mean & -4.42 & 0.48 & -3.38 & 1.63 & 0.90 & 1.37 &
\end{tabular}

Panel C: White, American-born women ages 21 to 25

Conditional on working, percent employed as or in

Tel. oper. Off. mach. Typist/secr. Office clerk Sales clerk Beautician Restaurant

\begin{tabular}{lccccccc}
\hline Percent dial in 1940 & $\begin{array}{c}-1.84^{* * *} \\
(0.24)\end{array}$ & $\begin{array}{c}0.06 \\
(0.16)\end{array}$ & $\begin{array}{c}1.03 \\
(1.20)\end{array}$ & $\begin{array}{c}-0.08 \\
(0.86)\end{array}$ & $\begin{array}{c}0.20 \\
(0.47)\end{array}$ & $\begin{array}{c}0.41^{* *} \\
(0.21)\end{array}$ & $\begin{array}{c}1.66^{* * *} \\
(0.51)\end{array}$ \\
\hline $\mathrm{N}$ & 790 & 790 & 790 & 790 & 790 & 790 & 790 \\
$R^{2}$ & 0.22 & 0.07 & 0.04 & 0.00 & 0.05 & 0.04 & 0.08 \\
$\mathrm{Y}$ Mean & -2.13 & 1.04 & 1.50 & 2.20 & 1.47 & 2.31 & 4.75 \\
& & & & & & & \\
\hline
\end{tabular}

Notes: Tables present long differences estimates, by age, of the effects of local dial adoption (measured as the fraction of a city on dial as of the 1940 Census [April 1940]) on young, white, American-born women's employment shares in select occupations. Sample restricted to cities in the AT\&T data whose first cutover occurred after the 1920 Census (January 1920). The left-most column provides the effect of cutovers on the percent of these women who were telephone operators in the telephone industry, as a reference point. The other occupations across columns are: (i) office machine operators, (ii) typists, stenographers, and secretaries, (iii) other office clerks, (iv) sales clerks, (v) beauty parlor workers, and (vi) restaurant workers. All regressions include log city size controls. *, **, *** represent significance at the $0.1,0.05$, and 0.01 levels, respectively. Robust SEs in parentheses. 


\section{C.8 Mechanical switching not related to broader technological progress}

A potential concern in this paper is that the effects of cutovers on employment rates (or lack thereof) may be confounded by concurrent technological changes with countervailing impacts on aggregate productivity, and in turn labor demand for all workers, including the young women which are the focus of our analysis. In this section we evaluate this possibility, comparing changes in employment in occupations closely related to major technologies of the early twentieth century. By most accounts, the two most transformative technologies of this period were electricity and automobiles, each of which diffused rapidly between 1900 and 1940 (Eli et al. 2022). Electricity, in turn, supported the growth of American manufacturing. To examine whether these changes coincided locally with telephone industry automation, we identify associated occupations and estimate whether they grew or contracted after mechanical switching was adopted.

Table C.6 estimates the post-cutover difference-in-difference in the per-capita number of (1) telephone operators, (2) electricians, (3) machinists, (4) automotive mechanics, (5) deliverymen, and (6) truck drivers, for the same midsize and smaller cities we study throughout the paper. As the table statistic show, each of these occupations was large, with 60,000 to 370,000 workers by 1940, and some grew by orders of magnitude between 1910 and 1940 (e.g., the number of auto mechanics in these cities grew from 600 to 130,000). Telephone operators per capita fell sharply, by roughly half the mean, in cities post-cutover. We find no such effects for workers in other technologicallyprogressive occupations. We interpret this evidence as indicating that cutovers did not locally coincide with the diffusion of these other technologies.

Table C.6: Changes in number of workers in select professions per capita, 1910-1940

\begin{tabular}{lcccccc}
\hline \hline & $(1)$ & $(2)$ & $(3)$ & $(4)$ & $(5)$ & $(6)$ \\
& Tel. operators & Electricians & Machinists & Auto mechanics & Deliverymen & Truck drivers \\
\hline Post-cutover & $-0.11^{* * *}$ & -0.01 & -0.04 & 0.01 & 0.02 & 0.01 \\
& $(0.01)$ & $(0.01)$ & $(0.06)$ & $(0.01)$ & $(0.01)$ & $(0.02)$ \\
\hline $\mathrm{N}$ & 11384 & 11384 & 11384 & 11384 & 11384 & 11384 \\
$R^{2}$ & 0.68 & 0.71 & 0.84 & 0.83 & 0.78 & 0.87 \\
Cities & 2846 & 2846 & 2846 & 2846 & 2846 & 2846 \\
Cut over & 261 & 261 & 261 & 261 & 261 & 261 \\
Y Mean & 0.25 & 0.29 & 1.06 & 0.38 & 0.33 & 0.84 \\
Ct. in 1910 ('000s) & 24.9 & 32.3 & 160.8 & 0.6 & 37.3 & 15.5 \\
Ct. 1940 ('000s) & 64.3 & 69.4 & 174.9 & 129.1 & 136.0 & 372.3 \\
\hline \hline
\end{tabular}

Notes: Table presents difference-in-difference estimates of the post-cutover change in the number of workers in six different occupational categories, per adult population. The occupations shown are representative of (and proxy for) the major technological changes taking place across the U.S. in the first half of the twentieth century, such as electrification, industrialization, and the diffusion of automobiles. Table statistics show the total number of workers in each occupation in 1910 an 1940 for the sampled cities. Observations are at the city-year level, restricted to cities with population $\leq 100 \mathrm{k}$ in 1920 . All regressions include city and year fixed effects, and $\log$ city size $\mathrm{x}$ year controls. $*, * *, * * *$ represent significance at the $0.1,0.05$, and 0.01 levels, respectively. SEs clustered by city in parentheses. 


\section{C.9 Countervailing forces to automation tempering employment impacts}

A growing literature, anchored in the writing of Acemoglu and Restrepo (2018, 2019a,b, 2020) has brought into focus the multiple ways in which automation can endogenously affect employment and the labor share. At the heart of the Acemoglu-Restrepo framework is the view that automation is distinct from other types of capital in that it does not strictly augment labor: it also replaces it. Acemoglu and Restrepo (2018) characterize aggregate production as the composite of myriad tasks along a fixed measure. Some of these tasks may be performed by machines, and others by labor, but each will be produced by the factor which has comparative advantage in that task. As existing tasks performed by labor are automated, new tasks in which labor has comparative advantage may be endogenously created (or machine-performed tasks upgraded to a level such that only humans can perform them, thus holding the measure of tasks fixed).

In this model, automation has countervailing effects on labor. Its first-order effect is displacement: tasks previously performed by workers can be more cheaply performed by capital, reducing labor demand, employment, and labor's share of income. This impact on labor, however, may be counteracted in four ways (Acemoglu and Restrepo 2019a). One is by increasing aggregate productivity: as the cost of producing automated tasks declines, the economy will grow, increasing demand for labor in non-automated tasks - including in both automated and non-automated sectors. Another countervailing effect is capital accumulation, as automation increases the returns to capital, which can in turn increase the returns to labor. A third is what Acemoglu and Restrepo label automation deepening: improvements in existing automation, which will weakly increase productivity without displacing labor. The fourth, and the focus of most of this work, is task reinstatement: the endogenous creation of new functions and activities in which labor has a comparative advantage - in essence, a form of directed technical change (Acemoglu 2002).

These and related papers, such as Nakamura and Zeira (2018) and Hémous and Olsen (2022), frame automation as a macroeconomic phenomenon. In this context, automation is taking place across the economy, which (under appropriate conditions) continually adjusts to a balance growth path characterized by ongoing automation and task creation, with a constant long-run labor share. But this framework is also useful for thinking about the effects of specific technologies like the one in this paper: mechanical call switching. As we show in Section 4 of the paper, mechanization had a large displacement effect, sharply and permanently reducing the fraction of young women who worked as telephone operators (Figure 4 of the paper). A shock of this size is large enough to have detectable aggregate impacts, yet we find no evidence that future cohorts' employment declined as a result of this automation event. The question is: why?

In this section, discuss the potential for (i) productivity effects, (ii) capital accumulation, (iii) automation deepening, and (iv) task reinstatement to explain this result. Our evidence suggests against the first three explanations. We provide direct evidence of task reinstatement, albeit with nuance: insofar as labor demand grew in other occupations, these occupations were not necessarily new to the labor market. Rather, our interpretation is that labor demand in jobs that employed women demographically similar to would-be telephone operators endogenously emerged in new businesses and industries. This conclusion is consistent with Acemoglu and Restrepo (2018, 2020) when tasks are defined to be sector- or business-specific. 


\section{C.9.1 Productivity effects and capital accumulation unlikely to offset job loss}

For several reasons, productivity effects and capital investment are unlikely to create enough labor demand for young women workers to offset the jobs lost to automation. The first of these is that although mechanical switching significantly increased AT\&T's labor efficiency (see Appendix Table A.1), the wider productivity impacts were likely small. Table C.7 provides back-of-the-envelope estimates of the potential for time savings across business telephone users, using data on the number of business telephones and telephone calls from the U.S. Census of Electrical Industries (U.S. Census Bureau 1902) and on AT\&T experimental estimates of the average improvement in connection times under mechanical switching (AT\&T 1923). Aggregating the 2.4 seconds saved per call across all business calls yields a total annual time savings of 8 million hours (roughly 4,000 full-time equivalents) across the economy in 1922. In practice, these time savings would have been widely distributed across telephone users, and not perfectly aggregable into FTEs. We estimate these savings to have been around 1.4 hours per telephone set.

Table C.7: Potential aggregate savings from mechanical switching at U.S. businesses

We calculate the potential aggregate savings of mechanical switching across all business telephone service by taking AT\&T's estimated savings per telephone call, and aggregating across all business calls.

(1) Bell system telephone calls (MM)

(2) Assumed fraction business

(higher than the $61 \%$ business fraction of telephones)

(3) Bell System business calls (MM) 12,425 Calculated: $(1)^{*}(2)$

(4) Avg. time saved per call (secs) $2.4 \quad$ AT\&T (1923)

(5) Aggregate time savings (hours, MM) 8.1 Calculated: $(3)^{*}(4) / 3600$

(6) Annual FTE-equivalents, at $2000 \mathrm{hrs}$ per FTE 4,055 Calculated: (5)*1e6/2e3

In practice, these savings will be widely distributed among users;

i.e., it's not that 4,000 FTEs will be saved at one employer but rather that small amounts of time will be saved by every user. These savings generally cannot be aggregated across firm boundaries into jobs.

What are the annual savings per business telephone station?

(7) Bell system telephones (1000s) 9,515 Census of Telephones (1922)

(8) Business fraction of telephones $\quad 61 \%$ Census of Telephones (1922)

(9) Bell System business telephones (1000s) $\quad 5,776$ Calculated: $(7)^{*}(8)$

(10) Annual calls per business telephone $\quad 2,151 \quad$ Calculated: $(3) * 1 \mathrm{e} 3 /(9)$

(11) Avg. time saved per call (secs) $2.4 \quad$ AT\&T (1923)

(12) Annual savings per business telephone (hours) $\quad 1.40$ Calculated: $(10)^{*}(11) / 3600$

Notes: Data from U.S. Census Bureau (1902) (see 1922 Census of Electrical Industries: Telephones) and AT\&T (1923) (AT\&T Plant and Engineering Conference of 1923).

The time savings are thus small, and the telecommunications that automation supported were not otherwise different from those under manual switching. Productivity gains across the economy resulting from the adoption of mechanical switching are thus ruled out as a driver of offsetting labor demand growth. Because its aggregate impacts (beyond displacement) were so limited, we likewise believe that mechanical switching was unlikely to trigger capital accumulation, or improvements in automation across other sectors of the economy. Moreover, insofar as countervailing demand 
does result from productivity gains or capital investment, there is little reason to think it would be concentrated among young women specifically. Directed task creation to take advantage of this specific, newly-abundant subset of the labor supply seems more likely.

\section{C.9.2 Task reinstatement: Labor demand in clerical work and restaurant work}

AT\&T's adoption generated some new labor demand directly: the company needed technicians to install and maintain the mechanical equipment, and perhaps office clerks to perform residual operator tasks that did not get automated. We see as much in our data: though not reported here, we have found that the number of electrical engineers and office clerks working in the local telephone industry increased after cutovers, although the growth in these categories of workers was minuscule compared to the decline in operators, and the engineers were almost exclusively men. As we show in the paper (e.g., Figure 5), employment of young women in other jobs in the telephone industry did not grow to offset the jobs lost to automation.

Instead, in what appears to be an example of task reinstatement, we find that employment grew in occupations like typists and secretaries or restaurant workers. To validate the view that labor demand grew in these occupations, as employers found new uses for these types of workers, we need a way to measure demand. For this, we return to our newspaper data sources. We run searches in Newspapers.com for help-wanted classified advertisements by city, job title, and year. Searches on Newspapers.com will return hits when a newspaper issue has the search term on at least one page. To identify job listings, we searching for the text $<$ [JOB TITLE] + "help wanted" $>$, which will typically position us in the classified advertisements section of each newspaper issue. From these searches, we are able to measure, for each city-year with newspaper coverage, the number of newspaper-days with a hit. We sum these hits by city and year, and normalize by the number of newspapers on Newspapers.com for that city and year, to ensure that our counts are more reflective of job advertisements more than the number of local newspapers (most city-years have at most one digitized newspaper, such that this adjustment is not material).

We then calculate the inverse hyperbolic sine of these counts, and in Table C.8 we estimate the difference-in-differences change after cutovers for the city-years in our primary sample (roughly 3,000 cities, 1910 to 1940) which are covered in Newspapers.com. We apply the same specification as previous tables, controlling for city population $\mathrm{x}$ year effects.

Among typists, stenographers, secretaries, and waitresses, we find that help-wanted advertisements for typists and waitresses register a significant, roughly $20 \%$ increase in the years after automation. This effect converts to a roughly $3.3 \%$ increase in advertisements for typists/stenographers/secretar when bundled together (typists comprise roughly $1 / 6$ of the collective search hits across these titles). To put the magnitudes in perspective, these magnitudes approximately match the increase estimated in Table 5 of the paper, where the typist/stenographer/secretary fraction of young women's employment increased $4.5 \%$ (0.5 percentage points (p.p.) off of a base of 11.6 p.p.), and restaurant workers increased $20 \%$ (0.83 p.p. off of a base of 4.15 p.p.). 
Table C.8: Search hits for help-wanted classified ads, by job title

\begin{tabular}{lcccc}
\hline & Typist & Stenographer & Secretary & Waitress \\
\hline Post-cutover & $0.19^{* *}$ & -0.02 & -0.05 & $0.17^{* *}$ \\
& $(0.08)$ & $(0.09)$ & $(0.11)$ & $(0.08)$ \\
\hline $\mathrm{N}$ & 25682 & 25682 & 25682 & 25682 \\
$R^{2}$ & 0.72 & 0.76 & 0.71 & 0.69 \\
Cities & 1056 & 1056 & 1056 & 1056 \\
Cut over & 119 & 119 & 119 & 119 \\
Y Mean & 0.52 & 1.06 & 1.56 & 0.46 \\
\hline \hline
\end{tabular}

Notes: Table presents difference-in-difference estimates of the post-cutover change in city-level help-wanted advertising for the occupations shown. Observations are at the city-year level, restricted to cities with population $\leq 100 \mathrm{k}$ in 1920 . The data for this table were collected by searching Newspapers.com for < [JOB TITLE] + "help wanted" >, city-by-city and year-byyear, from 1910 to 1940. From these searches, we obtain the number of newspaper-days in each city and year which have a page with both the job title and "help wanted", which we interpret as job listings in the classified section of the newspaper. We normalize this measure by the number of newspapers in each city and year (median 1, 75th percentile 2) to avoid double-counting. Sample restricted to city-years with newspapers. All regressions include city and year fixed effects, and log city size $\mathrm{x}$ year controls. *, **, *** represent significance at the $0.1,0.05$, and 0.01 levels, respectively. SEs clustered by city in parentheses.

\section{C.9.3 Mediators of task reinstatement}

With direct offsets, aggregate productivity effects, and capital deepening ruled out, the evidence in the forgoing sections suggest that the net effects of automating telephone operation on young women's employment results from dual impacts of displacement and endogenously-reinstated labor demand. A corollary question is then under what conditions the economy creates new demand that restores employment levels. When aggregate demand slack, endogenous task creation may be weakly incentivized, and the productivity impacts of automation modest, such that the displacement effects of automation may dominate, generating employment declines. Certain sectors of the economy may be more productive at task creation, especially for specific segments of the labor market (like young women in the early twentieth century). Complementary technology or innovation-led structural transformation may also facilitate endogenous task creation, as the returns to generating new tasks that fit with the modern technological environment increase, and the opportunity cost of replacing increasingly-obsolete tasks decline, in an evolving economy.

We explore these hypotheses below. To do so, we collect additional data that we use to group cities and compare the effects of cutovers across them. We first examine the technological environment, focusing on two of the defining technologies of the first half of the twentieth century, both of which increased productivity and led to factor reallocation across space and across sectors: electricity, and automobiles. Though we lack city- or county-level measures of electricity or automobile diffusion, census data permit reasonable proxies in the per-capita number of electricians and auto mechanics. We next consider local economic diversity, conjecturing that cities with a more diverse employment base may be more resilient to automation shocks, as there are many sectors in which countervailing labor demand can endogenously emerge. We compute, for each city and year, a Herfindahl index of employment across economic sectors. We also use these data to measure cities' 1910 manufacturing share of employment, which provides a distinct view of local economic structure and reinstatement potential. Finally, we investigate heterogeneity across cities which were more versus less severely exposed to the Great Depression, using the Fishback et al. (2005) measures of county per-capita 
retail sales contractions from 1929 to $1933 .{ }^{18}$ For each of these measures, we partition our sampled cities into quartiles, and compare the effects of automation across them.

Table C.9 presents the results, with each column heading identifying the interacted measure. We do not find any differential effects of cutovers across cities by technological conditions. They do, however, relate to two economic factors: manufacturing intensity and Great Depression severity. Because manufacturing was a predominantly male worker industry, manufacturing-intensive cities may have been less conducive environments for endogenous task creation and demand reinstatement for young women. Consistent with the logic of Acemoglu and Restrepo (2019b), we also find that in cities with the most severe contractions during the Great Depression, cutovers were followed by a decline in employment of young women. This suggests that aggregate demand has a direct impact on whether, when, and to what degree labor demand can recover from large automation shocks, and which workers (or cohorts) are most exposed. That the estimated effect is monotonic in depression severity further reinforces this result.

Table C.9: Changes in employment of young, white, American-born women around cutovers (diff-in-diff, by age, 16-25, interacted with potential sources of heterogeneity)

\begin{tabular}{lccccc}
\hline \hline & \multicolumn{2}{c}{ Per capita: } & $\begin{array}{c}\text { Sector } \\
\text { diversity }\end{array}$ & $\begin{array}{c}\text { Manufacturing } \\
\text { intensity }\end{array}$ & $\begin{array}{c}\text { Depression } \\
\text { severity }\end{array}$ \\
\hline Post-cutover & 0.21 & 0.55 & 0.11 & $2.04^{*}$ & $1.52^{*}$ \\
& $(1.39)$ & $(0.86)$ & $(1.14)$ & $(1.08)$ & $(0.91)$ \\
$*$ 2nd quartile intensity & -0.27 & -0.88 & -0.26 & $-2.37^{*}$ & -0.63 \\
$*$ 3rd quartile intensity & $(1.56)$ & $(1.06)$ & $(1.41)$ & $(1.33)$ & $(1.18)$ \\
& -0.51 & -1.27 & -0.01 & $-2.47^{* *}$ & $-2.08^{*}$ \\
$*$ 4th quartile intensity & $(1.55)$ & $(1.16)$ & $(1.28)$ & $(1.18)$ & $(1.18)$ \\
& 0.39 & 0.57 & -0.44 & $-2.66^{* *}$ & $-3.56^{* * *}$ \\
N & $(1.55)$ & $(1.18)$ & $(1.27)$ & $(1.28)$ & $(1.19)$ \\
$R^{2}$ & 113752 & 113752 & 113712 & 113712 & 113752 \\
Cities & 0.83 & 0.84 & 0.83 & 0.84 & 0.83 \\
Cut over & 2845 & 2845 & 2844 & 2844 & 2845 \\
Y Mean & 261 & 261 & 261 & 261 & 261 \\
\hline \hline
\end{tabular}

Notes: Table presents difference-in-difference estimates, by age, of the effects of local dial adoption on the percent of young, white, American-born women in successive cohorts who are working, for cities with population $\leq 100 \mathrm{k}$ in 1920 . Columns (1) and (2) partition cities into quartiles by the number of electricians and auto mechanics per capita; Column (3), by industrial diversity; Column (4), by manufacturing intensity; and Column (5), by Great Depression severity. For the latter, cities are assigned their county's value, as Depression severity is only observed at the county level. All regressions include city and year fixed effects, and log city size $\mathrm{x}$ year controls. $* * *, * * *$ represent significance at the $0.1,0.05$, and 0.01 levels, respectively. SEs clustered by city in parentheses.

\footnotetext{
${ }^{18}$ Although a natural first instinct might be to take advantage of the time dimension of our cutover panel variation, and explore heterogeneity across cities which were cut over to dial in 1929-1933 versus in other years, or in the 1920s versus in the 1930s, these comparisons present several challenges: (i) cutover timing correlates strongly with city characteristics; (ii) it abstracts away from cross-sectional variation in depression severity, which exceeds the time-series variation; (iii) in comparing cities automated in the 1929-1933 period against others, our tests would be underpowered; and (iv) it is unclear whether to treat the 1930 census data as being pre- or mid-depression, which began in late 1929 but did not reach peak intensity until 1932-1933.
} 


\section{C.10 Spillovers to other populations}

Although most of the paper focuses on the effects of cutovers on young, white, American-born women, it is also possible that the effects spilled over onto other populations, especially via labor market competition. In the following tables we explore changes in local employment of other demographic groups, specifically focusing on the two occupations which appear to have absorbed future cohorts of young, white, American-born women: (i) typists, stenographers, and secretaries (Table C.10), and (ii) waitressing (Table C.11). The table explores changes in the number of adults (of all ages) working in a given occupation around cutovers, and the percent of employment each occupation represents for different populations (by sex, race, and birthplace). We do not generally find widespread evidence of spillovers, though Table C.11 includes modest evidence that the growth in the percent of white, American-born women in restaurant work may have come at the expense of employment of black women (final column, significant at the $10 \%$ level).

Table C.10: Total employment + percent of assorted subgroups who are typists/stenographers

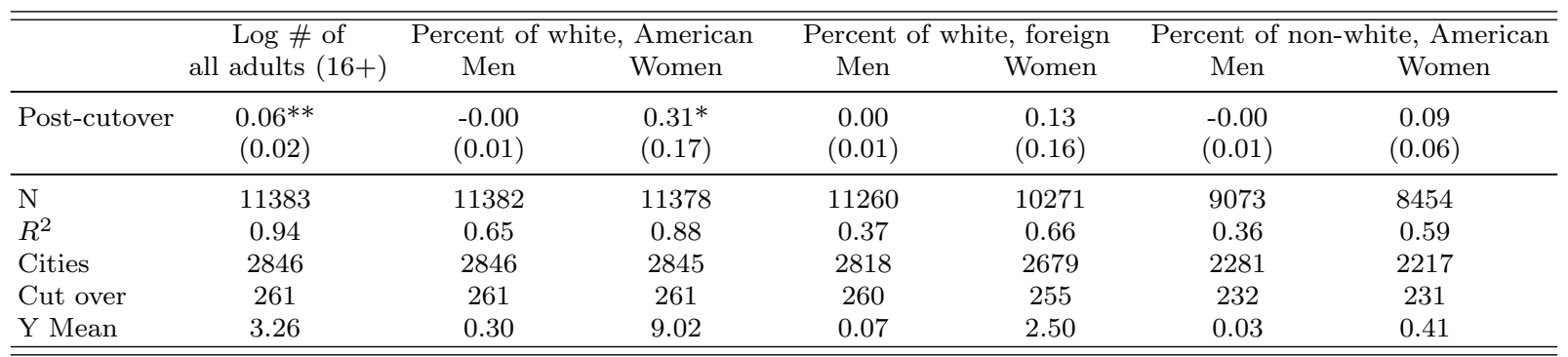

Notes: Table presents results from a DID regression estimating the changes around dial cutovers in the (log) number of adults in a city who are typists/stenographers/secretaries, and the percent of different subpopulations who are the same (binning the population by race, place of birth, and sex). All regressions include city and year fixed effects, and $\log$ city size $\mathrm{x}$ year controls. $*, * *, * * *$ represent significance at the $0.1,0.05$, and 0.01 levels, respectively. SEs clustered by city in parentheses.

Table C.11: Total employment + percent of assorted subgroups who are waiters/waitresses

\begin{tabular}{lccccccc}
\hline \hline & \multicolumn{2}{c}{ Log \# of } & \multicolumn{2}{c}{ Percent of white, American } & \multicolumn{2}{c}{ Percent of white, foreign } & \multicolumn{2}{c}{ Percent of non-white, American } \\
& all adults (16+) & Men & Women & Men & Women & Men & Women \\
\hline Post-cutover & 0.02 & -0.01 & $0.18^{*}$ & -0.02 & 0.09 & -0.25 & $-0.33^{*}$ \\
& $(0.03)$ & $(0.02)$ & $(0.10)$ & $(0.03)$ & $(0.14)$ & $(0.35)$ & $(0.18)$ \\
\hline $\mathrm{N}$ & 11383 & 11382 & 11378 & 11260 & 10271 & 9073 & 8454 \\
$R^{2}$ & 0.90 & 0.64 & 0.83 & 0.66 & 0.50 & 0.74 & 0.61 \\
Cities & 2846 & 2846 & 2845 & 2818 & 2679 & 2281 & 2217 \\
Cut over & 261 & 261 & 261 & 260 & 255 & 232 & 231 \\
Y Mean & 2.54 & 0.27 & 2.71 & 0.34 & 1.61 & 1.54 & 0.99 \\
\hline \hline
\end{tabular}

Notes: Table presents results from a DID regression estimating the changes around dial cutovers in the (log) number of adults in a city who are restaurant or food service workers, and the percent of different subpopula-tions who are the same (binning the population by race, place of birth, and sex). All regressions include city and year fixed effects, and log city size $\mathrm{x}$ year controls. $*, * *, * * *$ represent significance at the $0.1,0.05$, and 0.01 levels, respectively. SEs clustered by city in parentheses. 


\section{Appendix references}

Abramitzky, Ran, Leah Boustan, Katherine Eriksson, James Feigenbaum, and Santiago Pérez. 2021. "Automated linking of historical data," Journal of Economic Literature, Vol. 59, No. 3, pp. 865-918.

Acemoglu, Daron. 2002. "Directed Technical Change," The Review of Economic Studies, Vol. 69, No. 4, pp. 781-809.

Acemoglu, Daron and Pascual Restrepo. 2018. "The Race between Man and Machine: Implications of Technology for Growth, Factor Shares, and Employment," American Economic Review, Vol. 108, No. 6, pp. $1488-1542$.

_ 2019a. "Artificial Intelligence, Automation, and Work," in Agrawal, Ajay, Joshua Gans, and Avi Goldfarb eds. The Economics of Artificial Intelligence: An Agenda, Chicago: University of Chicago Press, pp. 197-236.

_ . 2019b. "Automation and New Tasks: How Technology Displaces and Reinstates Labor," Journal of Economic Perspectives, Vol. 33, No. 2, pp. 3-30.

. 2020. "Robots and Jobs: Evidence from U.S. Labor Markets," Journal of Political Economy, Vol. 128, No. 6, pp. 2188-2244.

American Federation of Labor (AFL). 1919. American Federation of Labor: History, Encyclopedia, and Reference Book.

AT\&T. 1923. "Chart T-10: Comparison of Service, Machine Switching vs. Manual," in Proceedings of the ATET Plant and Engineering Conference, Shawnee, Pennsylvania Available at AT\&T Archives and History Center (Warren, NJ), Box 185-07-02-03.

Bailey, Martha J., Connor Cole, Morgan Henderson, and Catherine Massey. 2017. How Well Do Automated Methods Perform in Historical Samples? Evidence from New Ground Truth. NBER Working Paper 24019.

Borusyak, Kirill, Xavier Jaravel, and Jann Spiess. 2021. Revisiting event study designs: Robust and efficient estimation. arXiv preprint arXiv:2108.12419.

Callaway, Brantly and Pedro HC Sant'Anna. 2021. "Difference-in-Differences with Multiple Time Periods," Journal of Econometrics, Vol. 225, No. 2, pp. 200-230.

Eli, Shari, Joshua Hausman, and Paul W. Rhode. 2022. "Transportation Revolution: The Car in the 1920s," AEA Papers \& Proceedings, Vol. 112, pp. 000-000.

Feigenbaum, James J. and Daniel P. Gross. 2021. Organizational Frictions and Increasing Returns to Automation: Lessons from ATET in the Twentieth Century. Working paper.

Fishback, Price V., William C. Horrace, and Shawn Kantor. 2005. "Did New Deal Grant Programs Stimulate Local Economies? A Study of Federal Grants and Retail Sales During the Great Depression," The Journal of Economic History, Vol. 65, No. 1, pp. 36-71.

Hémous, David and Morten Olsen. 2022. "The Rise of the Machines: Automation, Horizontal Innovation, and Income Inequality," American Economic Journal: Macroeconomics, Vol. 414, No. 1, pp. 179-223.

International Brotherhood of Electrical Workers (IBEW). 1915. The Journal of electrical Workers and Operators, 1915-1920. First volume in 1915.

International Brotherhood of Electrical Workers (IBEW) Telephone Operators' Department. 1921. The Union Telephone Operator, 1921-1922. First volume in 1921.

Nakamura, Hideki and Joseph Zeira. 2018. Automation and Unemployment: Help is on the Way. Working paper.

National Industrial Conference Board (NICB). 1926. Clerical Salaries in the United States.

Norwood, Stephen H. 1990. Labor's Flaming Youth: Telephone Operators and Worker Militancy, 1878-1923. 
Urbana: University of Illinois Press.

Price, Joseph, Kasey Buckles, Jacob Van Leeuwen, and Isaac Riley. 2019. Combining Family History and Machine Learning to Link Historical Records. NBER Working Paper 26227.

Ruggles, Steven. 2002. "Linking Historical Censuses: A New Approach," History and Computing, Vol. 14, No. 1-2, pp. 213-224.

Ruggles, Steven, Sarah Flood, Ronald Goeken, Josiah Grover, Erin Meyer, Jose Pacas, and Matthew Sobek. 2019. IPUMS USA: Version 9.0 [dataset]. Minneapolis, MN https://doi.org/10.18128/D010.V9.0.

Segrave, Kerry. 2017. The Women Who Got America Talking: Early Telephone Operators, 1878-1922. Jefferson: McFarland \& Company.

Sun, Liyang and Sarah Abraham. 2021. "Estimating Dynamic Treatment Effects in Event Studies with Heterogeneous Treatment Effects," Journal of Econometrics, Vol. 225, No. 2, pp. 175-199.

U.S. Bureau of Labor Statistics (BLS). 1932. "The Dial Telephone and Unemployment," Monthly Labor Review, Vol. 34, pp. 235-247.

U.S. Census Bureau. 1902. Census of Electrical Industries, 1902 to 1937 editions. Published as a special report in 1902-1912 and a formal industry census from 1917-1937.

U.S. Department of Labor. 1913. Annual Report of the Secretary of Labor, 1913-1933. First volume in 1913. 